\title{
Behaviour of Buried Concrete Chambers Under THERMO-MECHANICAL LOADS
}

\author{
by \\ Hossein Reshadi Nejad \\ Bachelor of Science, Sharif University of Technology, Iran, 2012 \\ A thesis \\ presented to Ryerson University \\ in partial fulfillment of the \\ requirements for the degree of \\ Master of Applied Science \\ in the Program of \\ Civil Engineering
}

Toronto, Ontario, Canada, 2014

(C)Hossein Reshadi Nejad 2014 


\section{Author's Declaration}

I hereby declare that I am the sole author of this thesis. This is a true copy of the thesis, including any required final revisions, as accepted by my examiners.

I authorize Ryerson University to lend this thesis to other institutions or individuals for the purpose of scholarly research.

I further authorize Ryerson University to reproduce this thesis by photocopying or by other

means, in total or in part, at the request of other institutions or individuals for the purpose of scholarly research.

I understand that my thesis may be made electronically available to the public. 


\title{
Behaviour of Buried Concrete Chambers Under Thermo-Mechanical Loads
}

\author{
Master of Applied Science 2014 \\ Hossein Reshadi Nejad \\ Civil Engineering \\ Ryerson University
}

\begin{abstract}
The corrosion of reinforcing steel in an aggressive environment can lead to the overall deterioration of concrete structures reinforced with steel. The non-corrodible nature of fibre-reinforced polymers (FRP) bars - along with their high strength and light weight - make them a feasible alternative to this type of deterioration. To determine suitability, a finite element investigation was conducted using ABAQUS software. A nonlinear three-dimension model was created to simulate the behaviour of buried chambers reinforced with steel or FRP bars. The model was verified against the experimental results obtained from a research program done at the University of Sherbrooke. The developed model was used to investigate the effects of the concretes compressive strength, the type of reinforcement, the reinforcement ratio and temperature changes on the behaviour of the chamber. Moreover, a three-dimensional model was created to investigate the effects of soil freezing around the chamber on global structural behaviour and nonlinear soil-chamber interaction.
\end{abstract}




\section{Acknowledgements}

First and foremost, I would like to express my deepest gratitude to my supervisor, Dr. Mohamed Lachemi, for his guidance, support and patience during the development of this thesis. His patience and constructive solutions and suggestions for the countless questions and challenges that this project faced are highly appreciated. I hope that I can continue my professional relationship with him throughout my career.

Next, I would like thank Dr. Aly Emam for guiding me in the organization of my research plans and showing me how to overcome the challenges. Without his help, guidance and suggestions, this project would not have been possible.

The collaboration and financial support of Hydro Quebec, who funded this research project, are also highly appreciated.

Finally, I would like to extend my deepest gratitude to my family. Words cannot express how grateful I am to my father, mother and brother. Without their moral support and motivation, I would not have been able to focus on my study.

Hossein Reshadi Nejad

July $10^{\text {th }}, 2014$ 


\section{Dedication}

To my lovely mother $\&$ father 


\section{Table of Contents}

Declaration

\begin{tabular}{ll}
\hline Abstract & iii
\end{tabular}

\begin{tabular}{|ll}
\hline Acknowledgements & iv
\end{tabular}

Dedication $\quad$ v

$\begin{array}{ll}\text { List of Tables } & \text { ix }\end{array}$

\begin{tabular}{ll} 
List of Figures & $\mathrm{x}$ \\
\hline
\end{tabular}

\begin{tabular}{lll}
\hline & Introduction & $\mathbf{1}$
\end{tabular}

1.1 General . . . . . . . . . . . . . . . . . . . . . . . . . . . . . . . . 1

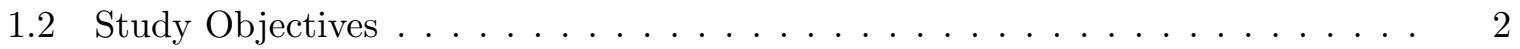

1.3 Thesis Layout $\ldots \ldots \ldots \ldots \ldots \ldots \ldots \ldots \ldots \ldots$

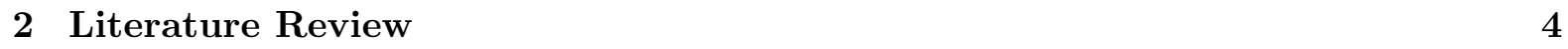

2.1 General . . . . . . . . . . . . . . . . . . . . . . . . . . 4

2.2 Buried Structures in Cold Regions and the Related Challenges . . . . . . . . . . 5

2.2 .1 Thermal Effects . . . . . . . . . . . . . . . . . 6

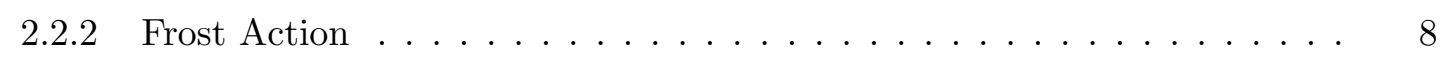

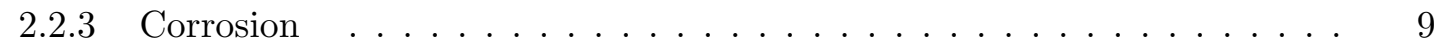

$2.3 \quad$ FRP as an Alternative Reinforcement $\ldots \ldots \ldots \ldots \ldots \ldots \ldots$

2.4 FRP as Internal Reinforcement . . . . . . . . . . . . . . . . . . . . . . . . . 11

$2.4 .1 \quad$ Flexural Capacity and Modes of Failure $\ldots \ldots \ldots \ldots$. . . . . . . . . 11

2.4 .2 Deflection and Cracking . . . . . . . . . . . . . . . . . . . . . . . . . . . . . . . .

2.4 .3 Ductility and Deformability $\ldots \ldots \ldots \ldots \ldots \ldots \ldots$

2.4 .4 Shear Capacity $\ldots \ldots \ldots \ldots \ldots \ldots$ 


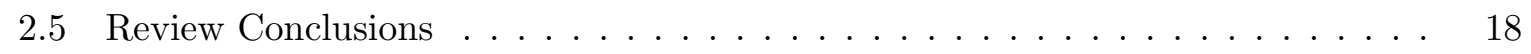

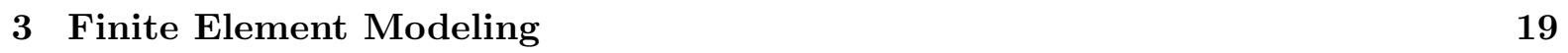

3.1 General . . . . . . . . . . . . . . . . . . . . . . . . . . . . . . . 19

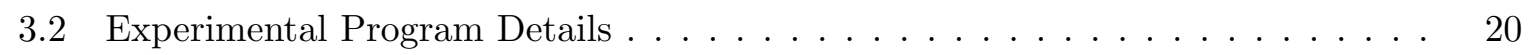

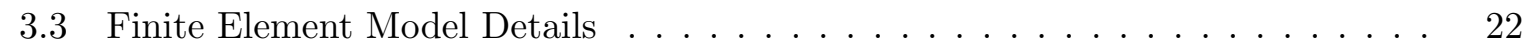

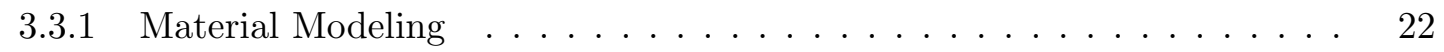

3.3 .2 Element Selection . . . . . . . . . . . . . . . . . . . . . . . . 32

3.3 .3 Loading and Boundary Conditions $\ldots \ldots \ldots \ldots \ldots \ldots \ldots \ldots$

$3.3 .4 \quad$ Nonlinear Solution and Convergence Criteria $\ldots \ldots \ldots \ldots . \ldots .34$

4 Model Validation and Parametric Study Results 35

4.1 General . . . . . . . . . . . . . . . . . . . . . . . . . . 35

4.2 Model Validation Process . . . . . . . . . . . . . . . . . . . . . . . . . 35

4.3 Parametric study . . . . . . . . . . . . . . . . . . . . . . . . . 41

4.3 .1 Concrete Compressive Strength $\ldots \ldots \ldots \ldots \ldots$. . . . . . . 42

4.3 .2 Reinforcement Type . . . . . . . . . . . . . . . . . . . . 47

4.3 .3 Reinforcement Ratio . . . . . . . . . . . . . . . . . . . . . . . 51

4.3 .4 Thermal Analysis of the Chamber . . . . . . . . . . . . . 53

\begin{tabular}{|lll}
5 Cold Weather Soil Chamber Interaction & 61
\end{tabular}

5.1 General. . . . . . . . . . . . . . . . . . . . . . . . . . . . . 61

5.2 Soil Structure Interaction Concept $\ldots \ldots \ldots \ldots \ldots \ldots \ldots \ldots$

$5.2 .1 \quad$ Finite Element Codes . . . . . . . . . . . . . . . . . . . . . 63

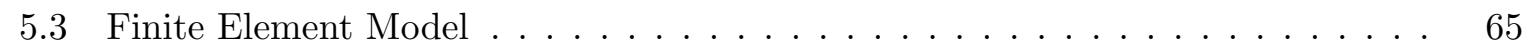

5.3 .1 Constitutive Model of Concrete Chamber . . . . . . . . . . . 65

5.3 .2 Constitutive Model for Backfill Material $\ldots \ldots \ldots \ldots \ldots$

5.3 .3 Selection of Elements . . . . . . . . . . . . . . . . . . . 68

5.3 .4 Boundary and Load Conditions $\ldots \ldots \ldots$

5.3 .5 Solution Procedure $\ldots \ldots \ldots \ldots \ldots \ldots$

5.4 Results and Discussion $\ldots \ldots \ldots \ldots \ldots \ldots \ldots \ldots$

5.4 .1 Stress Distributions in the Buried Chamber . . . . . . . . . . . 73

6 Conclusions and Future Work $\quad 81$

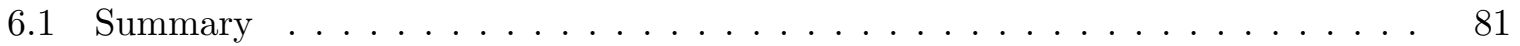

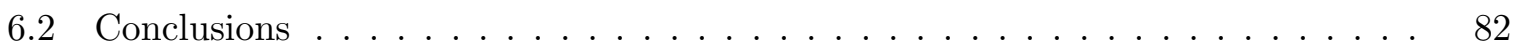

6.3 Recommendations for Future research $\ldots \ldots \ldots \ldots \ldots \ldots \ldots$ 
\begin{tabular}{|l|l|}
\hline Appendix A Specimen Geometry & 85
\end{tabular}

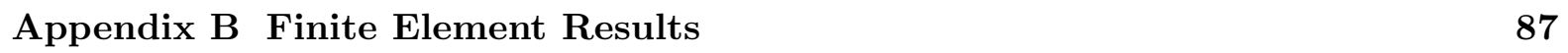

\begin{tabular}{|ll}
\hline Appendix C Input File & 94
\end{tabular}

\begin{tabular}{ll}
\hline References & 108
\end{tabular} 


\section{List of Tables}

4.1 Material properties of the GFRP and steel reinforced concrete chamber . . . . 38

4.2 Properties of GFRP, CFRP and steel bars . . . . . . . . . . . . . . . . . 48

4.3 Summary of different reinforcement configuration $\ldots \ldots \ldots \ldots$. . . . . . . . . 52

4.4 Thermal properties of steel and GFRP reinforced concrete chamber . . . . . . . 53

$5.1 \quad$ Elastic properties of concrete chamber reinforced with FRP and Steel bars. . . 65

5.2 Recommended properties for backfill soils $\ldots \ldots \ldots \ldots \ldots$

5.3 Thermal properties for soil and water $\ldots \ldots \ldots \ldots$. . . . . . . . . . . . . . .

$5.4 \quad$ Aaverage freezing depth for any number of freezing degree days . . . . . . . . . 72 


\section{List of Figures}

2.1 Surface and ground temperature (Williams and Gold, 1976) . . . . . . . . . . . 7

2.2 A buried structure subject to temperature variations $\ldots \ldots \ldots \ldots$. . . . . 8

2.3 Strain and stress distribution at ultimate conditions (ISIS Canada, 2007) (a) Balanced failure $\varepsilon_{c}=\varepsilon_{c u}, \varepsilon_{f r p}=\varepsilon_{f r p u}$ (b) Compression Failure $\varepsilon_{c}=\varepsilon_{c u}, \varepsilon_{f r p}<\varepsilon_{f r p u}$

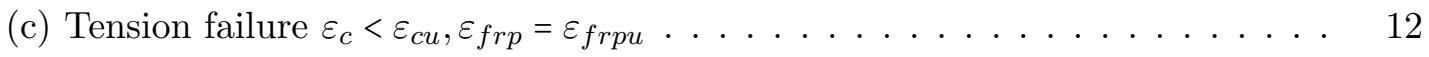

3.1 Dimensions of the modelled concrete chamber (D'Amours, et al., 2013) . . . . . 21

3.2 Typical test set-up (D'Amours, et al., 2013) . . . . . . . . . . . . . . 21

3.3 The tensile and compressive stress/strain curve of steel . . . . . . . . . . . . 23

3.4 The tensile and compressive stress/strain curve of GFRP bar . . . . . . . . . . . 24

3.5 Response of concrete to uniaxial loading in tension (ABAQUS/Standard User's

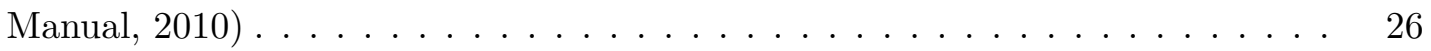

$3.6 \quad$ Cracking patterns along side of the chamber (D'Amours, et al., 2013) . . . . . 27

3.7 Concrete load-strain relationships of CH2 (D'Amours, et al., 2013) . . . . . . . . 28

3.8 Response of concrete to uniaxial loading in compression (ABAQUS/Standard User's Manual, 2010) . . . . . . . . . . . . . . . . . . . . . 29

$3.9 \quad$ Yield surface in plane stress (ABAQUS/Standard User's Manual, 2010) . . . . . 31

3.10 Node ordering, face numbering, and element numbering of integration points for Shell S4R (ABAQUS/Standard User's Manual, 2010) . . . . . . . . . . . . . . . 32

3.11 Details of load cell and load plate assembly (D'Amours, et al., 2013) . . . . . . 33

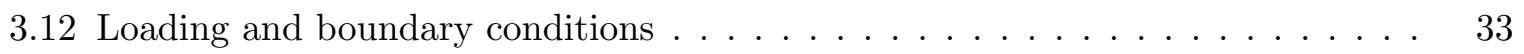

4.1 Overview of the concrete strain layout on the surface area of the chamber (D'Amours,

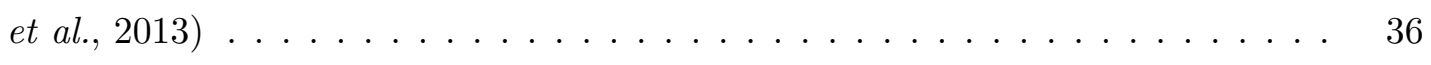

$4.2 \quad$ Typical chamber finite element mesh $\ldots \ldots \ldots \ldots \ldots \ldots \ldots$

4.3 The locations of the strain gauges (D'Amours, et al., 2013) . . . . . . . . . . . 38

4.4 Comparison of Concrete load-strain relationships at CRO for steel reinforced concrete chamber . . . . . . . . . . . . . . . . . . . 39 
4.5 Comparison of Concrete load-strain relationships at CTO for steel reinforced concrete chamber . . . . . . . . . . . . . . . . . . . . 39

4.6 The locations of the strain gauges (D'Amours, et al., 2013) . . . . . . . . . . . 40

4.7 Comparison of load-strain relationship of GFRP reinforcement at B1 for GFRP reinforced concrete chamber . . . . . . . . . . . . . . . . . . . 40

4.8 Comparison of load-strain relationship of GFRP reinforcement at B11 for GFRP reinforced concrete chamber . . . . . . . . . . . . . . . . . 41

4.9 Effect of increasing compressive strength of concrete on load-deflection relationship at center of the manhole . . . . . . . . . . . . . . . . . 43

4.10 Relationship between concrete compressive strength and ultimate load capacity 44

4.11 The location of GFRP reinforcement (shown as red line) . . . . . . . . . . . 46

4.12 Effect of increasing compressive strength of concrete on load-strain relationship of the GFRP reinforcement . . . . . . . . . . . . . . . . . . . . 47

4.13 Effect of different types of reinforcement on the load-deflection relationship of

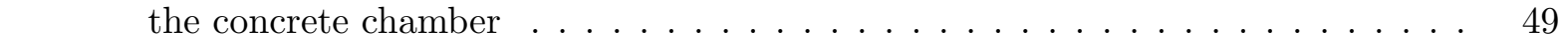

4.14 Von Mises equivalent stress in the chamber reinforced with steel and GFRP bars loaded up to their ultimate loads . . . . . . . . . . . . . . . . . 50

4.15 Effect of different types of reinforcement on load-strain relationship of reinforcement 51

4.16 Effect of reinforcement ratio on load-deflection relationships of concrete chamber

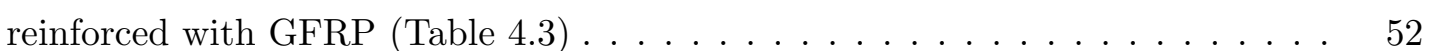

4.17 Soil temperature versus Depth (Fielding, 1976) . . . . . . . . . . . . . . . 54

4.18 Normal freezing index in degree days based on the period 1931 to 1960 for Canada

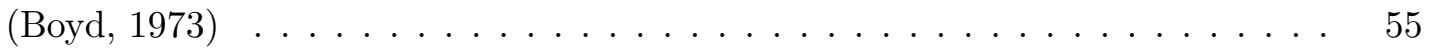

4.19 Schematic front view of the chamber $\ldots \ldots \ldots \ldots \ldots$. . . . . . . . . . 55

4.20 Predicted crack patterns due to temperature changes for Quebec (cracked elements $=$ grey, intact elements $=$ red $) \ldots \ldots \ldots \ldots 6$

4.21 Predicted crack patterns due to temperature changes for Ontario (cracked elements $=$ grey, intact elements $=$ red $) \ldots \ldots \ldots \ldots \ldots$. $\ldots \ldots \ldots$

4.22 Distribution of equivalent stress of chamber reinforced with steel and GFRP bars due to the action of temperature changes for Quebec (Soil depth=0.5 to1.5 m) 58

4.23 Distribution of equivalent stress of chamber reinforced with steel and GFRP bars due to the action of temperature changes for Quebec (Soil depth=2.0 to $3.0 \mathrm{~m}$ ) 59

4.24 Distribution of equivalent stress of the chamber reinforced with steel and GFRP bars due to the action of temperature changes for Ontario $\ldots \ldots \ldots$. . . . . 60 
5.1 Mechanisms of soil arching over a buried structure (a) embankment installation (b) trench installation (Kim and Yoo, 2005) . . . . . . . . . . . . . . . . 63

$5.2 \quad$ Linear Drucker-Prager model: Yielding surface (ABAQUS/Standard User's Man-

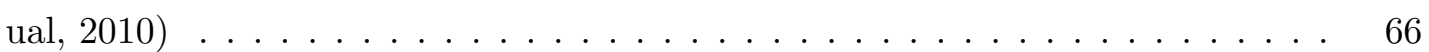

5.3 Finite element mesh in for soil and chamber in three dimensional view . . . . 70

5.4 Equivalent stress distributions in the concrete chamber reinforced with FRP and steel bars $($ backfill height $=1.5 \mathrm{~m})$. . . . . . . . . . . . . . . . . 74

5.5 Equivalent stress distributions in the concrete chamber reinforced with FRP and steel bars $($ backfill height $=2 \mathrm{~m}) \ldots \ldots \ldots \ldots$. . . . . . . . . . . 75

$5.6 \quad$ Equivalent stress distributions in the concrete chamber reinforced with FRP and steel bars $($ backfill height $=2.5 \mathrm{~m}) \ldots \ldots \ldots \ldots \ldots$

5.7 Effect of freezing/thawing on Equivalent stress distributions in steel reinforced concrete chamber (backfill material: Silty-Clay and Silty-Sand; backfill height=1.5m)

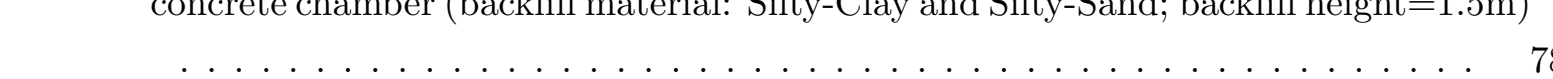

5.8 Effect of freezing/thawing on Equivalent stress distributions in steel reinforced concrete chamber (backfill material: Silty-Clay and Silty-Sand; backfill height=2m)

$\square \ldots \ldots \ldots \ldots \ldots \ldots \ldots \ldots$

5.9 Effect of freezing/thawing on Equivalent stress distributions in steel reinforced concrete chamber (backfill material: Silty-Clay and Silty-Sand; backfill height $=2.5 \mathrm{~m}$ )

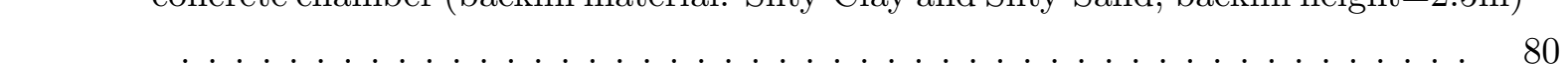

A.1 Shop drawing for the concrete chamber(Elevation faces A-C) . . . . . . . . . . 85

A.2 $\quad$ Shop drawing for the concrete chamber(Elevation faces B-D) $\ldots \ldots \ldots$. . . . . 86

B.1 Compressive equivalent plastic strain (PEEQ) contours and GFRP reinforcement stresses (RBFOR) for the chamber reinforced with GFRP bars $\left(f_{c}^{\prime}=25 \mathrm{MPa}\right.$, Ultimate $\operatorname{Load}=900 \mathrm{kN}) \ldots \ldots \ldots \ldots$. . . . . . . . . . . . 88

B.2 Compressive equivalent plastic strain (PEEQ) contours and GFRP reinforcement stresses (RBFOR) for the chamber reinforced with GFRP bars $\left(f_{c}^{\prime}=35 \mathrm{MPa}\right.$, Ultimate Load $=1000 \mathrm{kN}) \quad \ldots \ldots \ldots$. . . . . . . . . . . . . 89

B.3 Compressive equivalent plastic strain (PEEQ) contours and GFRP reinforcement stresses (RBFOR) for the chamber reinforced with GFRP bars $\left(f_{c}^{\prime}=45 \mathrm{MPa}\right.$, Ultimate Load $=1100 \mathrm{kN}) \quad \ldots \ldots \ldots$. . . . . . . . . . . . . . . 90

B.4 Compressive equivalent plastic strain (PEEQ) contours and GFRP reinforcement stresses (RBFOR) for the chamber reinforced with GFRP bars $\left(f_{c}^{\prime}=55 \mathrm{MPa}\right.$, Ultimate Load $=1140 \mathrm{kN}) \ldots \ldots \ldots \ldots$. . . . . . . . . . . . . 91 
B.5 Compressive equivalent plastic strain (PEEQ) contours and GFRP reinforcement stresses (RBFOR) for the chamber reinforced with GFRP bars $\left(f_{c}^{\prime}=65 \mathrm{MPa}\right.$, Ultimate $\operatorname{Load}=1175 \mathrm{kN}) \ldots \ldots \ldots$. . . . . . . . . . . . . 92

B.6 Compressive equivalent plastic strain (PEEQ) contours and GFRP reinforcement stresses (RBFOR) for the chamber reinforced with GFRP bars $\left(f_{c}^{\prime}=75 \mathrm{MPa}\right.$, Ultimate Load $=1230 \mathrm{kN}) \ldots \ldots \ldots \ldots$. . . . . . . . . . . . 93 


\section{Chapter 1}

\section{Introduction}

\subsection{General}

Underground structures such as power plants, tunnels, culverts, closed chambers and pipelines are strongly influenced by the existing ground medium. Unlike surface structures, the structural analysis and design of buried structures should account for the interaction of the host medium with the structure. Hence, changes in the properties of both soil and structure can have a significant role in the behaviour of buried structures under different conditions. This role is more considerable in cold regions where structures are subjected to cycles of freezing and thawing combined with deicing salts. This combination can endanger the short- and long-term durability of buried structures due to premature degradation of concrete and corrosion of the reinforcing steel bars.

Canada is categorized as a cold region, with all parts of the country affected by seasonally frozen ground. In Canada, the estimated cost of concrete repair due to corrosion of steel reinforcing bars is more than $\$ 20$ billion annually. Therefore, it is essential to search for and shed some light on feasible solutions to this economically challenging problem. Experimental and/or analytical approaches can be used to investigate available alternatives to minimizing or avoiding corrosion of steel reinforcement in buried concrete structures.

Despite the numerous advantages of experimental techniques, experimental work can be physically demanding and expensive, with several testing setups required to investigate the effects of design parameters, material properties and loading conditions. Hence, an analytical approach and numerical simulations are cost-effective techniques for parametric investigations of such complex multi-parameter interactions. This study presents a parametric numerical simulation of buried concrete chambers using finite element analysis. The developed model has been verified using available experimental test data. The main parameters included in 
the study are concrete grade, type of reinforcement, type of soil and embedded depth of the chamber. The results encompass two main correlated spheres: parametric three-dimensional stress analysis models and the influence of aggressive environmental conditions (temperature fluctuations and freeze-thaw cycles) on soil-chamber-interaction behaviour.

\section{$1.2 \quad$ Study Objectives}

Steel is commonly used as reinforcement for concrete underground structures. The materials behaviour has been widely investigated and documented. The characteristics of concrete underground structures reinforced with steel are now well-recognized; adequate knowledge is available on their reaction under different load conditions, and on the parameters that affect their performance. Nonetheless, there is a lack of research into the performance and design of concrete underground structures reinforced with new fibre-reinforced polymers (FRP).

Further research is therefore required to better understand the behaviour of FRP-reinforced underground structures. Greater knowledge will enhance the short- and long-term durability of underground structures exposed to aggressive environments, an issue that costs millions of dollars in repair and rehabilitation in North America and around the world. Thus, a parametric study is needed to investigate factors affecting the behaviour of buried concrete structures reinforced with FRP.

Based on the literature review, the structural analysis and design of buried structures are strongly influenced by mutual interaction between the structure and its surrounding soil. There are many research reports that focus on evaluating factors influencing mechanical behaviour of buried structures. However, this behaviour, especially in cold regions, is a complex problem with many correlated factors such as soil-structure interactions, confining pressure on exterior structure walls due to the frost heave of the soil, deformation due to structure temperature variation and movement of the surrounding soil due to thawing settlement and soil consolidation (Nixon and Burgess, 1999; Huang et al., 2004; Jin and Yu, 2005). At present, there is a lack of three-dimensional numerical models that consider the above-mentioned factors together, so it is necessary to study these factors via a numerical technique such as the finite element method in order to improve our understanding of the behaviour of buried structures in cold regions. Numerical simulation is a cost-effective approach for parametric investigations of structures with complicated interaction. Hence this study includes the following elements:

1. Presenting a brief literature review of the predominant factors associated with the above raised research questions.

2. Developing a three-dimensional nonlinear finite element model for the buried chamber 
using ABAQUS.

3. Verifying the developed model numerical results using some of the available experimental data for both steel and GFRP as concrete reinforcements.

4. Conducting a limited parametric numerical study for the stress analysis of the chamber under quasi-static loads.

5. Investigating of the effects of environmental conditions (temperature changes and soil freezing) surrounding the chamber on the global structural behaviour and nonlinear soil chamber interaction.

\subsection{Thesis Layout}

Following this introduction, a literature review on the essential durability-limiting factors associated with buried structures in cold regions is presented in Chapter 2. Three major factors are discussed: thermal effects, frost action and corrosion. Close attention is given to the introduction of FRP (fibre reinforced polymer) as an alternative reinforcement material for protecting buried structures against corrosion.

Chapter 3 presents the components of a nonlinear finite element (FE) model for simulating a concrete chamber reinforced with FRP or steel bars. Chapter 4 reports the validation procedure of the FE model versus experimental results, and details a parametric study conducted to investigate the effect of key factors on the performance of FRP and steel-reinforced concrete chambers. The effects of thermal gradient on the response of the concrete chamber are presented and discussed at the end of the chapter.

Chapter 5 presents a collection of the important literature published on determining the effect of the surrounding soil on box structures, including Marston-Spangler theory and the application of a finite element analysis program. This is followed by the FE simulation process for investigating the effect of freezing and thawing on the concrete chamber. The chapter also details various parametric studies conducted to determine the effect of the type of reinforcement and backfill material on chamber behaviour.

Finally, Chapter 6 is a brief summary of this study in which the research outcomes, conclusions and recommendations are presented. The chapter is concluded by a few suggestions for future research that may help shed more light on the topic. 


\section{Chapter 2}

\section{Literature Review}

\section{$2.1 \quad$ General}

Millions of people live and work in major cities with multiple closed networks for transportation systems, utilities, and buildings. On the basis of a study done by Vuchic (2005), the global urban population is expected to grow considerably over the coming decades. In fifty years, many cities will grow in size from small to medium, medium to large, and large to mega. The population growth problem, combined with limited urban space, has often led planners and engineers to consider underground space.

Underground spaces have generally been used for typical urban functions such as transportation (streets, subways, railways) and public-service utilities (water supply ducts, sewers). They have also been utilized for storage, security, underground electric stations and other applications. The fundamental goal for developing underground space is to ensure that the design and subsequent construction of underground structures meet the requirements of sustainable development. To achieve this objective, it is important to identify the potential risks associated with underground structures in a particular location and provide solutions to reduce the severity of potential consequences.

Concrete is the main building material for all different types of underground structures because of its durability, formability and strength. It is a flexible material which can be designed to reach targets in strength, permeability, density and color. However, concrete structures exposed to aggressive environments suffer from degradation and deterioration. In the case of underground structures, subsoil and ground water environments may contain aggressive agents like chloride, sulphates and acids, which can cause serious damage to such structures. Plus, because buried structures are covered with soil, accessibility for maintenance activities is difficult and often costly. Therefore, suitable mitigating measures should be identified and designed to 
reduce the potential hazards associated with the durability of a buried structure.

Generally, deterioration issues causing durability problems in concrete structures are considered based on:

- Corrosion of reinforcement

- Physical deterioration and damage process in concrete

- Chemical deterioration process in concrete

It is well-known that the main durability problem for concrete structures, buried or unburied, is the corrosion of reinforcing steel. Physical deterioration and damage is defined as processes causing movement and cracking in concrete structures. In buried concrete structures, the physical deterioration can arise from various mechanisms, including freeze and thaw effect (frost actions) and thermal effects. Chemical deterioration attacks concrete directly; some comes from internal sources, such as alkali-silica reactivity, and some is induced by external factors such as sulfate attacks and/or deicing salt. The combination of these deterioration processes can cause substantial durability problems. Thus, the following section presents a brief overview of literature related to reinforcing steel corrosion. It also provides an overview of the two essential durability limiting factors for buried structures: frost action and thermal effects. Finally, FRP is introduced as an alternative reinforcement for more durable and corrosion-resistant buried concrete structures.

\subsection{Buried Structures in Cold Regions and the Related Chal- lenges}

The behaviour of underground structures in cold regions differs from other climates. Damage occurs mainly because of frost heave or thaw settlement of the surrounding soil, and because of expansion and contraction of the structure due to temperature fluctuation. These two phenomena can impact the mechanical state of the structure and seriously endanger its safety. In order to ensure safety and durability in cold regions, it is necessary to consider the effects of temperature fluctuation and freeze-thaw conditions on the structure and surrounding soil materials.

In addition, it has been determined that the major issue associated with deterioration of concrete structures is corrosion of reinforcing steel. Due to a lack of knowledge of the field performance of corroded structures and the high cost of inspection, maintenance and repair, many studies have focused on investigating a feasible alternative to decrease the damage associated with corrosion. 


\subsubsection{Thermal Effects}

Temperature effects have been recognized as a significant criterion in the serviceability of concrete structures, especially underground structures. High levels of stress may be generated due to non-uniform temperature distribution through the structural components. Underground structures are highly restrained by the surrounding soil and their reinforcements, therefore the restrained thermal expansion, contraction or rotation can generate enough tensile stress to cause cracking in an underground structure. Such cracking can seriously endanger the serviceability and durability of the structure.

The temperature of a buried structure is highly dependent on its surrounding soil. If there are any temperature changes in the soil, this affects the temperature of the buried structure. Soil temperature changes from month to month and is the function of several factors (Williams and Gold, 1976). Solar radiation is probably the most influential factor contributing to the cycling variation of both air and soil temperature (Gold, 1967). The amount of solar energy absorbed by the ground surface governs the average annual ground temperature. Ground surface characteristics, including snow and vegetation, are another important factor, influencing temperature with their insulating and protecting effects. The thermal properties of soil are the third most important factor affecting soil temperature; they determine the response of the soil to the temperature changes at ground surface. The main thermal properties of soil are thermal conductivity, heat capacity and latent heat, which depend on soil temperature, soil type, water or ice content, degree of segregation and soil density (Andersland and Ladanyi, 2004).

As mentioned earlier, the factors affecting ground temperature are air (or ground surface) temperature, heat flow from the interior of the earth, and soil thermal properties. If the thermal properties of ground are constant, the features of ground temperature can be generally described by the following equation (Williams and Gold, 1976):

$$
T(x, t)=T_{m}+A \exp \left(-x \sqrt{\frac{\pi}{\alpha t_{0}}}\right) \cos \left(\frac{2 \pi t}{t_{0}}-x \sqrt{\frac{\pi}{\alpha t_{0}}}\right)
$$

where,

$\mathrm{T}(\mathrm{x}, \mathrm{t})=\mathrm{t}$ emperature at a given time $(\mathrm{t})$ and depth below the surface $(\mathrm{x})$

$T_{m}=$ the average temperature for a period

$\mathrm{A}=$ the amplitude of a temperature variation at the given depth that is equal to the difference between the maximum and minimum temperatures for the period, amplitude

$t_{0}=$ time for one cycle

$\alpha=$ thermal diffusivity (rate of heat flow in the ground)

Figure 2.1 graphically represents the above equation for a specific annual temperature variation. 
As shown in Figure 2.1, the amplitude of the temperature variation decreases exponentially with increased distance from the surface. In this case, at depths below 5 or 6 meters, the temperature of the soil remains constant through the year.

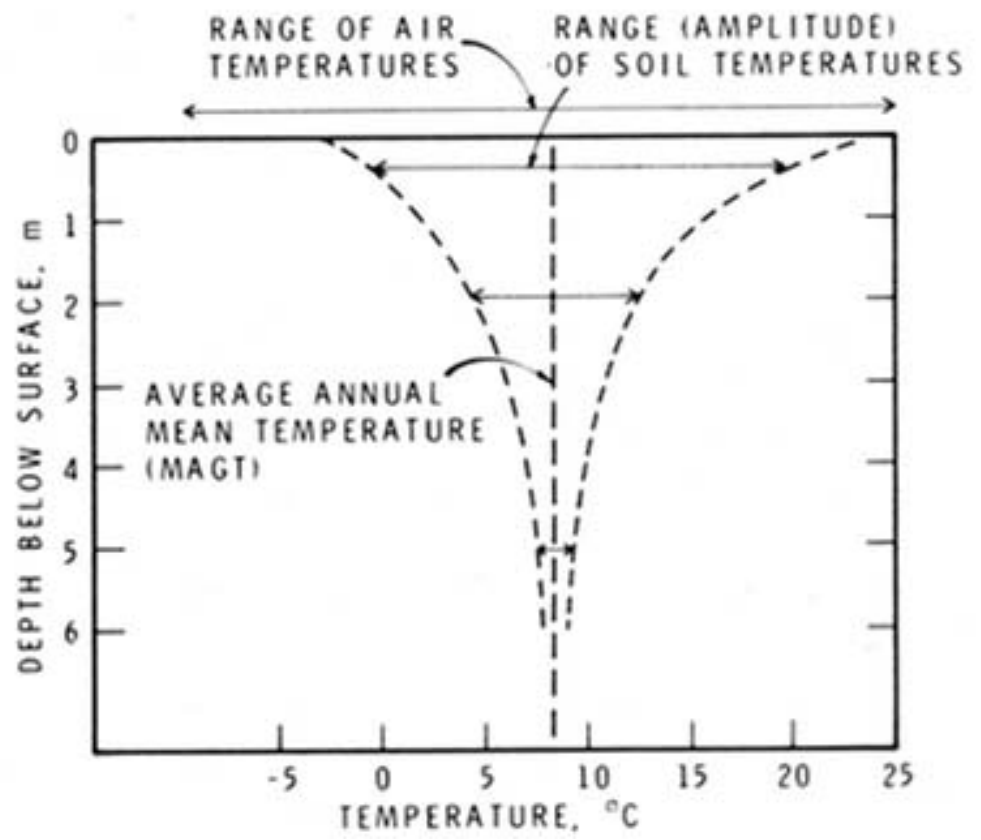

Figure 2.1: Surface and ground temperature (Williams and Gold, 1976)

If a buried structure is placed close to the ground surface (Figure2.2), the temperature will change substantially through its depth. Differential temperatures can create horizontal movements, and if such movements are restrained by surrounding soil and reinforcement, thermal cracking will occur. Also, in some cases, it has also been observed that different temperatures may be generated on the outer and inner surfaces of the buried structure, which can produce vertical movements. 


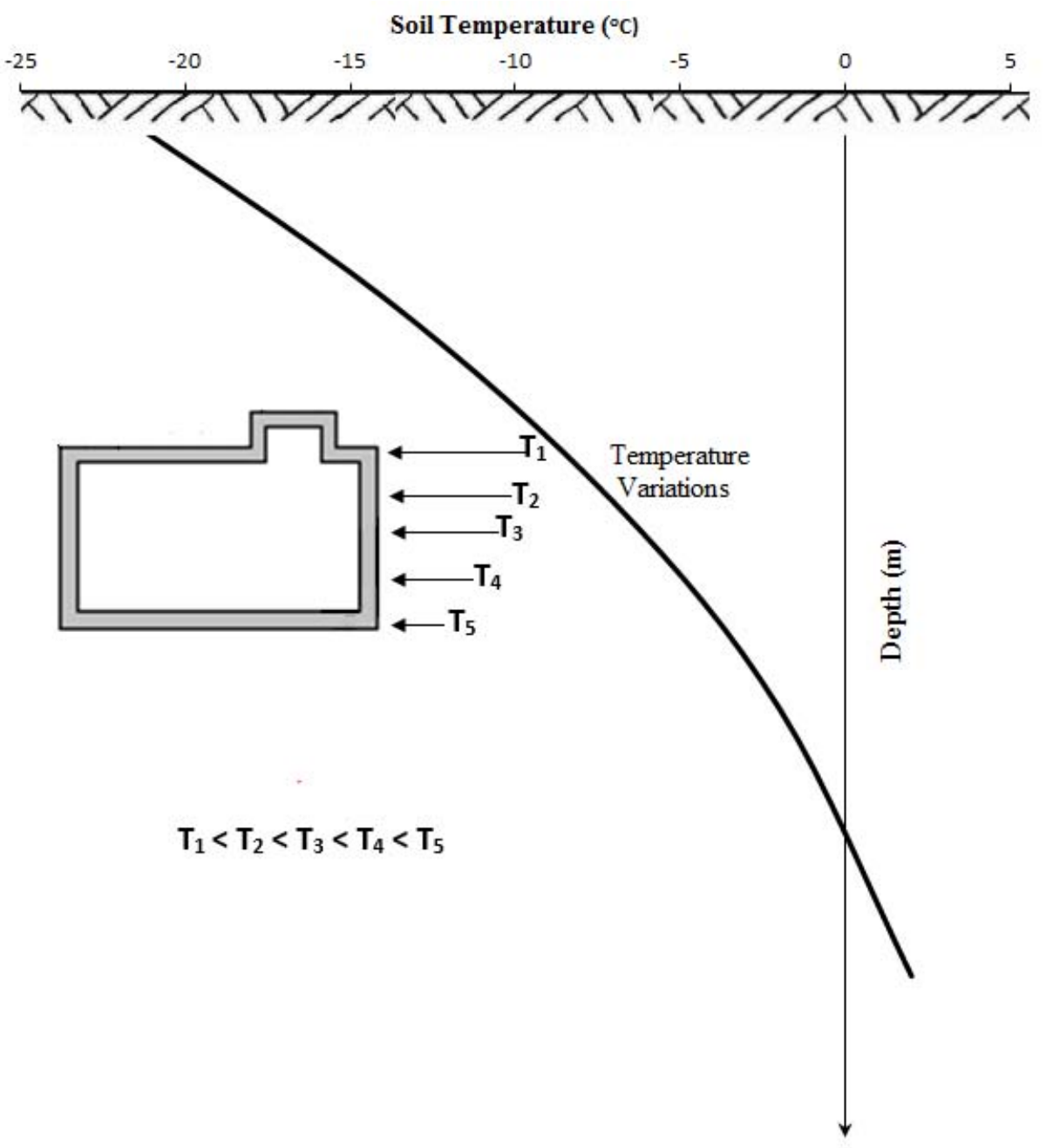

Figure 2.2: A buried structure subject to temperature variations

\subsubsection{Frost Action}

Frost action, including the process of frost heaving and thaw weakening, is a common durability problem for structures in cold regions, which cover more than half of all land area on the earth.

\section{- Frost heave}

Frost heave is a process associated with the volumetric increase of freezing water in soil. When the air temperature reaches values below $0 C^{o}$, water contained in the pores of soil can freeze. The conversion of liquid water to ice creates a volumetric increase of $9 \%$. If the ice lens continues to grow, ice crystals can generate enough hydraulic pressure to push 
soil particles upward. This upward movement can cause substantial damage to pavement in cold regions (Michalowski and Zhu, 2005a). In concrete pavement, the uneven heaving of soil below the concrete slab can cause cracking or lifting. However, the effects of frost actions are not limited to pavement. Underground structures built above the frost line can also be damaged when their surrounding soil freezes (Zhu, 2005). The increase in hydraulic pressure in the soil skeleton can generate high levels of stress, which may result in cracking and crushing of the concrete. The intensity of frost action is affected by factors including type of soil, availability of unfrozen water and the duration and intensity of freezing temperature.

The susceptibility of soil to frost action is based on their percentage of finer grains. If the soil contains 3 percent or more of finer grains, it is classified as frost-susceptible soil. For example, coarse sands and gravels with less than 3 percent fines are not considered frost-susceptible. On the other hand, silts can be very susceptible to frost actions because they have high permeability and small voids. Likewise, clays can be susceptible to frost action because of their tiny voids. However, due to their low permeability, the growth of ice lens is much slower.

\section{- Thaw Weakening}

Soil temperature gradually decreases as spring approaches, and the ice lens begins to melt. If the rate of melting is higher than the rate of water drainage, the remaining water will soften the soil and may decrease its bearing capacity. Consequently, the soil will consolidate under its weight or under external loads. This consolidation may be accompanied by thaw settlement, which can cause severe damage to structures. The amount of settlement is governed mainly by soil type, drainage condition and rate of thawing (Phukan, 1985; Simonsen and Isacsson, 1999).

\subsubsection{Corrosion}

The deterioration of steel-reinforced concrete structures is a critical global issue, due to high repair and replacement costs and reduction of service life.The average age of over 600,000 bridges in the United States is over 45, and approximately one-fifth of those bridges are in need of repair or replacement due to structural or functional deficiency. The cost of bridge repairs has been estimated at more than $\$ 50$ billion, with a $\$ 1-3$ trillion price tag for all concrete structures in the country. In Canada, it has been reported that $40 \%$ of bridges, highways and parking facilities are structurally deficient, with an estimated concrete repair cost of more than $\$ 6$ billion for parking facilities, and $\$ 10-20$ billion for bridges. In Europe, the annual cost of repair for all concrete structures is estimated to be about $£ 1$ billion (Leung and Balendran, 
2003; Isgor and Razaqpur, 2002; Nkurunziza, et al., 2005; Thompson and Yunovich,et al., 2003; Naus, 2007).

The major cause of deterioration of reinforced concrete (RC) highway structures and parking garages is corrosion. Under normal conditions, reinforcing steel does not corrode in concrete due to the high alkaline environment of concrete ( $\mathrm{pH}$ greater than 13). However, in the presence of adequate moisture, temperature and chlorides, a critical reduction in $\mathrm{pH}$ occurs, resulting in corrosion of steel reinforcement. Corrosion is an expansive reaction that causes cracks and spalling of concrete, which can result in major durability problems for structures subjected to aggressive environments.

\subsection{FRP as an Alternative Reinforcement}

Historically, steel has most commonly been used as reinforcement. However, steel-reinforced concrete is prone to corrosion damage when exposed to chlorides and other aggressive chemicals. As mentioned earlier, steel corrosion is a global problem associated with concrete structures. Buried structures placed in an aggressive environment and exposed to other types of deterioration can accelerate the corrosion mechanism, and the corrosion of steel bars results in major direct and indirect costs, from repairs to economic losses due to traffic jams. Thus, extensive research efforts have been carried out to protect RC structures against corrosion.

Engineers have taken various strategies (Mindess and Young, 1981) such as reducing concrete permeability, adding protective membranes to the concrete, placing a protective coating on steel, and suppressing the electrochemical process. Regardless of all these efforts, however, corrosionrelated problems have not been completely solved. Literature reviews suggest that the most effective approach for protecting steel reinforcement is the application of fusion-bonded epoxy coating. However, field and research data indicate that commonly-used epoxy-coated reinforcing bars cannot guarantee the safety of structures against corrosion (Clear, et al., 1995). In recent years, fiber-reinforced polymers (FRP) have been progressively considered as a general solution to corrosion problems in bridge decks and other structures due to their resistance to corrosion, high strength-to-weight ratio, good fatigue properties, and ease of handling (Porter and Harries, 2007; Nanni and Faza, 2002; Rosenboom and Rizkalla, 2006; Gutirrez, et al., 2007). Physical and mechanical properties of FRPs are obviously different from steel, leading to differences in the structural behaviour of concrete members. The following section is a brief summary of the mechanical behaviour of FRPs and their use as internal reinforcement rebar in concrete components. 


\subsection{FRP as Internal Reinforcement}

Glass fiber reinforced polymers (GFRP) and carbon fiber reinforced polymers (CFRP) can be used as an alternative to steel for internal reinforcement of concrete structures. The use of FRP materials has become more popular in structures exposed to aggressive environments due to their non-corrosive nature and high strength-to-weight ratio. FRP reinforcements can be found in shapes such as bars, stirrups, tendons, anchors, etc. The major differences between FRPreinforced concrete and conventional steel-reinforced concrete arise from the tensile behaviour of FRP bars, which are described by linear elastic stress-strain relationship up to failure. As a result, FRP-reinforced concrete members fail in brittle mode, which changes their ultimate strength, serviceability, and deformability. This section presents the effects of using FRP bars as reinforcement on the behaviour of concrete members.

\subsubsection{Flexural Capacity and Modes of Failure}

Generally, there are two types of expected failure modes for flexural concrete members; rupture of reinforcements and the crushing of concrete. For conventional steel-reinforced concrete, the tension failure of steel bars is the most favorable mode of failure. Steel-reinforced concrete sections are preferably under-reinforced to ensure yielding of steel before crushing of concrete. This is to take advantage of the plastic behaviour of steel after yielding, such as ductility and warning before failure. On the other hand, FRP bars do not exhibit any plastic deformation before failure, which means that the tension failure of FRP can be sudden and catastrophic (Theriault and Benmokrane, 1998; Jaeger, et al., 1997; GangaRao and Vijay, 1997). As a result, crushing concrete is considered a favorable mode of failure for FRP-reinforced concrete structures. Previous research (Nanni, 1993) shows that concrete crushing provides some plastic behaviour before failure. However, both modes of failure (FRP rupture and crushing concrete) are acceptable in controlling flexural design of FRP-reinforced concrete members, as long as strength and serviceability criteria are satisfied (ACI 440, 2001; CHBDC, 2000; ISIS Canada, 2007).

The flexure capacity of FRP-reinforced concrete can be obtained using the same approach developed for steel-reinforced structures (ACI 440, 2001); strain compatibility, internal force equilibrium and controlling mode of failure. Nevertheless, it should be noted that experimental results indicate that the code equations underestimate the moment capacity of FRP-reinforced concrete members, which can be raised by $20 \%$ in some cases (Masmoudi, et al., 1998; Pecce, et al., 2000; Theriault and Benmokrane, 1998) due to ultimate concrete strains that are higher when observed in experiments than what is assumed by codes. Stress, strain, and internal forces for three possible scenarios for a rectangular section reinforced with FRP bars (according to 
the ISIS Canada (2004) manual) are shown in Figure 2.3 .

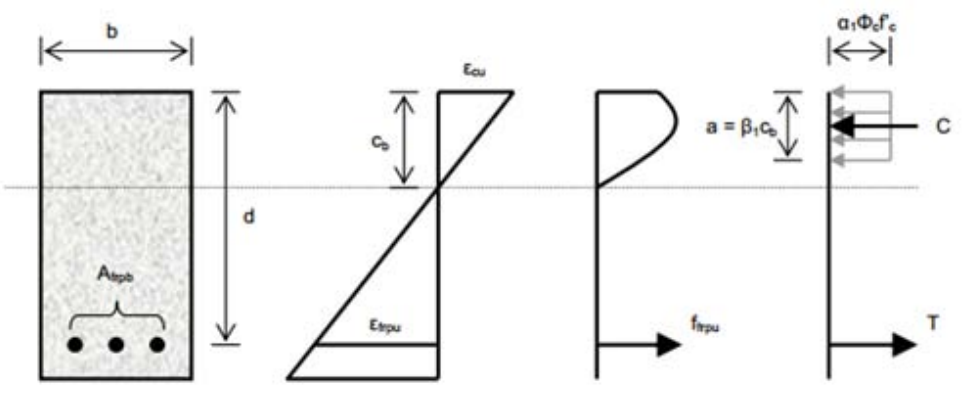

(a)

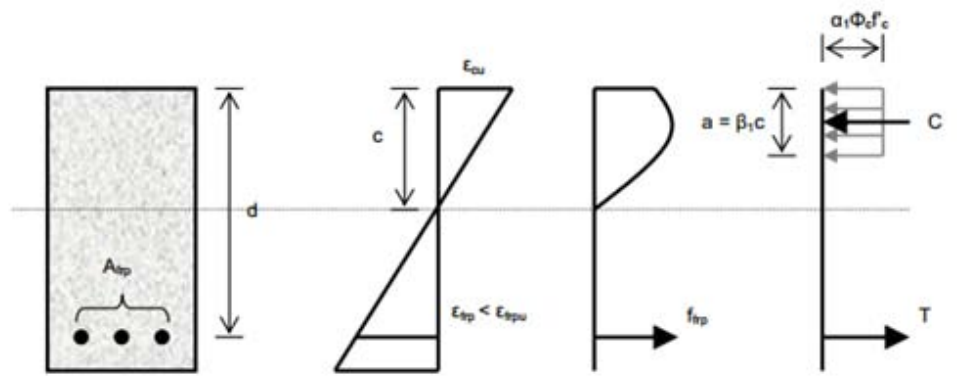

(b)

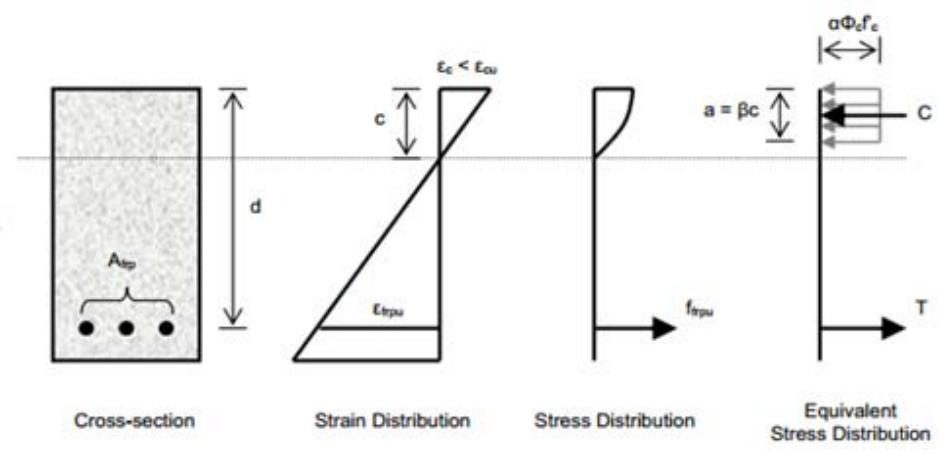

(c)

Figure 2.3: Strain and stress distribution at ultimate conditions (ISIS Canada, 2007)

(a) Balanced failure $\varepsilon_{c}=\varepsilon_{c u}, \varepsilon_{f r p}=\varepsilon_{f r p u}$ (b) Compression Failure $\varepsilon_{c}=\varepsilon_{c u}, \varepsilon_{f r p}<\varepsilon_{f r p u}$ (c)

Tension failure $\varepsilon_{c}<\varepsilon_{c u}, \varepsilon_{f r p}=\varepsilon_{f r p u}$

Several parameters affect the flexural capacity of concrete members reinforced with FRP bars. Concrete strength and longitudinal bar ratio are the most common factors changed by engineers to enhance flexural capacity. For example, for an under-reinforced section, increasing 
the compressive strength of concrete may not noticeably improve the flexure capacity of the section. This is attributed to the flexure capacity of the under-reinforced section, which is more closely related to reinforcement strength than concrete strength. On the other hand, for an over-reinforced section, improving concrete strength could be more helpful. Accordingly, these two factors should be considered simultaneously.

Kara and Ashour (2012) developed a numerical method for estimating moment capacity of FRP reinforced concrete beams. The proposed model was verified by experimental results and was employed to study the effect of increasing the area of FRP bars and concrete strength on flexural capacity. The study indicates that concrete compressive strength has a significant impact on the moment capacity of over-reinforced beams and no effect on the moment capacity of FRP under-reinforced ones. In addition, increasing FRP reinforcement for over-reinforced sections slightly changes the moment capacity.

Kobayashi and Fujisaki (1995) found that adding FRP compression reinforcements has little effect on moment capacity of the section due to the low modulus of elasticity of the FRP bars, which does not allow them to carry considerable compressive loads. Furthermore, FRP reinforcement has a significantly lower compressive strength than tensile strength, and the response of FRP bars to compression loads is variable. Therefore, it is recommended to ignore the compressive strength of FRP bars in design calculations (Almusallam, et al., 1997).

\subsubsection{Deflection and Cracking}

Due to the relatively low modulus of elasticity of commercially-available FRP reinforcement, concrete members reinforced with FRP bars experience reduced stiffness after cracking of concrete (ISIS Canada, 2007). Consequently, larger deformations and crack widths are expected for concrete members reinforced with FRP than with steel. In this sense, serviceability criteria including deflection and cracking are the main issues related to behaviour and design (ACI 440, 2001). Many studies have been carried out on the behaviour of reinforced concrete members under service load. The following paragraphs briefly present some of the previous work done in this field.

Buyle-Bodin, et al. (1995) studied the flexural response of E-glass-reinforced concrete beams. An experimental comparison was carried out between concrete beams reinforced with GFRP and those reinforced with steel. The researchers concluded that the deflection of GFRPreinforced concrete beams was two and three times larger than the deflection of the steelreinforced beams. Moreover, it was observed that the classical reinforced concrete equations are applicable for predicting the behaviour of GFRP-reinforced beams in flexure.

Benmokrane (1996) compared the behaviour of two sets of GFRP-reinforced beams with 
steel-reinforced beams. The study aimed to investigate cracking behaviour, modes of failure, load capacity, load deflection, and strain distribution. The deflection of the GFRP-reinforced beams was two to three times that of the steel-reinforced beams, and more and wider cracks were reported for GFRP-reinforced beams at service loads. Moreover, a perfect bond between FRP bars and the surrounding concrete was observed.

Another experimental study was carried out by Benmokrane and Masmoudi (1996) to investigate the effect of reinforcement ratio on the load deflection and ultimate capacities of 12 GFRP-reinforced concrete beams. Reinforcement ratios ranged between 0.56 and $2.15 \%$. The maximum deflection of the beams with $0.56 \%$ reinforcement ratio was approximately double that of the maximum deflection of those with $2.15 \%$. However, the maximum deflection of beams with $2.15 \%$ reinforcement was still larger than the code limit at serviceability. Hence, the researchers concluded that the deflection problem of beams reinforced with GRFP bars cannot be solved simply by increasing the reinforcement ratio.

Toutanji and Saafi (2000) tested a series of beams reinforced with GFRP and steel, and observed larger deflection and crack width for beams reinforced with GFRP bars. They compared the deflection and crack width based on experiment results and the ACI equation for steel-reinforced structures, and concluded that the proposed equations for predicting deflection and crack of steel-reinforced structures may not be applicable for GFRP-reinforced beams. Consequently, they proposed a modified equation based on Bransons equation for calculating deflection for FRP-reinforced concrete structures.

El-Salakawy and Benmokrane (2004) tested 10 full-size one-way bridge slabs reinforced with steel bars and different types and ratios of FRP bars. The results indicated that the main issues associated with FRP-reinforced slabs were deflection and cracking characteristics. In addition, due to the high strength of FRP bars, the strength of FRP-reinforced slabs was not a main concern. The study concluded that reinforcement diameter and spacing had no significant effect on the deflection and ultimate capacity of the slabs, however, reduction of bar spacing improved cracking characteristics.

It can be concluded that the major concern in FRP-reinforced members is serviceability criteria (deflection and crack width). All the above-mentioned experimental studies show that the deflection of FRP-reinforced concrete members is two to four times greater than it is in steel-reinforced concrete members. Therefore, the key to designing FRP-reinforced members is providing a cost-effective combination of these two key points; the desired deflection combined with the possibility of reduced reinforcement in cross-section. 


\subsubsection{Ductility and Deformability}

Ductility is a structural design requirement in most design codes. In general, it is defined as the amount of inelastic deformation that occurs before a complete failure. For steel-reinforced concrete structures, it is defined as ratio of deformation at post-yielding stage to yielding deformation. Ductility provides many benefits to the performance of concrete structures; the most important one is a pre-warning of structural failure. Ductile structures can undergo significant deformation before failure, allowing occupants to leave the building before collapse. Consequently, steel-reinforced concrete members have to be properly reinforced and dimensioned to exhibit desirable ductile behaviour.

The linear elastic behaviour of FRP bars up to failure means no plastic deformation happens before yielding. Plastic deformation allows the consumption of a large amount of energy in structures (Kim, et al., 2008). The absence of yielding in FRP bars may suddenly release a significant energy at failure, causing serious damage to the structure (Jeong, 1994). However, FRP-reinforced concrete members exhibit large deformation and can absorb energy through elastic deformation (Thriault, 1998). Therefore, the conventional definition of ductility is not applicable for FRP-reinforced members. In this sense, researchers have considered other techniques for defining ductility, such as deformability and energy-based approaches. In the energy-based approach, ductility is defined as energy-absorbing capacity (Wang and Belarbi, 2011). In the deformation-based approach, ductility is expressed as the ratio of the deformability margin between the ultimate stage and the service stage (Jaeger, et al., 1997). The deformability-based approach is used mainly for FRP-reinforced concrete members, while the energy-based approach can be used for any structure.

The deformability concept for FRP-reinforced structures was first developed by Abdelrahman (1996). The proposed deformability ratio $\mu_{a}$ was defined as the ratio of the deflection at ultimate $\Delta_{u}$ to the equivalent deflection at ultimate load based on un-cracked section properties $\Delta_{l}$.

$$
\mu_{a}=\frac{\Delta_{u}}{\Delta_{l}}
$$

Mufti, et al. (1996) developed the deformability index based on the deformation and the moment at service limit state and at the ultimate state. This index was adopted by CHBDC (2000). The index is measured by the following dimensionless equation:

$$
\mu_{m}=\left(\frac{\Psi_{u}}{\Psi_{s}}\right)\left(\frac{M_{u}}{M_{s}}\right)
$$

Where, $\Psi_{u}$ and $M_{u}$ are the curvature and moment at ultimate state. $\Psi_{s}$ and $M_{s}$ are the 
curvature and moment at service limit state. CHBDC (2000) code requires that the allowable deformability index be 4 and 6 for rectangular and $\mathrm{T}$ sections, respectively.

Vijay and GangaRao (2001) studied the effect of failure mode on ductility/deformability of FRP-reinforced beams. A high deformability index was achieved in compression failure of GFRP-reinforced beams, which was attributed to plastic hinge formation, confinement, significant concrete cracking in the compression zone, and stress redistribution. Accordingly, current design codes for such members recommend compression failure modes to achieve higher deformability.

\section{- Ductility Improvement}

The use of high-strength concrete (HSC) in reinforced concrete members is rapidly increasing due to its higher stiffness and strength (ACI 440, 2001). However, using HSC in combination with FRP can cause significant problems related to ductility (GangaRao and Vijay, 1997a) due to the higher brittle nature of high-strength concrete over normal concrete. Several studies have been carried out on improving the ductility of FRP-reinforced concrete (Harris and Somboonsong, 1998; Qu, et al., 2009; Alsayed and Alhozaimy, 1999). Naaman (2003) summarized the few available techniques for improving the ductility of FRP-reinforced concrete members as: 1) confinement of concrete, 2) placing pre-stressed reinforcement in layers, 3) using the combination of FRP and steel reinforcement, 4) using unbonded tendons, 5) changing the design process, and 6) increasing concrete stiffness.

\subsubsection{Shear Capacity}

The shear strength of concrete members is provided by the following mechanisms (Remirez, et al., 1998): 1) uncracked concrete core, 2) interlocking action of aggregates, 3) dowel action of longitudinal reinforcing bars, 4) residual tensile strength existing between inclined cracks, and 5) transverse reinforcement (if it exists).

Aggregate interlock results from the friction between crack faces and is mainly dependent on crack width. As a crack gradually opens, the effect of the interlocking action is reduced (Razaqpur, et al., 2004). Dowel action is generated from the shear resistance of the reinforcing bars crossing the cracked plane. The basic explanation of residual stresses is that when concrete first cracks, tensile forces can still transfer through the cracks. This could happen until the crack width is in the range of 0.05 to $0.15 \mathrm{~mm}$ (Joint ACI-ASCE Committee 445, 1998). Transverse reinforcements are mainly used to increase shear resistance of reinforced concrete members. They also provide more confinement to concrete in compression, resulting in greater ductile behaviour and higher concrete strength.

Compared to steel-reinforced sections with the same reinforcement ratio, a section reinforced 
with FRP has deeper and wider cracks due to the relatively low modulus of elasticity in FRP bars. Deeper cracks reduce shear strength due to the smaller compression area of the cross section. Wider cracks decrease the effects of aggregate interlock and residual stresses on shear strength. Furthermore, due to low shear stiffness and wider cracks, the contribution of dowel action can be less than in steel-reinforced members. Tottori and Wakui (1993) reported that the dowel capacity of sections reinforced with FRP is about $70 \%$ of those reinforced with steel. Fico, et al. (2008) recommended ignoring the shear strength provided by longitudinal FRP reinforcements. Consequently, members reinforced with longitudinal FRP bar exhibit lower shear strength than those with the same ratio of steel reinforcement, a finding that has been confirmed by several experimental studies (Yost, et al., 2001; Gdoutos, et al., 2000; Kara, 2011).

Ashour (2006) tested a series of 12 simply-supported FRP-reinforced concrete beams without transverse reinforcement under the four-point bending system. The tested beam specimens had different reinforcement ratios and beam depths. The predominant failure modes were flexure and shear failures; flexure failure occurred mostly due to the rupture of GFRP bars, and shear failure began with the formation of diagonal crack under the load point and extended up to the level of the GFRP reinforcement. Finally, the cracks propagated horizontally at the level of the GFRP bars, causing bond failure between the bars and the concrete. Ashour compared the experimental and theoretical predictions of shear capacity in different literatures, and found that ACI committee 440 (2001) and Michaluk, et al. (1998) significantly underestimated the shear capacity of GFRP beams, while the formula proposed by Deitz, et al. (1999) was a more reasonable estimation of the shear capacity of FRP-reinforced concrete beams.

Another experimental study of the shear capacity of FRP-reinforced concrete beams without transverse reinforcement was reported by El-Sayed, et al., (2006). They investigated the effects of reinforcement ratio and modulus of elasticity of the longitudinal reinforcement on shear capacity of beams. Nine simply-supported concrete beams were tested in a four-point bending system, and it was concluded that the concrete shear capacity of FRP-reinforced concrete beams was proportional to the cubic root of the ratio of axial stiffness of FRP and steel bars. The results also indicated that the shear capacity of reinforced-concrete beams without stirrups is dependent on the axial stiffness of the longitudinal reinforcing bars. As a result, a higher reinforcement ratio or modulus of elasticity of the reinforcing bars provides higher shear strength.

An experimental study of the performance of GFRP shear reinforcement for concrete beams by Ahmed, et al. (2010) evaluated the shear performance of concrete beams reinforced with GFRP stirrups with different shear reinforcement ratios. Four large-scale concrete beams were tested under a four-point bending system, with results that indicated that GFRP stirrups improved the shear strength of specimens. It was also observed that beams with smaller stir- 
rup spacing showed higher shear capacity, and the study concluded that the predicted shear strengths determined using ACI 440.1R-06 (2006) and CHBDC (2006) equations were in good agreement with experimental values.

\subsection{Review Conclusions}

In the last decades, FRP composites have been introduced as an alternative for more durable and corrosion resistance concrete, particularly for hostile environment. The non-corrodible nature of FRP bars - along with their high strength and light weight - make them a feasible alternative to this type of deterioration. However, the linear-elastic behaviour of the FRP material makes its application questionable. Extensive research studies have been conducted on the behaviour of beams, slabs, columns and other components reinforced with FRP bars, resulting in design guidelines and technical specifications regarding the use of FRP composites as an internal reinforcement (ACI 440, 2001; ISIS Canada, 2007; CHBDC, 2000). There is lack of sufficient data on behviour of FRP-reinforced buried concrete structures. Therefore, the objective of the research is to shed some light on the ongoing efforts of using FRP bars as a feasible alternative to steel-reinforced buried concrete structures.

In addition to corrosion related problems, the physical deterioration process can have a significant impact on the global structural behavior of buried concrete structures in cold regions. There is a lack of knowledge of the environmental conditions that may lead to the physical deterioration of the buried concrete structure. Thus, another objective of the research presented herein is to gain a better of a better understanding of the behaviour of buried concrete structures subjected to various loading and environmental conditions in cold regions. 


\section{Chapter 3}

\section{Finite Element Modeling}

\section{$3.1 \quad$ General}

There are two main types of processes for solving physical engineering problems:

1. The empirical solution

2. The theoretical solution

Empirical solutions use building samples that have the same or smaller scale of the problem being investigated to determine cause-and-effect relationships. Theoretical solutions use a mathematical approach consisting of analytical and numerical solutions. Analytical solutions are achieved by formulating equations for the entire body to achieve desired values at any specific location in that body. Complicated geometries, materials and loadings often mean that an analytical solution requires excessive algebraic efforts and is not obtainable. In a numerical solution, on the other hand, the entire body is divided into smaller units (elements). Instead of formulating mathematic equations for the whole body, they are formulated for each element and combined to obtain the solution for the whole body.

We therefore need to rely on numerical methods for problems with complicated physics and/or geometry. Different types of numerical algorithms each have their own advantages and disadvantages. The Finite Element Method (FEM) is one of the most popular methods, and has been widely applied to engineering problems. It has been successfully used in several engineering applications such as stress analysis and heat transfer, and so far, unlike experimental procedures, numerical analysis has been flexible and cost-effective, especially in large-scale problems involving changing design parameters, material properties and load conditions. However, it will always rely on experimental analysis to verify and validate numerical simulations and their associated assumptions. 
In this study, a non-linear finite element model (FEM) was constructed to investigate the effects of using FRP bars as reinforcement in buried concrete structures (concrete chambers). The commercially-available finite element analysis software package, ABAQUS, was used in this study, and the experimental results achieved by D'Amours, et al. (2013) were used to validate the model. Two chambers with identical steel and GFRP reinforcement were tested as part of the experimental protocol and the data set was used to verify the numerical simulation model results.

This chapter presents the components of the FEM model development including material models, element types and boundary conditions. It describes the assumptions and solution method used in modeling, and details the parametric study used to investigate the effect of key factors on the performance of both steel- and FRP-reinforced concrete chambers.

\subsection{Experimental Program Details}

An experimental investigation conducted at the University of Sherbrooke (2013) on behaviour of steel- and GFRP-reinforced concrete chambers under static load (DAmours, et al., 2013). The experimental results of these chambers provided an opportunity for numerical modeling and comparisons. One of the main concerns in this research is to build practical correlations between experimental and analytical data. This section is presented main points in the experiments that were considered in numerical modeling. A view of the chamber and its dimensions is shown in Figure 3.1. General reinforcement layouts and sectional details of the chamber are provided in Figures A.1 to A.2 (Appendix A).

The properties of the concrete were taken from the compression tests on concrete cylinder samples of the concrete that were used to cast the chambers. These tests were conducted on the same day the chamber was tested (DAmours et al., 2013). The compressive strengths of concrete varied between 71 and $82 \mathrm{MPa}$. The steel and GFRP reinforcement properties were taken from the manufacture data.

The chambers were subjected to concentrated load at the top of the chamber with quick cycles of loading, unloading and reloading (see Figure 3.1). The load was increased up to 1200 $\mathrm{kN}$. This maximum load was divided into ten loading steps; the load was increased from zero to a relative maximum load level at each step, and then unloading occurred before proceeding to the new level of applied load. The load test setup is shown in Figure 3.2.

The purpose of using loading-unloading cyclic techniques is to provide more information of the behaviour of the specimen under the same load level. Moreover, they allow for safe performance of the test during instrument readings (Mettemeyer and Nanni, 1999). However, in finite element modeling, the results have been validated from the experiments themselves 
and from the refinement sensitivity analysis. Moreover, there is no concern about the safe performance of a model in finite element modeling. The loading in the numerical analysis was therefore applied as a steady load up to $1200 \mathrm{kN}$.

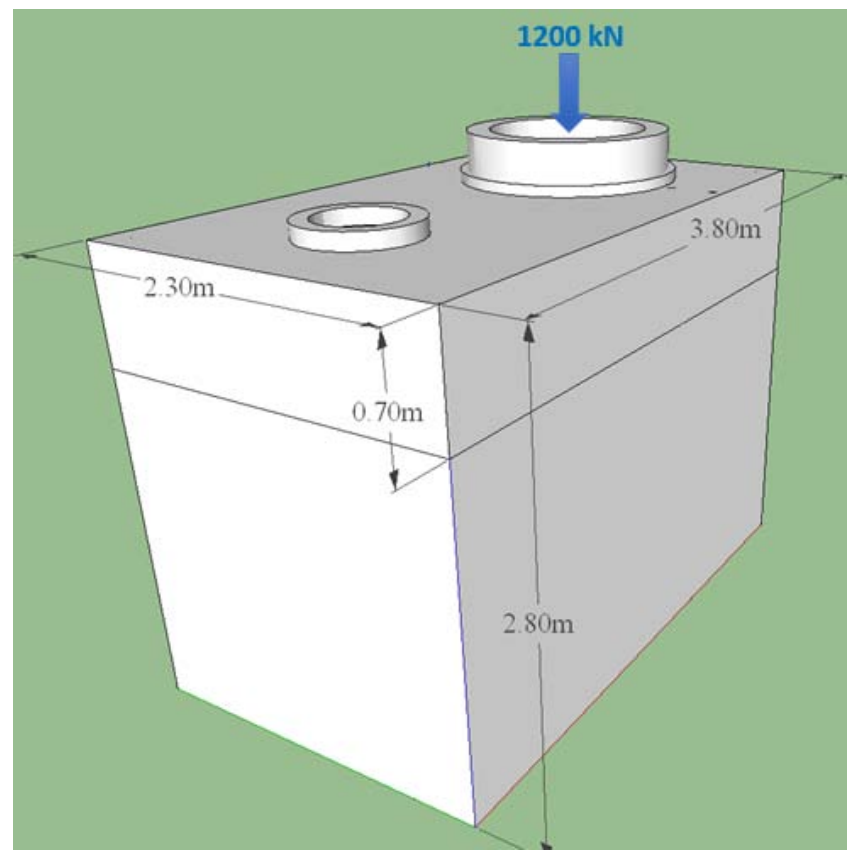

Figure 3.1: Dimensions of the modelled concrete chamber (D'Amours, et al., 2013)

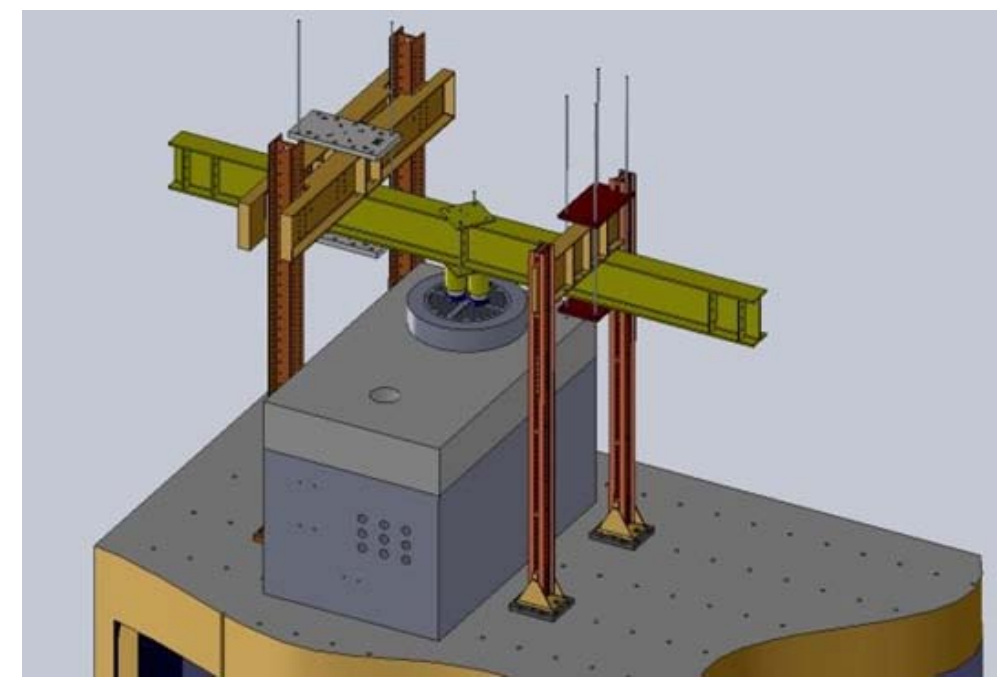

Figure 3.2: Typical test set-up (D'Amours, et al., 2013) 


\subsection{Finite Element Model Details}

To study the behaviour of concrete chambers, a three-dimensional finite element model (FEM) of the full-scale chambers was created. The model included 3-D shell elements with material non-linearity provided by ABAQUS. The reinforcement was defined as smeared layers in shell elements. Incremental static load was applied up to $1200 \mathrm{kN}$, and the chamber concrete base was assumed to be fixed. The following sections describe the model components and the methodology used to model the concrete chamber subjected to static loads.

\subsubsection{Material Modeling}

Material properties of the concrete chamber were taken from experimental and manufacturing data. Material properties of concrete and steel were defined using standard properties, density, modulus of elasticity, Poissons ratio, elastic strain, and plastic strain of concrete and steel. Material properties of FRP were defined using the aforementioned parameters with the exception of plastic strain. This section introduces the detailed constituent properties used for the analysis of the FRP- and steel-reinforced concrete chamber presented in this thesis.

\section{Steel}

The welded steel wire mesh used for concrete reinforcement (D'Amours, et al., 2013) had a reinforcement grade of 400W (G30.18-M92) with a density of $7860 \mathrm{Kg} / \mathrm{m}^{3}$. The manufacturer ${ }^{1}$ reported the yield strength and ultimate strength of steel as $400 \mathrm{MPa}$ and $540 \mathrm{MPa}$, respectively. Yielding strain was reported to be 0.002 , with a Young modulus of elasticity of $200 \mathrm{GPa}$. The wire mesh steel is described with a simple bilinear stress-strain curve in which no strain hardening of material is taken into account. As shown in Figure 3.3 , the behaviour of steel in tension and compression are idealized as being linear in elastic range up to yielding strength, and constant in plastic range after yielding strain.

\footnotetext{
${ }^{1}$ http://www.webcivil.com/rcrebar.aspx
} 


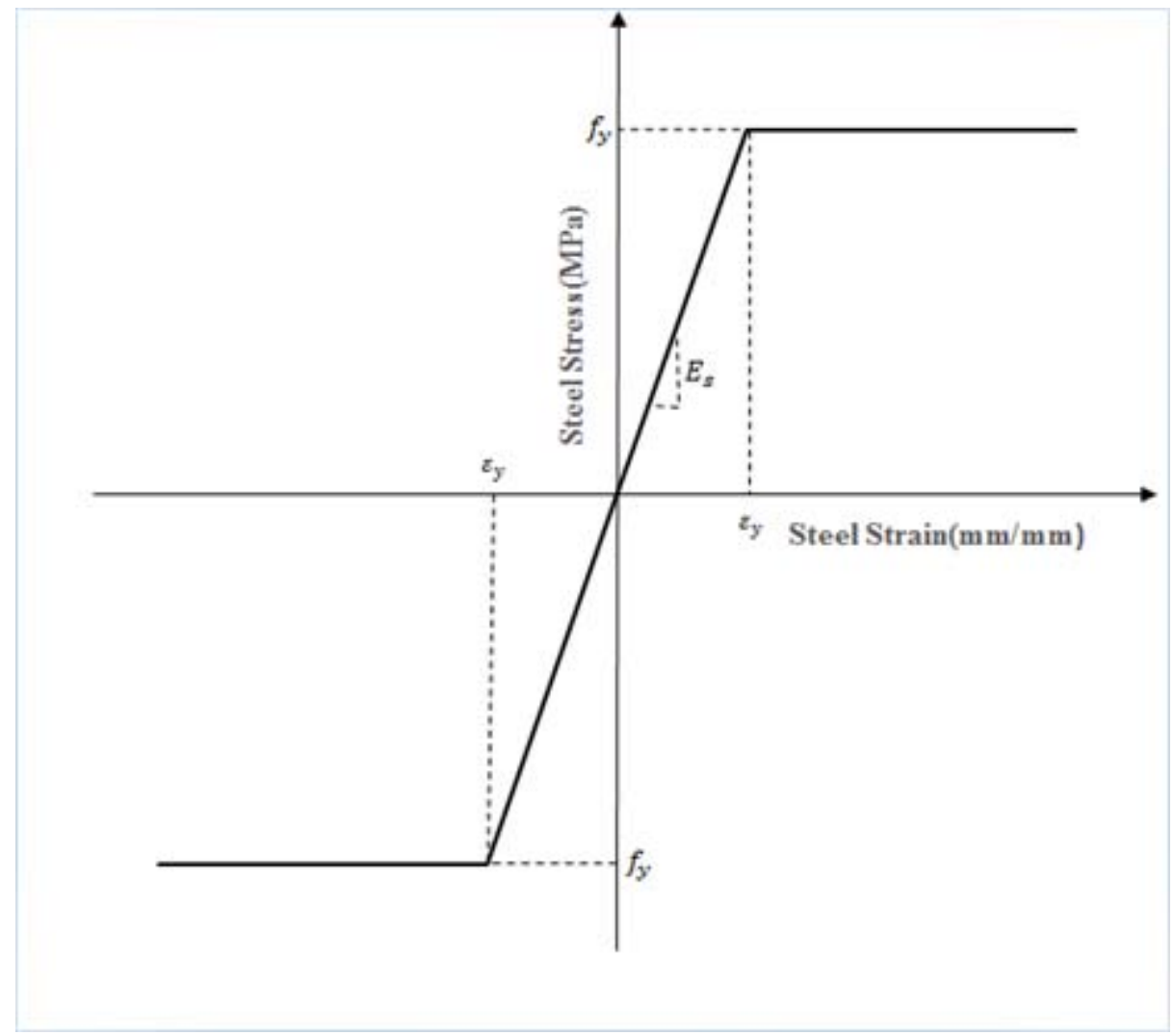

Figure 3.3: The tensile and compressive stress/strain curve of steel

\section{Glass Fiber Reinforced Polymer (GFRP)}

GFRP reinforcing bars were provided by Pultrall Company ${ }^{2}$, which reported the ultimate tensile strength and modulus of elasticity of FRP as $1350 \mathrm{MPa}$ and $65 \mathrm{GPa}$, respectively. The compressive strength of the FRP bars was adopted as half of the tensile strength, according to studies carried out by Deitz, et al. (2003). Young's modulus in compression was taken to be similar to Young's modulus in tension, as recommended by [ACI 440 (2001)]. Poisson's ratio of FRP was taken at 0.25. The linear-elastic model was used to describe the behaviour of FRP bars up to failure, in which no plastic deformation before yielding was taken into account. The linearly elastic behaviour of GFRP bars until failure in tension and compression is shown in Figure 3.4 .

\footnotetext{
${ }^{2}$ http://www.trancels-pultrall.com/
} 


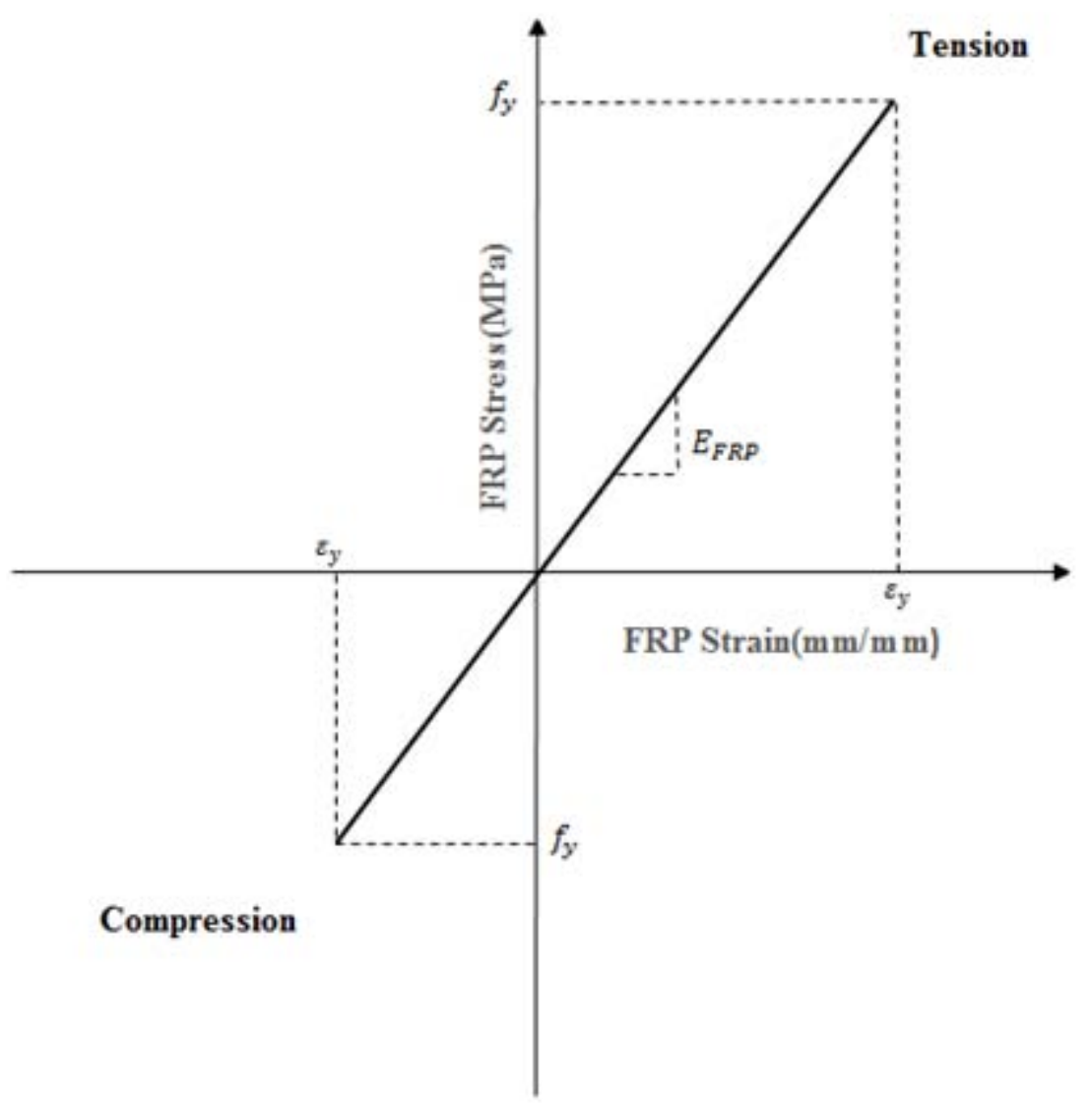

Figure 3.4: The tensile and compressive stress/strain curve of GFRP bar

\section{Concrete}

The stress-strain response of concrete follows a nonlinear relationship under tension and compression. Nonlinear behaviour of concrete arises primarily from at least one of the following components: cracking of concrete in tension, crushing of concrete in compression, yielding reinforcements and interaction between aggregates and reinforcements. There are several material models available for describing the mechanical behaviour of concrete; in this thesis, the damage plasticity model provided in ABAQUS has been used to describe nonlinearity in concrete material (ABAQUS/Standard User's Manual, 2010).

Concrete damage plasticity was proposed by Lubliner, et al. (1989) and Lee and Fenves (1998). This model has a wide range of capabilities for modeling concrete in all types of structures subjected to different loading conditions (ABAQUS/Standard User's Manual, 2010). It assumes different responses of concrete under tension and compression, resulting in two failure 
mechanisms: tensile cracking and compressive crushing. One of the main advantages of such a model is its ability to overcome some of the convergence difficulties associated with the most brittle smeared cracking models (De Borst and Nauta, 1984; Galvez, et al., 2002; Rots, et al., 1985). The following sections discuss the main components of the damaged plasticity model for concrete.

\section{- Elastic Properties}

TThe elastic characteristics of concrete have been defined using modulus of elasticity and Poisson's ratio. The modulus of elasticity was estimated using concrete strength and density. According to experimental data, the average concrete compressive strength $\left(f_{c}^{\prime}\right)$ was $75 \mathrm{MPa}$ for concrete specimens. Poisson's ratio for concrete was taken as 0.2 (Chaallal and Lachemi, 2010) and the modulus of elasticity was determined according to the following equation (CSA A23.3-04, 2004):

$$
E_{c}=\left[3300 \sqrt{f_{c}^{\prime}}+6900\right]\left(\frac{\gamma_{c}}{2300}\right)^{1.5} M P a ; 1500 \leq \gamma_{c} \leq 2500 \frac{\mathrm{kg}}{\mathrm{m}^{3}}
$$

Where $\gamma_{c}$ is density of concrete. For concrete with normal density and compressive strength between 20 and $40 \mathrm{MPa}$, the modulus of elasticity was calculated by the following simplified equation (CSA A23.3-04, 2004):

$$
E_{c}=4500 \sqrt{f_{c}^{\prime}}, M P a
$$

\section{- Tension Stiffening}

The resistance of concrete under direct tension is usually neglected. However, concrete can carry tensile stress through cracks due to its interaction with reinforcements. This contribution of the reinforcement on concrete is called tension stiffening, which is used to describe the overall stiffness of reinforced concrete after cracking. It approximately models phenomena like bond slip and dowel action associated with the contribution of concrete to carry tensile stresses.

In tension stiffening models in which post-failure stress is a function of cracking strain $\left(\varepsilon_{t}^{c r}\right)$, cracking strain is defined as the total strain minus the elastic strain related to undamaged material (ABAQUS/Standard User's Manual, 2010):

$$
\begin{gathered}
\varepsilon_{t}^{c r}=\varepsilon_{t}-\varepsilon_{t}^{e l} \\
\varepsilon_{t}^{e l}=\frac{f_{t}}{E_{c}}
\end{gathered}
$$


Where,

$\varepsilon_{t}=$ total tensile strain

$\varepsilon_{t}^{e l}=$ elastic strain

$E_{c}=$ initial stiffness of concrete

$f_{t}=$ tensile stress at $\varepsilon_{t}$

Figure 3.5 shows the tensile behaviour of concrete. Prior to cracking, the response is linear up to tensile strength $\left(f_{c r}\right)$, which is determined by the cracking criterion model. After cracking, tensile stress decreases with respect to the strain across the crack, which describes post-cracking behaviour.

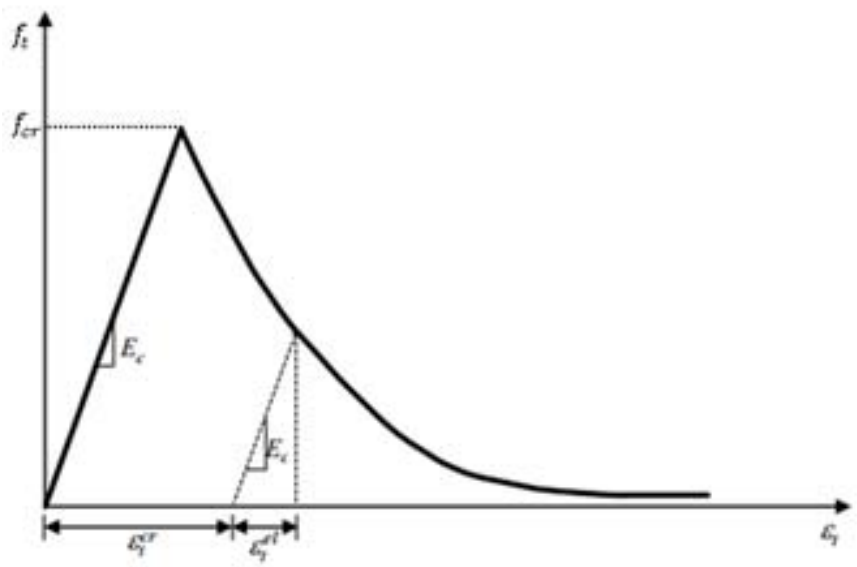

Figure 3.5: Response of concrete to uniaxial loading in tension (ABAQUS/Standard User's Manual, 2010)

Several models have been proposed to represent tensile response, ranging from simple to complex (Vecchio and Collins, 1982; Hwang and Rizkalla, 1983; Shima, et al., 1987; Marzouk and Chen, 1993; Fields and Bischoff, 2004). The Collins-Mitchell model is one of the simplest mathematical formulas used to describe the deseeding branch of tensile behaviour of concrete, yet it is well-accepted by designers. In that model, concrete tensile stress-strain response is proposed as (Collins and Mitchell, 1997):

$$
f_{t}=\left\{\begin{array}{cl}
E_{c} \varepsilon_{t} & \varepsilon_{t} \leq \varepsilon_{c r} \\
\frac{f_{c r}}{1+\sqrt{500 \varepsilon_{t}}} & \varepsilon_{t} \geq \varepsilon_{c r}
\end{array}\right.
$$

Where,

$$
\varepsilon_{c r}=\text { cracking strain }
$$




$$
f_{c r}=E_{c} \varepsilon_{c r}, \text { cracking stress }
$$

To form the Collins-Mitchell equation, cracking strain $\left(\varepsilon_{c r}\right)$ is needed. To capture that information, the crack patterns of the chamber were considered at different load levels. Figure 3.6 shows the crack propagation patterns formed along the side of the chamber from a load level of $1200 \mathrm{kN}$. The first crack occurred at a $270 \mathrm{kN}$ load level, as shown in Figure 3.6. The concrete strain around this crack was recorded using the strain gauge (CH2); Figure 3.7 shows shows the concrete load-strain relationships of this strain gauge. It can be seen from Figure 3.7 that the instrument became unstable after $42 \mathrm{micro} \mathrm{mm} / \mathrm{mm}$. As reported by D'Amours, et al. (2013), this was due to the appearing the crack at this location. this occurred due to the appearance of the crack at this location. Thus, the cracking strain was taken as $0.000042 \mathrm{~mm} / \mathrm{mm}$ and cracking stress was calculated as 1.49 MPa using Equation 3.5.

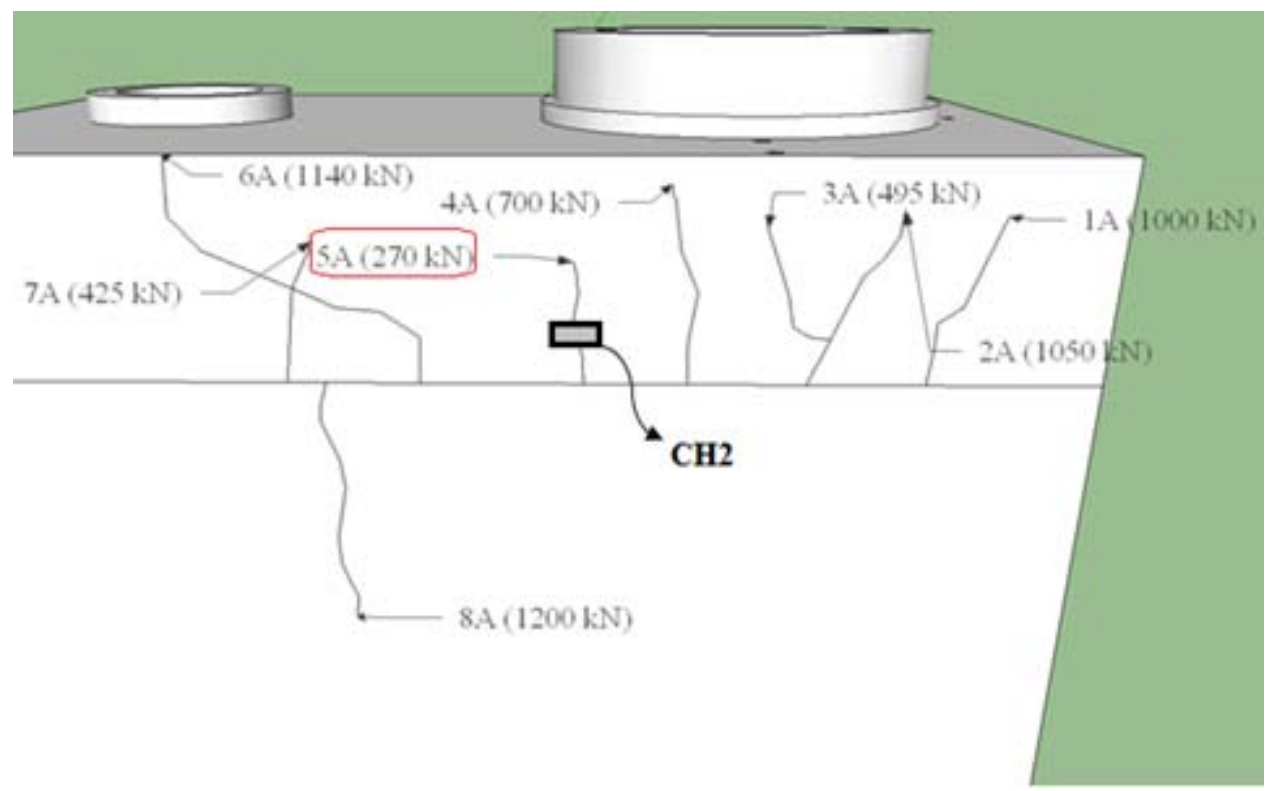

Figure 3.6: Cracking patterns along side of the chamber (D'Amours, et al., 2013) 


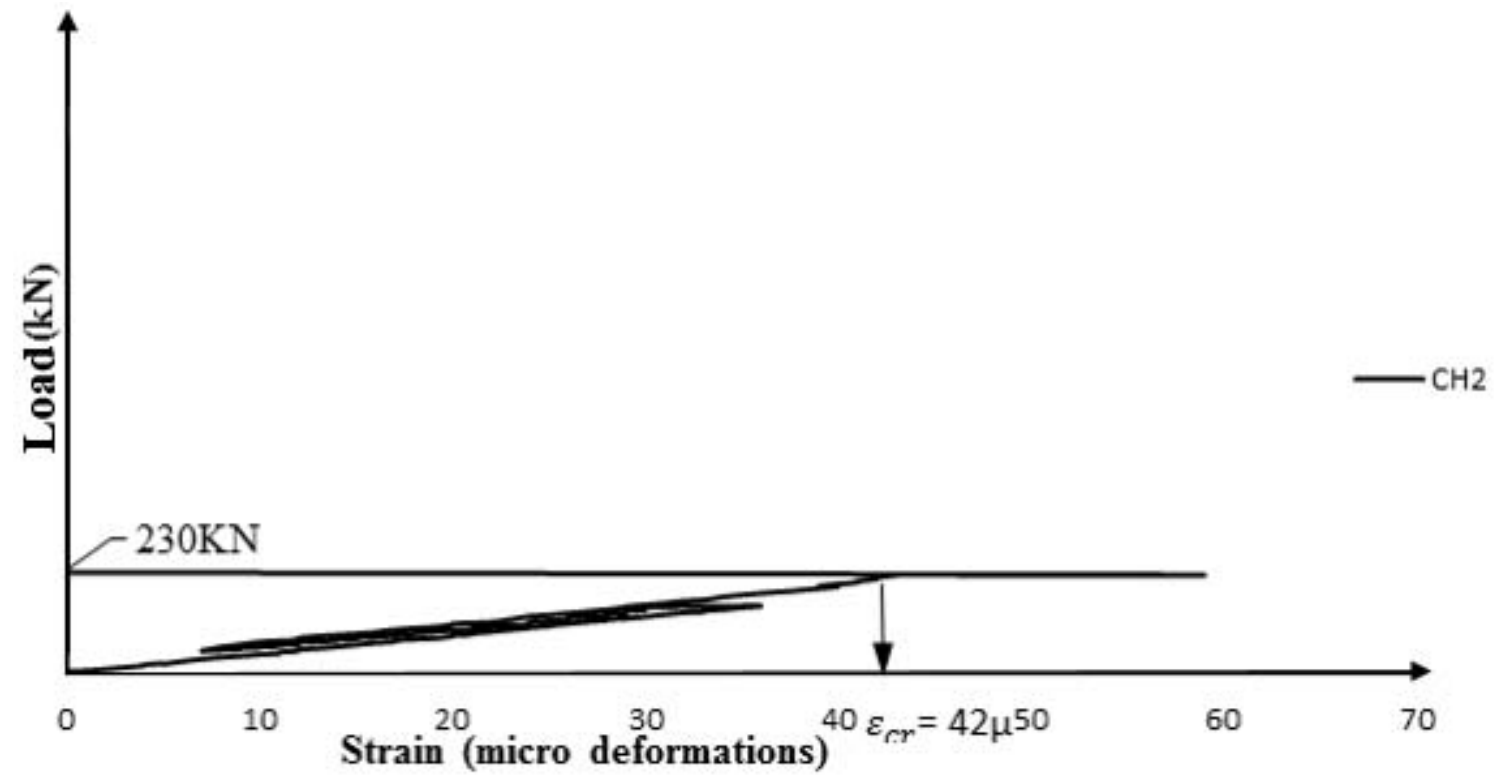

Figure 3.7: Concrete load-strain relationships of CH2 (D'Amours, et al., 2013)

\section{- Compressive Behaviour}

The concrete damage plasticity model assumes that uniaxial compression behaviour of concrete is defined according to its compressive stress $\left(f_{c}\right)$ and inelastic strain $\left(\varepsilon_{c}^{i n}\right)$. The inelastic compressive strain $\left(\varepsilon_{c}^{i n}\right)$ was calculated using the following equations (ABAQUS/Standard User's Manual, 2010):

$$
\varepsilon_{c}^{i n}=\varepsilon_{c}-\varepsilon_{c}^{e l}
$$

Where,

$\varepsilon_{c}^{e l}=\frac{f_{c}}{E_{c}}$, elastic compressive strain

$\varepsilon_{c}=$ total compressive strain

As shown in Figure 3.8, the compressive behaviour of concrete was linear up to the initial yield $\left(f_{c 0}\right)$. In the plastic range, the response is described by stress hardening, followed by strain softening beyond the ultimate stress $\left(f_{c u}\right)$ (ABAQUS/Standard User's Manual, 2010). 


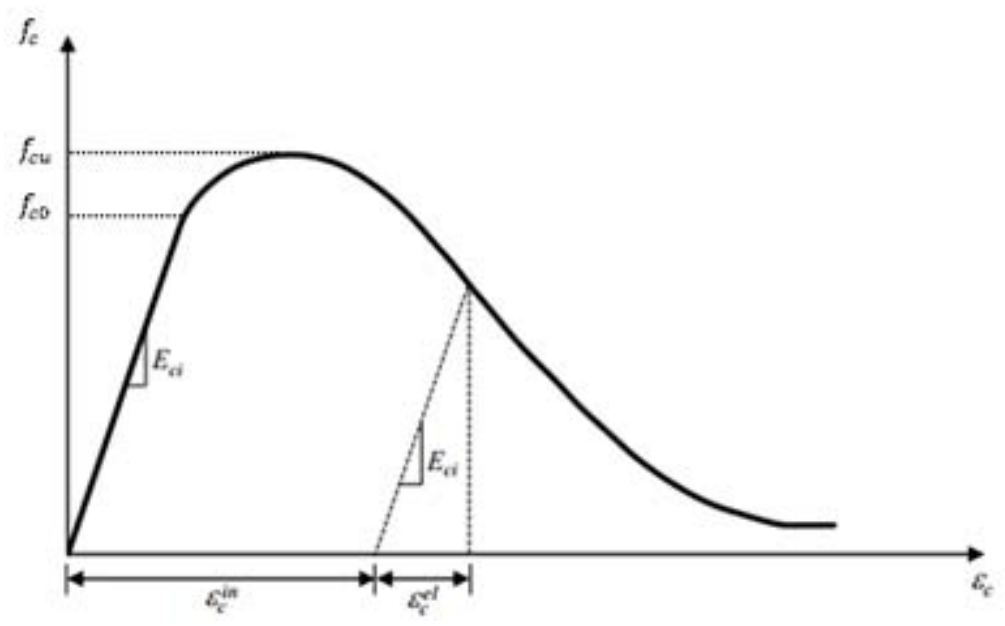

Figure 3.8: Response of concrete to uniaxial loading in compression (ABAQUS/Standard User's Manual, 2010)

Collins and Mitchell (1987) modified the compressive stress-strain curve proposed by Thorendfeldt, Tomaszewicz and Jensen (1987) and Popovics (1973) represent the behaviour of highstrength concrete under compression. The relationship between the compressive stress $\left(f_{c}\right)$ and the related strain $\left(\varepsilon_{c}\right)$ is given by the following equation:

$$
\frac{f_{c}}{f_{c}^{\prime}}=\frac{n\left(\varepsilon_{c} / \varepsilon_{c}^{\prime}\right)}{n-1+\left(\varepsilon_{c} / \varepsilon_{c}^{\prime}\right)^{n k}}
$$

Where,

$f_{c}^{\prime}=$ concrete compressive strength, $\mathrm{MPa}$

$\varepsilon_{c}^{\prime}=$ strain at $f_{c}^{\prime}$

$\mathrm{n}=$ curve fitting factor

$\mathrm{k}=$ factor to control the slope of the descending branch of the stress-strain curve

The role of the curve fitting factor is to provide more linear response for high-strength concrete with the decreasing difference between the initial tangent stiffness $\left(E_{c}\right)$ and secant stiffness $\left(E_{s e c}\right)$. It is given by following equation (Collins and Mitchell, 1997):

$$
n=0.8+\frac{f_{c}^{\prime}}{17}\left(f_{c}^{\prime} i n M P a\right)
$$

The factor $(\mathrm{k})$ captures a more rapidly descending branch of stress-strain curve for high-strength concrete and the increase in post-peak decay in stress. It is calculated as follows (Collins and 
Mitchell, 1997):

$$
\left\{\begin{array}{cc}
1.0 & \varepsilon_{c} / \varepsilon_{c}^{\prime} \leq 1.0 \\
0.67+\frac{f_{c}^{\prime}}{62} \geq 1.0 & \varepsilon_{c} / \varepsilon_{c}^{\prime} \geq 1.0
\end{array}\right.
$$

The strain at $f_{c}^{\prime}$ can be calculated as:

$$
\varepsilon_{c}^{\prime}=\frac{f_{c}^{\prime}}{E_{c}}\left(\frac{n}{n-1}\right)
$$

Therefore, if $\mathrm{n}, \mathrm{k}$, and $\varepsilon_{c}^{\prime}$ are known, concrete compressive stresses $f_{c}$ can be computed using Equation 3.7 for different compressive strain $\varepsilon_{c}$.

\section{- Concrete Plasticity}

Concrete plasticity is defined in terms of plastic flow and yield surface in the concrete damage plasticity model, which assumes non-associated potential plastic flow to describe the plastic strain. The Drucker-Prager (1952) hyperbolic function was used to model the flow potential (G) as follows (ABAQUS/Standard User's Manual, 2010):

$$
G=\sqrt{\left(\epsilon \sigma_{t 0} \tan \Psi\right)^{2}+\bar{q}^{2}}-\bar{p} \tan \Psi
$$

Where,

$\Psi=$ dilation angle measured in the p-q plane at high confining pressure, assumed as $34^{\circ}$ which is usually taken between $31^{\circ}$ to $36^{\circ}$ (Kmiecik and Kamiski, 2011; Nielsen and Hoang, 2011).

$\sigma_{t 0}=$ the uniaxial tensile stress at failure

$\epsilon=$ flow potential eccentricity; eccentricity defines the rate of hyperbolic flow potential approaches. taken as the default value, $\epsilon=0.1$ which indicates that the material has the same dilation angle over different confining pressure stresses

The yield surface in the concrete damage plasticity model was defined using the yield function proposed by Lubliner, et al. (1989) and Lee and Fenves (1998). The evaluation of the yield function depends on both tensile plastic strain $\left(\varepsilon_{t}^{i n}\right)$ and compressive plastic strain $\left(\varepsilon_{c}^{i n}\right)$. In terms of effective stresses, the yield function is defined as (ABAQUS/Standard User's Manual, 2010):

$$
F=\frac{1}{1-\alpha}\left(\bar{q}-3 \alpha \bar{p}+\beta\left(\varepsilon_{t}^{i n}\right)\left(-\bar{\sigma}_{\max }\right)-\gamma\left(-\bar{\sigma}_{\max }\right)\right)-\bar{\sigma}_{c}\left(\varepsilon_{c}^{i n}\right)
$$

Here, 


$$
\begin{aligned}
& \alpha=\frac{\left(\sigma_{b 0} / \sigma_{c 0}\right)-1}{2\left(\sigma_{b 0} / \sigma_{b 0}\right)-1} ; 0 \leq \alpha \leq 0.5 \\
& \beta=\frac{\sigma_{c}\left(\varepsilon_{c}^{i n}\right)}{\sigma_{t}\left(\varepsilon_{i n}^{t}\right)}(1-\alpha)-(1+\alpha) \\
& \gamma=\frac{3\left(1-K_{c}\right)}{2 K_{c}-1}
\end{aligned}
$$

Here,

$\bar{\sigma}_{\max }=$ the maximum principal effective stress

$\bar{\sigma}_{t}\left(\varepsilon_{t}^{i n}\right)=$ the effective tensile cohesion stress

$\bar{\sigma}_{c}\left(\varepsilon_{c}^{i n}\right)=$ the effective compressive cohesion stress

$\sigma_{b 0} / \sigma_{c 0}=$ the ratio of initial equiliaxial compressive yield stress to initial compressive yield stress, the most reliable value is 1.16 which is taken as the default value by the ABAQUS user's

manual.

$K_{c}=$ the ratio of the second stress invariant on tensile meridian to that of the compressive meridian, at initial yield for any given value of the pressure invariant. The value of 0.666 was assumed in this study, as recommended by ABAQUS users manual (2010).

The yield surface is shown in Figure 3.9 for plane stress.

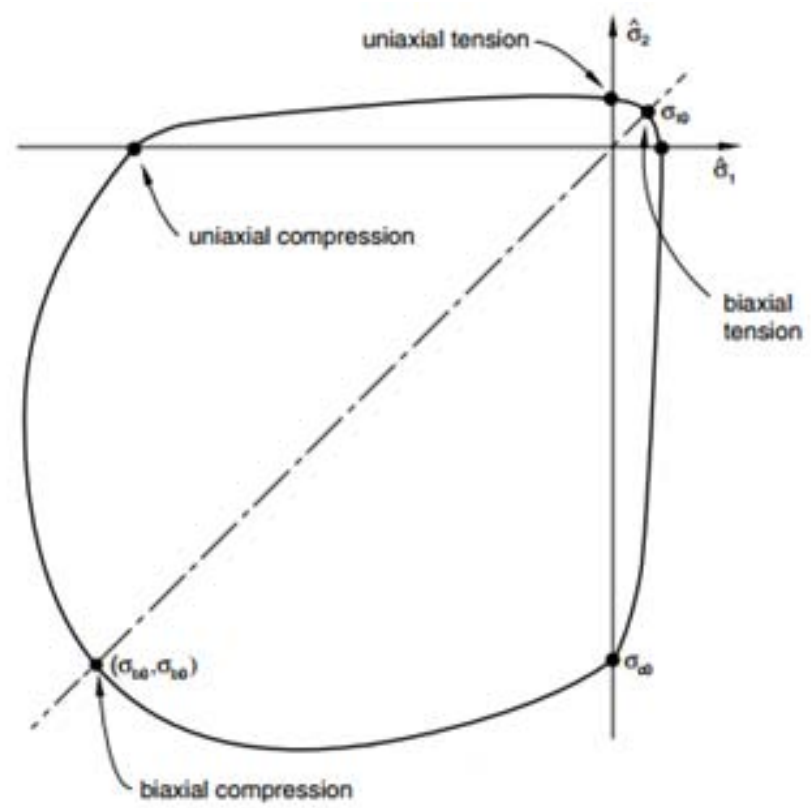

Figure 3.9: Yield surface in plane stress (ABAQUS/Standard User's Manual, 2010) 


\subsubsection{Element Selection}

\section{Shell Element}

The modeling of the reinforced concrete chamber used a three-dimensional, four-node, generalpurpose shell S4R with six degrees of freedom at each node, as shown in Figure 3.10. S4R is a general purpose element, with reduced integration. It can be used in linear or nonlinear analysis, allows mechanical or thermal loadings, and is able to represent output results for the distribution of shear force and bending moments at various load levels. It has a great capability to model the behaviour of reinforced concrete structures in which one dimension (thickness) is smaller than the others. Moreover, this element can accommodate layers of reinforcement at specified locations. These layers, called smeared or rebar layers, are created based on the geometry and material properties of the reinforcements. Perfect bond between reinforcements and concrete is assumed in defining rebar layers, and the stiffness of layers is automatically transferred to the nodes of the shell element.
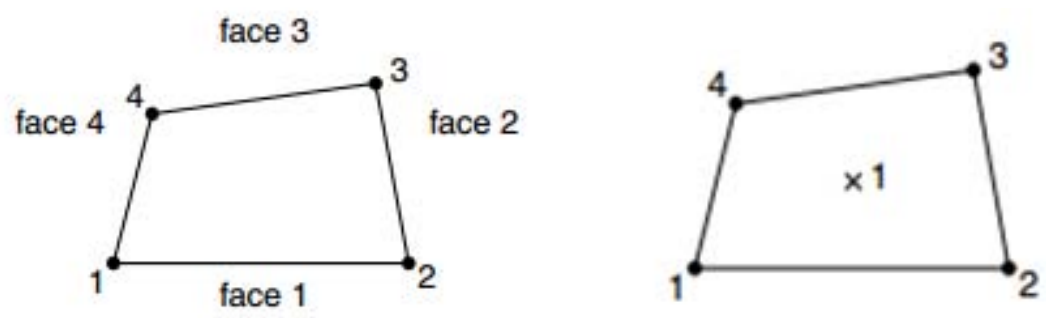

Figure 3.10: Node ordering, face numbering, and element numbering of integration points for Shell S4R (ABAQUS/Standard User's Manual, 2010)

\subsubsection{Loading and Boundary Conditions}

The concrete chamber tested at the University of Sherbrooke (D'Amours, et al., 2013) was subjected to concentrated load at the top of the chamber. The load test setup is shown in Figure 3.11. In the model development for ABAQUS, a reference node using coupling constraint was introduced for distributing the load to the top surface of the manhole, as shown in Figure 3.12 . As reported by D'Amours et al. (2013), the chamber was prevented from moving in horizontal and vertical directions, fixing the bottom surface of chamber. Figure 3.12 shows the specimen with the resulting boundary conditions. 


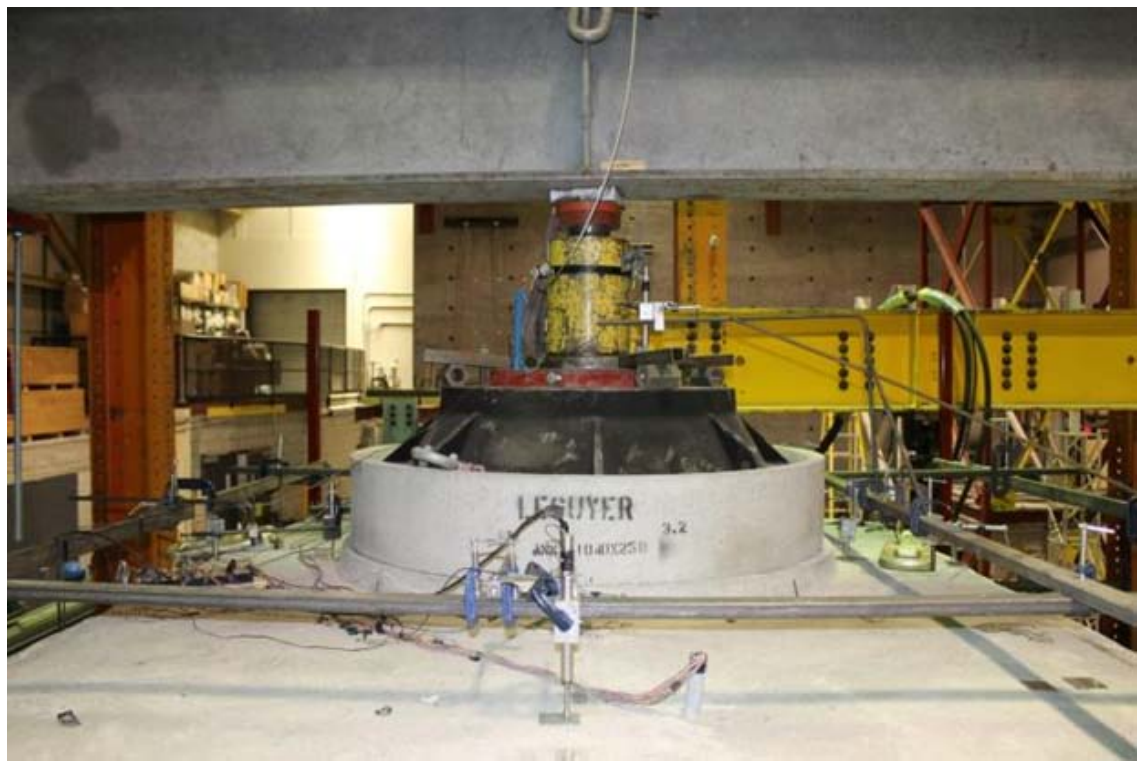

Figure 3.11: Details of load cell and load plate assembly (D'Amours, et al., 2013)
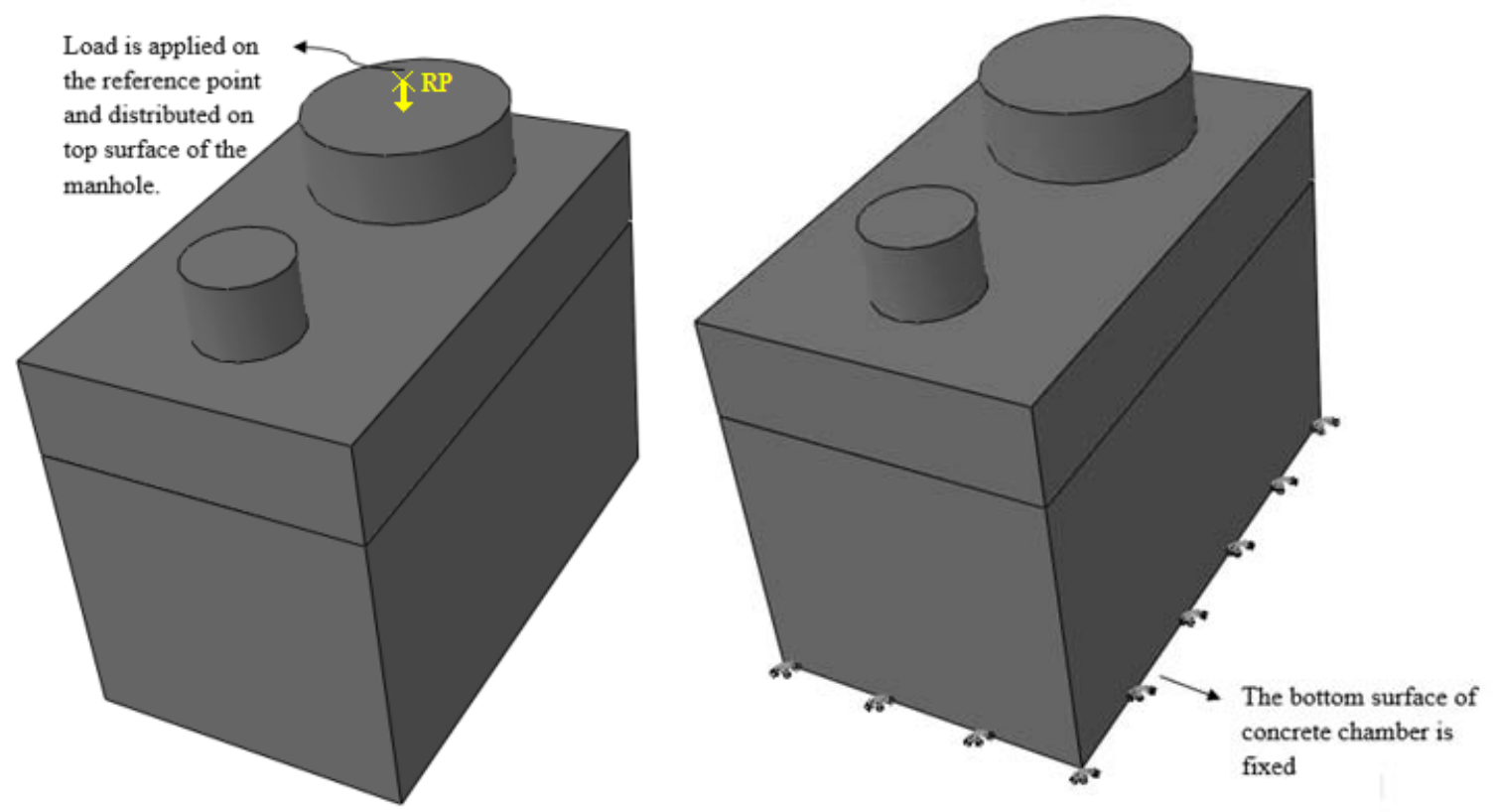

Figure 3.12: Loading and boundary conditions 


\subsubsection{Nonlinear Solution and Convergence Criteria}

A nonlinear response is one in which a structures stiffness changes as it deforms. The actual response of all structures is nonlinear. However, linear analysis is a convenient assumption that is often acceptable for design purposes. Despite this fact, a linear solution is not sufficient for many structure simulations, including concrete structures. The response of concrete material under a static load is nonlinear, mostly due to the existence of material softening during cracking of concrete. The ABAQUS library suggests two approaches for solving this class of problem (ABAQUS/Standard User's Manual, 2010): the first is to use the Modified Riks method (Crisfield, 1981; Ramm, 1981; Powell and Simons, 1981) to solve nonlinear equilibrium equations. The second is to solve the problem using the explicit integration rule (ABAQUS/Standard User's Manual, 2010).

In general, the main objective of analysis is to calculate internal forces (I) from external forces $(\mathrm{P})$. The net force acting at every node must be zero for the body to be in static equilibrium as follows:

$$
P-L=0
$$

The Modified Riks method uses the Newton-Raphson method (Iserles, 2008) to solve this equation for all nodes in the structure. In a nonlinear analysis, the solution can usually not be done in one process. ABAQUS therefore divides the solution into a number of load increments and uses the iterative procedure to find the acceptable approximate equilibrium configuration at the end of each load increment. The sum of all these incremental responses is the approximate solution for the nonlinear analysis. On the other hand, the explicit integration rule allows the solution to proceed without iterations. ABAQUS breaks the solution down to numbers of time increments. The explicit operator solves the equilibrium equations at the beginning of each increment $(t)$, and the accelerations calculated at time $t$ are used to find the velocity at time $t+\Delta t / 2$ and displacement at time $t+\Delta t$ (Hibbitt and Karlsson, 1979). Thus, the cost of each

increment is much smaller than in the Riks method because there is no iterative procedure for solving equations. Hence, the Risk Method requires solving a large number of equations with a procedure that requires tremendous computation, disk space and memory for problems involving a high amount of nonlinearity (ABAQUS/Standard Users Manual, 2010). Therefore, the explicit procedure was taken as the solution scheme for modeling the concrete chamber under static load. 


\section{Chapter 4}

\section{Model Validation and Parametric Study Results}

\subsection{General}

FE models were developed for concrete chambers reinforced with steel and GFRP bars, as described in Chapter 3. Each model was calibrated to achieve the best agreement with experimental results provided by D'Amours, et al. (2013). Section 4.2 presents a brief comparison of the calibrated FE and the experimental results. At the end of this chapter, the results of a parametric study are presented and discussed. The parameters of the study include type of reinforcement, concrete compressive strength, reinforcement ratio and temperature change effects.

\subsection{Model Validation Process}

To understand the differences in behaviour of concrete chambers reinforced with steel and FRP, an identical chamber was manufactured with the same dimensions and material properties, using FRP rebars as reinforcement instead of steel. The test was set up at University of Sherbrooke with similar boundary and load conditions as the steel-reinforced chamber.

In order to monitor specimen behaviour, a number of instruments and gauges were mounted on the specimen itself (Figure 4.1). These instruments measured surface strains, changing the strain of reinforcements, displacements and total applied loads to the specimen during testing. 

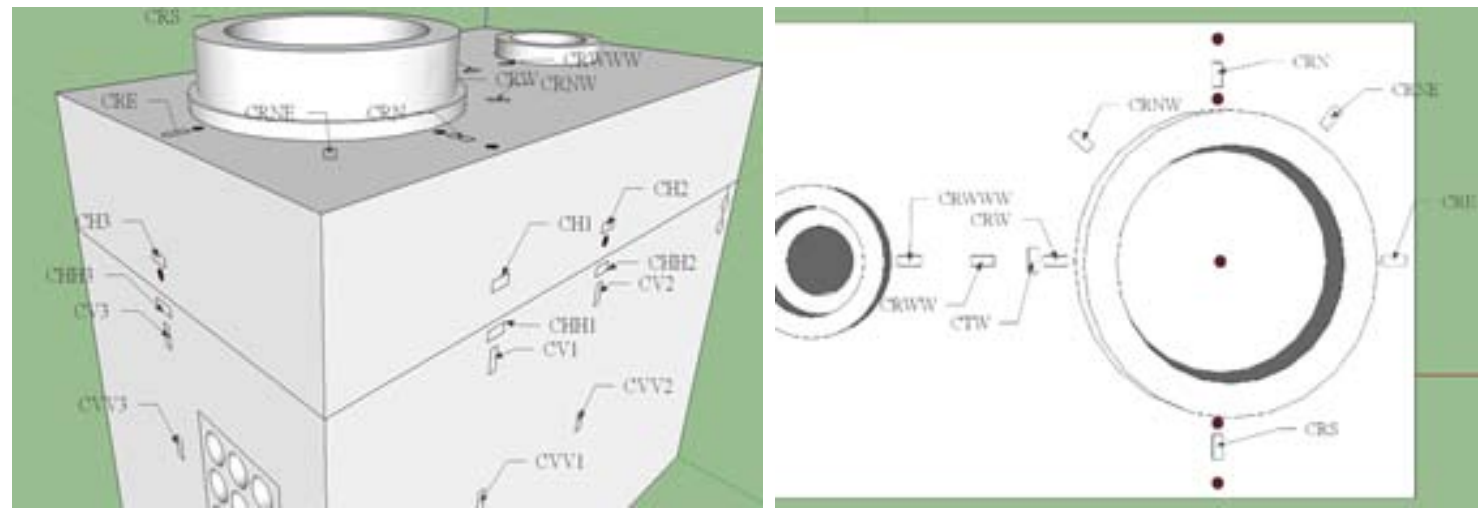

Figure 4.1: Overview of the concrete strain layout on the surface area of the chamber

(D'Amours, et al., 2013)

Steel- and FRP-reinforced concrete chambers were analyzed using the FE analysis procedure discussed in the previous chapter. The procedure used for modeling the FRP-reinforced concrete chamber was similar to the one used for the steel-reinforced chamber. The only difference was that the material properties of steel had been changed to FRP, as described in Chapter 3 .

Shell element (S4R) was used to represent the behaviour of the chamber. Each node had six degrees of freedom, 3-translation and 3-rotational degrees of freedom. Steel and FRP reinforcements in the concrete chamber were defined using a rebar layer option in the shell elements. For each layer, each of the following parameters were needed: the cross-sectional area of each rebar, the rebar spacing in the plane of the shell element, the position of the rebar in the thickness direction, and the angular orientation (ABAQUS/Standard User's Manual, 2010).

Since the size of the elements has a significant impact on FE results, the meshing of the chamber was taken into special consideration. The chamber was divided into elements, each having a quadrilateral shape. Two mesh sizes were used to model the chamber: the 100100 $\mathrm{mm}$ mesh of the S4R element for the chamber, and $5050 \mathrm{~mm}$ mesh of the S4R element for the two manholes. A typical mesh used in this chamber is shown in Figure 4.2. 


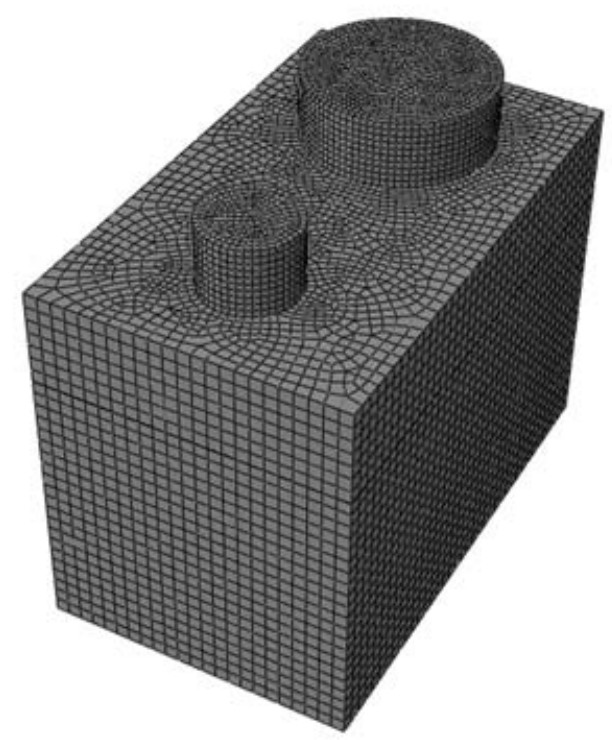

Figure 4.2: Typical chamber finite element mesh

The concrete response in tension and compression was modeled using stress-strain curves proposed by Collins and Mitchell, 1997. As mentioned in Chapter 3, to characterize concrete behaviour, the following properties are needed: concrete compressive strength, cracking stress and modulus of elasticity of concrete.

The concrete compressive strength in the model was taken from compression tests on concrete cylinder specimens cast for the chamber. These tests were conducted on the same day the chamber was tested (D'Amours, et al., 2013). The compressive strengths of concrete varied between 71 and $82 \mathrm{MPa}$. Hence, the concrete chamber was modelled using $75 \mathrm{MPa}$ concrete compressive strength as an average value. The modulus of elasticity of the concrete was calculated as 35,480 MPa, using Equation 3.1. The cracking stress of 1.49 $\mathrm{MPa}$ was taken from experimental results. GFRP, steel, and concrete material properties are listed in Table 4.1.

Comparisons of the numerical and experimental results of the steel-reinforced concrete chamber were conducted at instrument and gauge locations shown in Figure 4.3. They are presented below in terms of load strain curves (Figures 4.4 and 4.5 . 
Table 4.1: Material properties of the GFRP and steel reinforced concrete chamber

\begin{tabular}{|l|l|l|}
\hline \multirow{4}{*}{ Steel } & Yield stress $\left(f_{y}\right)$ & $400 \mathrm{MPa}$ \\
\cline { 2 - 3 } & Ultimate stress $\left(f_{u}\right)$ & $540 \mathrm{MPa}$ \\
\cline { 2 - 3 } & Modulus of,Elasticity $\left(E_{s}\right)$ & $200 \mathrm{GPa}$ \\
\cline { 2 - 3 } & Poisson Ratio $\left(v_{s}\right)$ & 0.3 \\
\hline \multirow{4}{*}{ GFRP } & Ultimate tensile stress $\left(f_{u}\right)$ & $1350 \mathrm{MPa}$ \\
\cline { 2 - 3 } & Modulus of Elasticity $\left(E_{F R P}\right)$ & $65 \mathrm{GPa}$ \\
\cline { 2 - 3 } & Poisson Ratio $\left(v_{F R P}\right)$ & 0.25 \\
\hline \multirow{5}{*}{ Concrete } & Compressive strength $\left(f_{c}^{\prime}\right)$ & $75 \mathrm{MPa}$ \\
\cline { 2 - 3 } & Tensile strength $\left(f_{t}\right)$ & $1.49 \mathrm{MPa}$ \\
\cline { 2 - 3 } & Modulus of Elasticity $\left(E_{c}\right)$ & $35480 \mathrm{MPa}$ \\
\cline { 2 - 3 } & Poisson Ratio $\left(v_{c}\right)$ & 0.2 \\
\hline
\end{tabular}

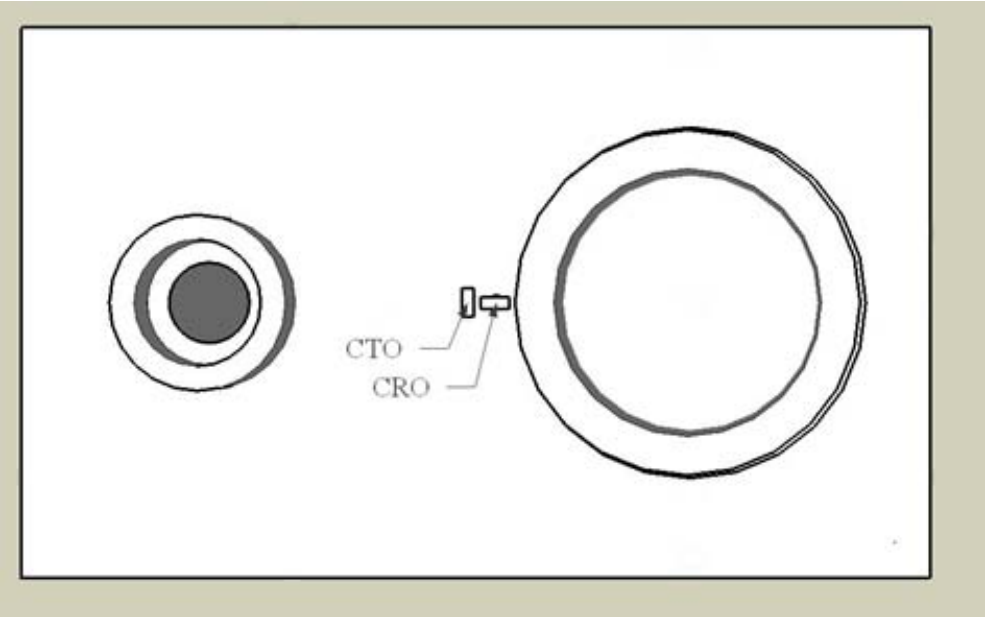

Figure 4.3: The locations of the strain gauges (D'Amours, et al., 2013) 


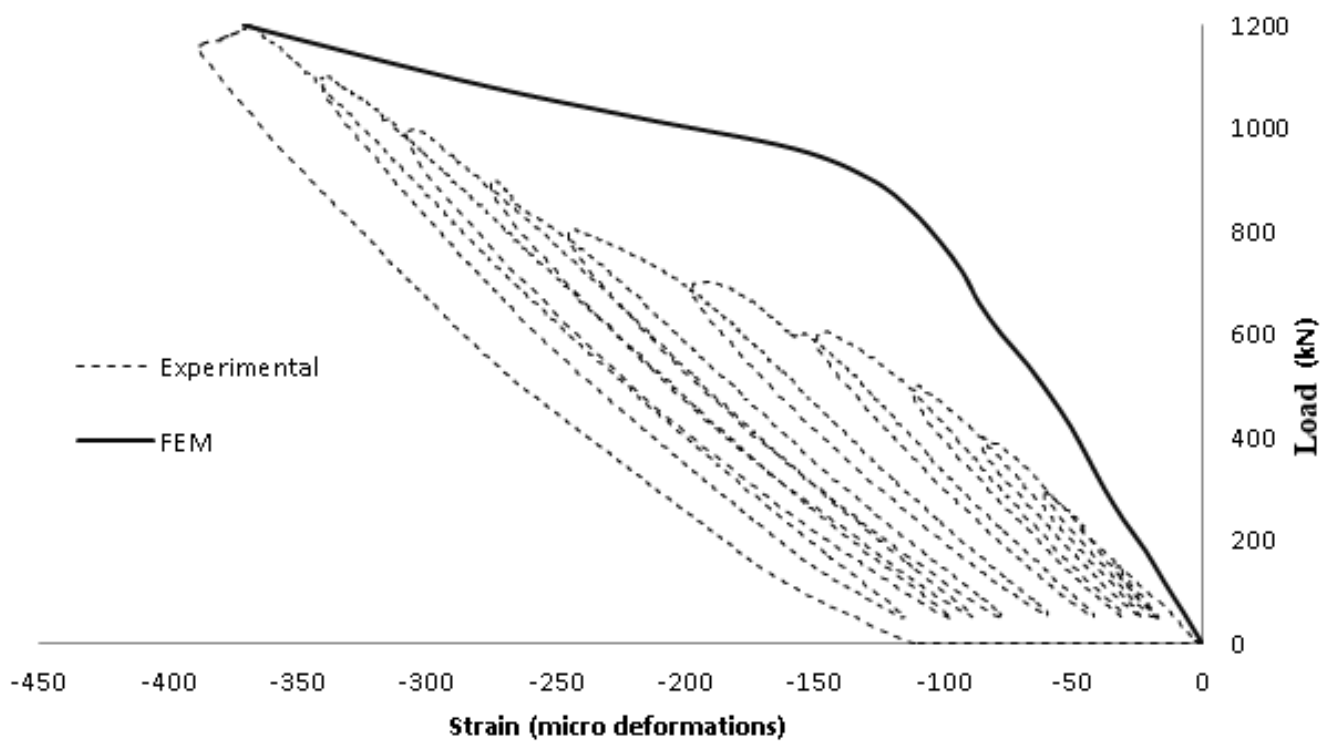

Figure 4.4: Comparison of Concrete load-strain relationships at CRO for steel reinforced concrete chamber

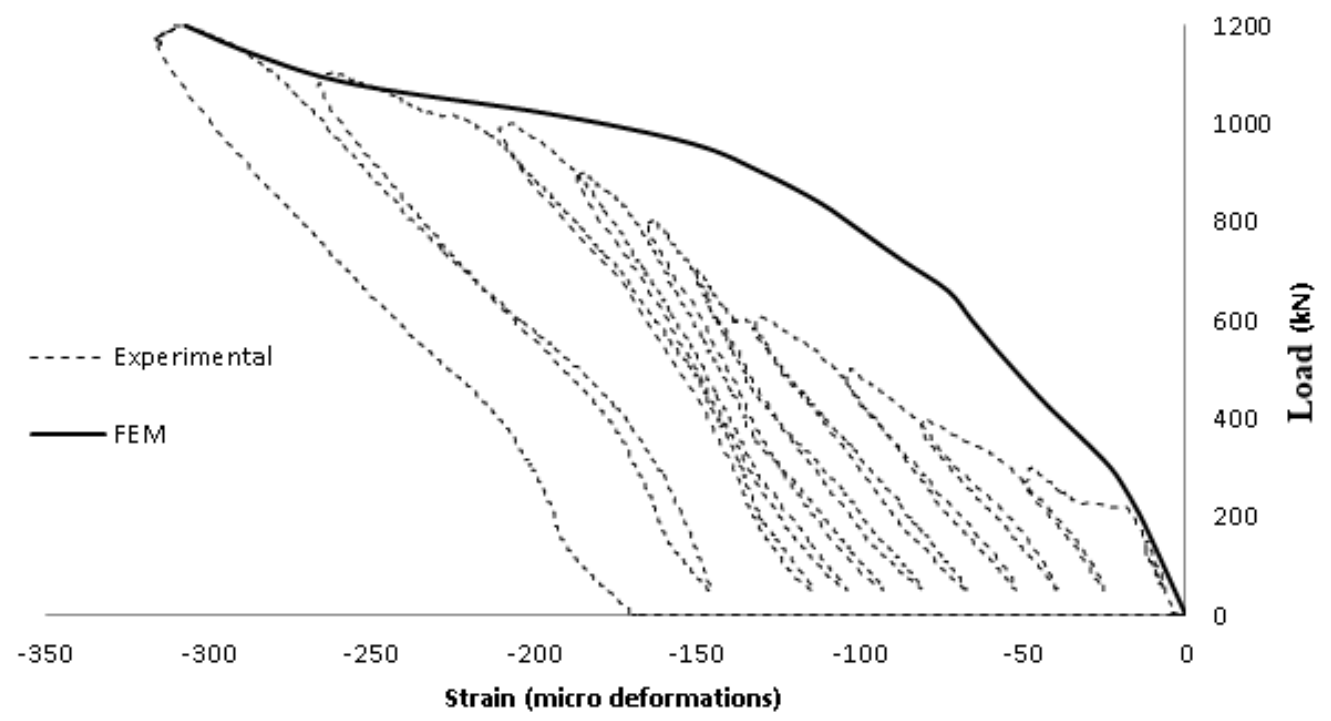

Figure 4.5: Comparison of Concrete load-strain relationships at CTO for steel reinforced concrete chamber

Chamber FRP reinforcement strains were recorded with a number of gauges; their locations are shown in Figure 4.6. The load versus corresponding strain in the FRP bars is presented in 
Figures 4.7 and 4.8 for both the FE analysis and the experimental results.

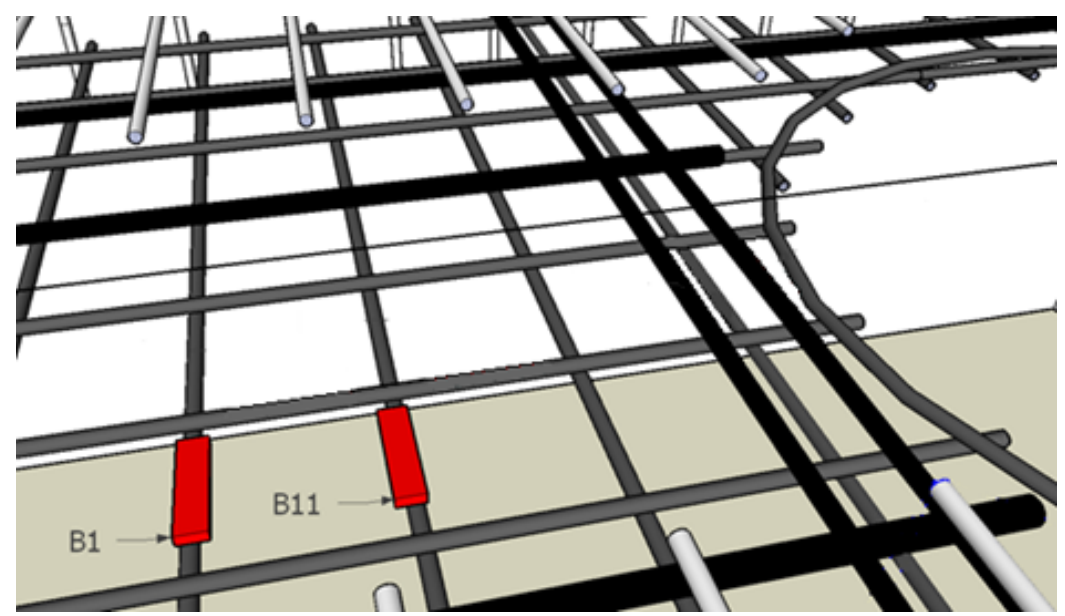

Figure 4.6: The locations of the strain gauges (D'Amours, et al., 2013)

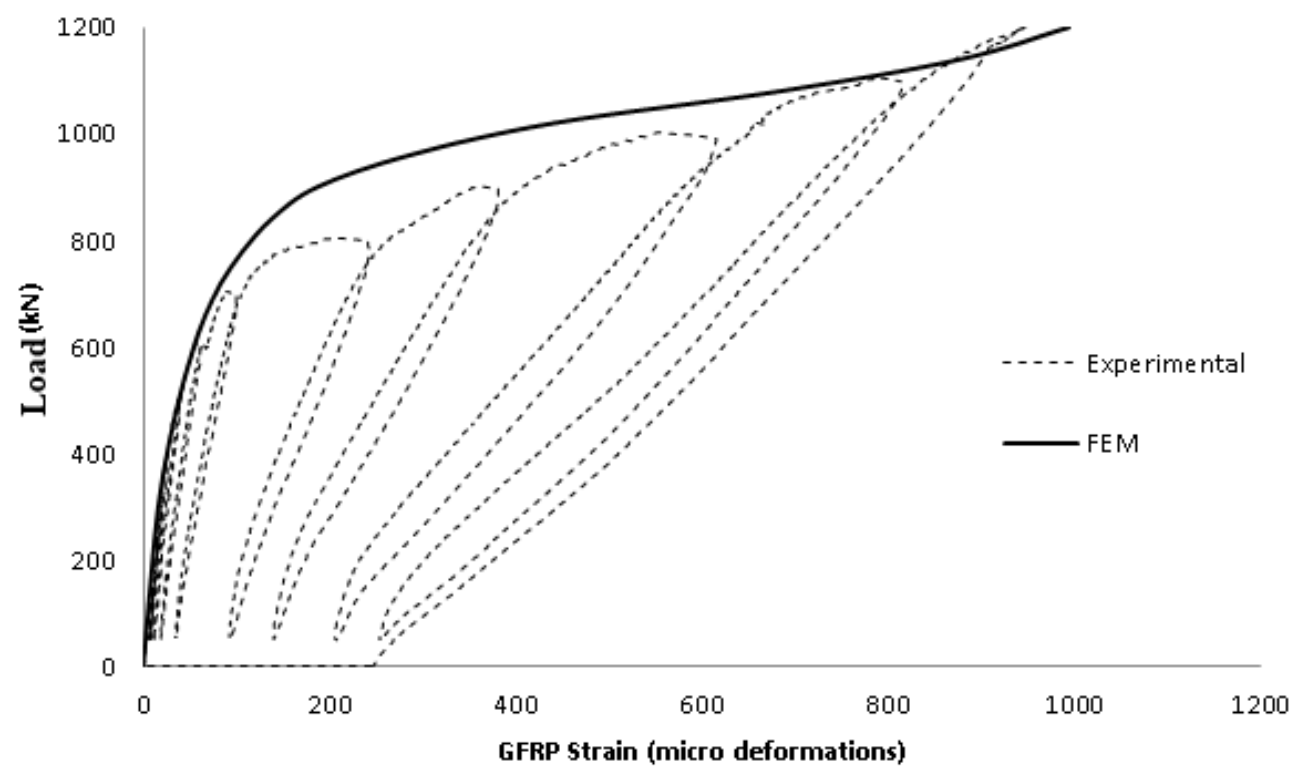

Figure 4.7: Comparison of load-strain relationship of GFRP reinforcement at B1 for GFRP reinforced concrete chamber 


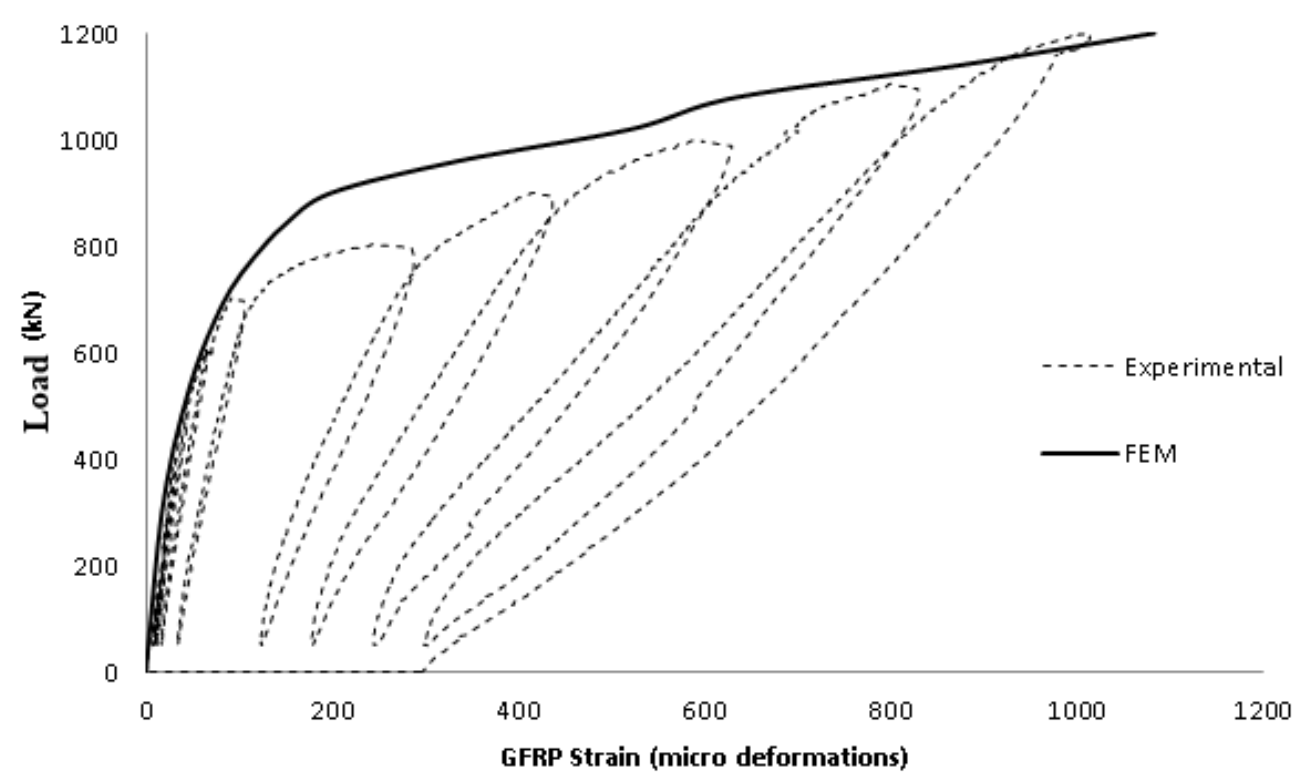

Figure 4.8: Comparison of load-strain relationship of GFRP reinforcement at B11 for GFRP reinforced concrete chamber

It is evident from the figures that the numerical model is in reasonable correlation with the experimental results. As the model was validated, it was used to conduct a study into the influence of the key parameters on concrete chamber performance.

\subsection{Parametric study}

After validating the FE model based on the experimental results, this modeling technique proved to be effective in predicting the behaviour of concrete chambers reinforced with steel and FRP. The next step was to use the verified model to investigate the effects of three key parameters on the behaviour of concrete chambers: compressive strength of concrete (section 4.3.1), reinforcement types (section 4.3.2), reinforcement ratio (section 4.3.3).For each parameter, the variable was changed, but the concrete chamber stayed consistent, with the same geometry, material properties, and assumptions used in the previous chapter. The results were based on the chamber under static load at the top of the manhole in terms of load-deflection, stress distribution and cracking pattern. The investigation resulted in a series of conclusions about the effects of the studied parameters on the behaviour of concrete chambers.

In addition, the validated model was used to investigate the effects of thermal gradients on the concrete chamber (section 4.3.4). As mentioned in Chapter2, the temperature of the soil 
changes with depth. Since the chamber is placed in soil, it is subjected to temperature changes all along its depth.

\subsubsection{Concrete Compressive Strength}

The current design codes and guidelines divide concrete material into two different categories based on their compressive strength: normal-strength concrete (NSC) and high-strength concrete (HSC). NSC has a compressive strength ranging between 25 and $40 \mathrm{MPa}$, while HSC is $40 \mathrm{MPa}$. Using HSC in concrete structures is an attractive option due to its superior strength, stiffness and durability. These benefits lead the construction industry to use HSC with FRP bars, a combination that improves the stiffness of a cracked concrete section, enhancing the serviceability criteria of FRP-reinforced members.

The modeling procedure of the high-strength concrete $\left(f_{c}^{\prime}=75 \mathrm{MPa}\right)$ is presented in Chapter 3. To evaluate the effects of compressive strength of concrete on the behaviour of the concrete chamber, compressive strength was reduced from 75 to $25 \mathrm{MPa}$ in 10 increments. Collins equations were used to represent the stress-strain response of normal concrete in tension and compression (Equations 3.5 and 3.7), with the only changes being the compressive and tensile strength of concrete.

\section{Load-Deflection Response}

Figure 4.9 illustrates the load-deflection $(P-\Delta)$ response of the centre of the manhole within the studied range of concrete compressive strength. The general response of the model can be described as an approximately bilinear relationship. The linear relationship between load and deflection can be observed all the way up to the cracking load. The slope of this portion represents the un-cracked stiffness of the chamber. The nonlinear response starts after the cracking load, where the tensile stresses exceed the tensile strength of concrete elements. In the concrete damage plasticity model, these elements are considered damaged elements. The reduction of the stiffness of the damaged elements $(E I)$ is given in terms of a scalar degradation variable $(d)$ as (ABAQUS/Standard User's Manual, 2010):

$$
E I=(1-d) E I_{0}
$$

Where $E I_{0}$ is the initial (undamaged) stiffness of the material, $d$ is stiffness degradation variable, which ranges from zero (undamaged material) to one (fully damaged material) and can be obtained from the strength reduction of the post-cracking stress-strain curve of concrete in compression and tension. Therefore, the damage associated with the failure mechanism of concrete (cracking and crushing) results in a reduction of element stiffness. As shown in Figure 
4.9, the $P-\Delta$ relationship is linear elastic at low load levels. Once cracking takes place, the slope of the diagram decreases as the chamber becomes softer due to the cracking. It represents the reduction in stiffness due to cracking.

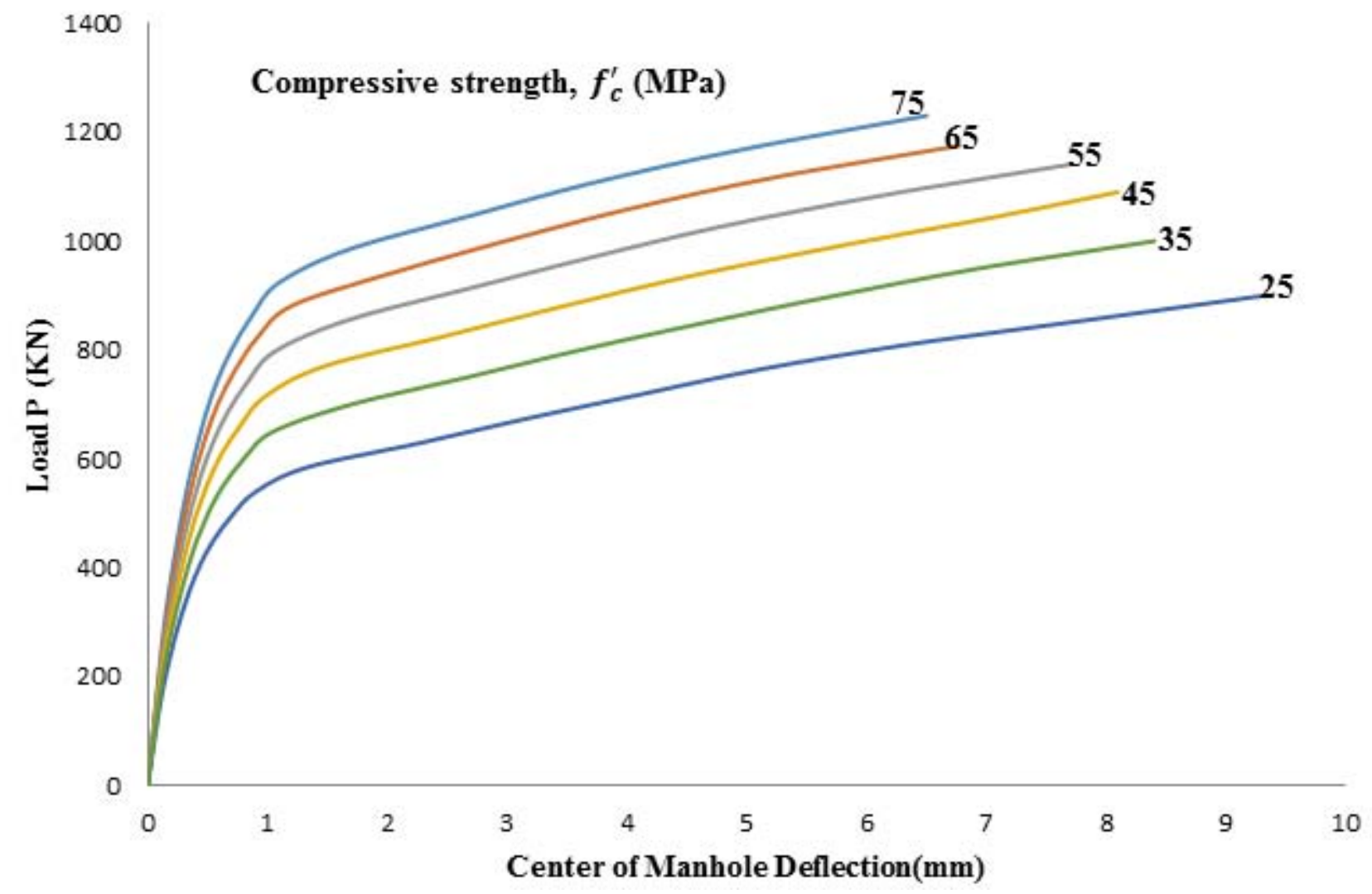

Figure 4.9: Effect of increasing compressive strength of concrete on load-deflection relationship at center of the manhole

It can be concluded from Figure 4.9 that an increase in concrete strength led to a higher cracking load and less deflection at the same loading level. This is related to the fact that increased compressive strength makes concrete stronger in tension. The change of compressive strength from 25 to $75 \mathrm{MPa}$ increased the cracking load by $52 \%$. After cracking, the slope of the graph declined remarkably, representing the reduction in stiffness. The load-deflection was almost linear after cracking up to ultimate load, especially in the case of concrete with low compressive strength $(25 \mathrm{MPa})$. Figure 4.9 also illustrates that an increase of compressive strength raised the ultimate load capacity and maximum deflection at centre of the manhole. To gain a better understanding of this observation, the relationship between concrete compressive 
strength and ultimate load capacity is plotted in Figure 4.10 .

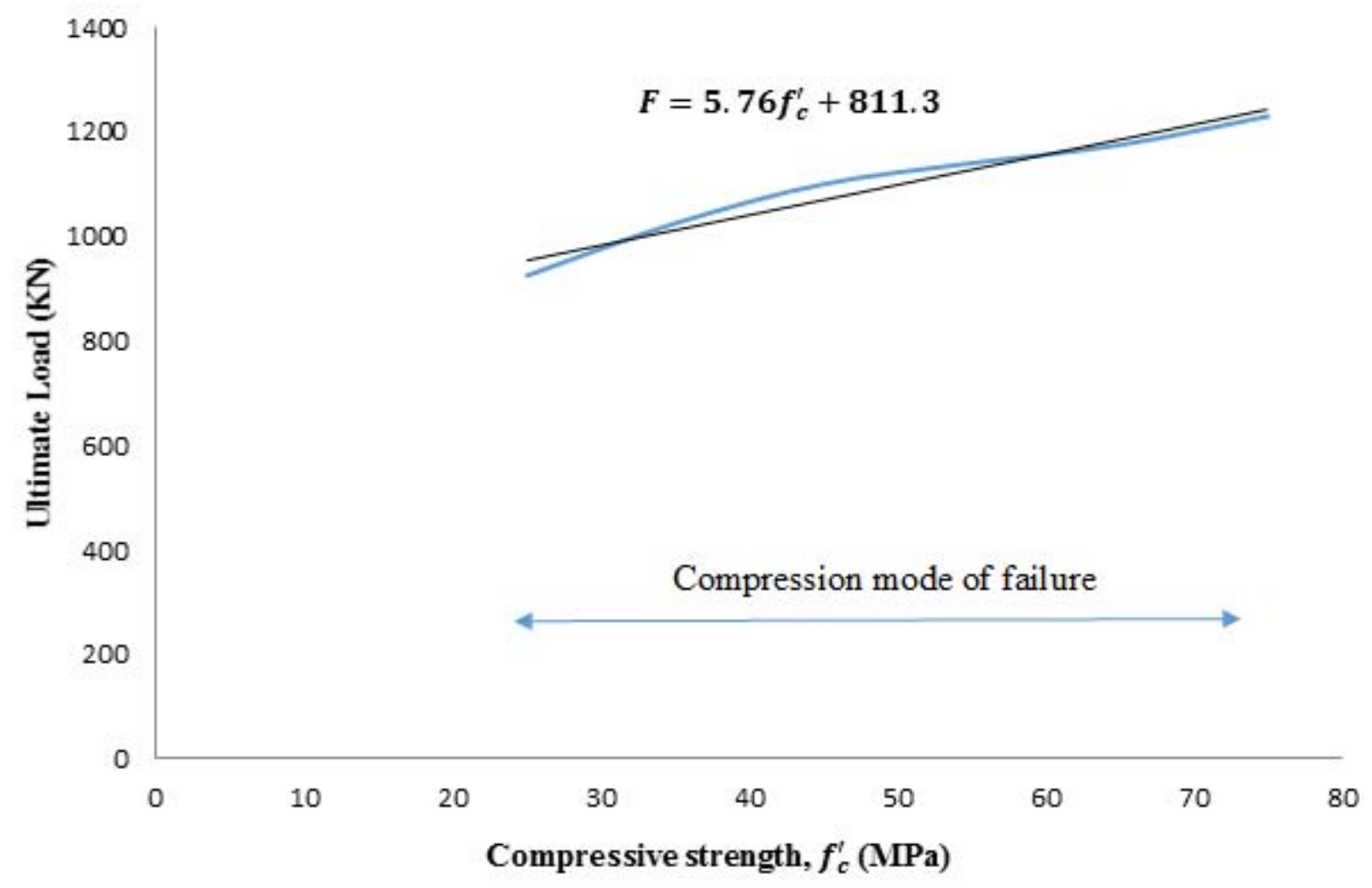

Figure 4.10: Relationship between concrete compressive strength and ultimate load capacity

As shown in Figure 4.10, the relationship between ultimate load capacity and concrete compressive strength can be described with the linear equation. This figure also shows the expected modes of failure of the section with different concrete strengths. The failure modes of a concrete section can be identified with compression of reinforcement ratio, and with balanced reinforcement ratio of the section. Both the reinforcement ratio and balanced reinforcement ratio of a section reinforced with FRP are calculated using the following equations (CAN/CSA S6-06, 2009; CSA-S806-02, 2002; Canada, ISIS, 2007):

$$
\begin{gathered}
\rho_{f r p}=\frac{A_{f r p}}{b d} \\
\rho_{b}=\alpha_{1} \beta_{1} \frac{\Phi_{c}}{\Phi_{f r p}} \frac{f_{c}^{\prime}}{f_{\text {frpu }}}\left(\frac{0.0035}{0.0035+\varepsilon_{f r p u}}\right)
\end{gathered}
$$


Where,

$\Phi_{c}$ and $\Phi_{f r p}=$ material resistance factor for concrete and FRP

$f_{c}^{\prime}=$ compressive strength of concrete $(\mathrm{MPa})$

$b=$ the width of compression side of member $(\mathrm{mm})$

$d=$ the distance between extreme compressive fibre to tension reinforcement $(\mathrm{mm})$

$A_{\text {frp }}=$ area of FRP reinforcement $\left(\mathrm{mm}^{2}\right)$

$f_{\text {frpu }}=$ ultimate tensile strength of $\mathrm{FRP}(\mathrm{MPa})$

$\varepsilon_{f r p u}=$ ultimate tensile strain of FRP

$\alpha_{1}=0.85-0.0015 f_{c}^{\prime} \geq 0.67$

$\beta_{1}=0.97-0.0025 f_{c}^{\prime} \geq 0.67$

If FRP reinforcement ratio $\rho_{f r p}$ is larger than balance reinforcement ratio $\rho_{f r p b}$, failure begins with crushing of concrete. When $\rho_{f r p}$ is lesser than $\rho_{f r p b}$, failure is governed by FRP rupture. As mentioned in Chapter 2, there are two common types of expected failure mode for concrete members reinforced with FRP bars; rupture of reinforcements and crushing of concrete. Hence the ultimate load capacity of the chamber was defined by concrete reaching its ultimate compressive strain $\left(\varepsilon_{c u}=0.0035\right)$ or GFRP reinforcement exceeding its yield strength.

According to the theory of plasticity, the cumulative plastic strain (PEEQ or PEEQT) has the closest correlation with the corresponding uniaxial plastic strain in compression or tension (ABAQUS/Standard User's Manual, 2010). Therefore, the crushing of concrete occurs when the cumulative plastic strain in compression (PEEQ) reaches its ultimate value of 0.0035 $(\mathrm{PEEQ}=0.0035)$. The ABAQUS/Standard (2010) provides rebar force output with output variable of RBFOR. Thus, rupture of reinforcement occurs when the tensile or compressive stresses (RBFOR) developed in the rebar exceed the strength of GFRP bars in tension and compression.

All sections of the chamber became over-reinforced at concrete compressive strengths of 25 to $75 \mathrm{MPa}$. As expected, the FEM results also indicated that the failure was governed by crushing of concrete at critical sections. Figure B.1 to B.6 in Appendix B show the contours of compressive plastic strain and maximum stress developed in GFRP bars for the chamber with a different concrete strength. These figures show that the concrete reached the maximum compressive strain $\left(\varepsilon_{c u}=0.0035\right)$ before the GFRP failed.

\section{Reinforcement Strains}

The GFRP reinforcement strains were recorded for the particular reinforcing bar shown in Figure 4.11 (shown as a red line). Reinforcement strains are plotted against total applied load. Figure 4.12 illustrates the load-strain response of the GFRP reinforcement within the studied 
range of concrete compressive strength. All chambers were loaded up to $1200 \mathrm{kN}$.

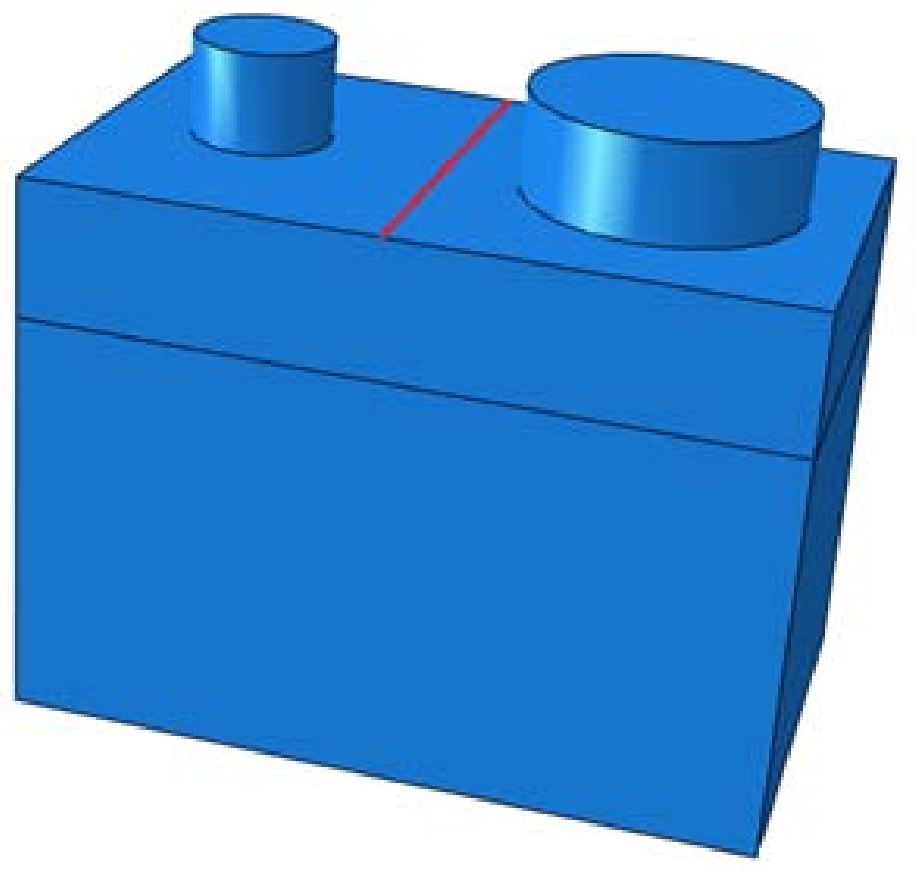

Figure 4.11: The location of GFRP reinforcement (shown as red line)

Figure 4.12 indicates that all chambers showed linear strain behaviour before cracking. Sudden increases in reinforcement strain occurred just after cracking, and the chambers behaved linearly up to $1200 \mathrm{kN}$. It can be noted that increasing the concrete strength significantly decreased the maximum amount of reinforcement strain developed in the GFRP reinforcing bar. The maximum predicted reinforcement strains were 5,808 and 91,975 micro strain for the chambers with concrete strengths of 25 and $75 \mathrm{MPa}$, respectively. This can be attributed to the fact that an increase in compressive strength makes the chamber stronger, and the chamber deflects less under the load, reducing the amount of reinforcement strain. 


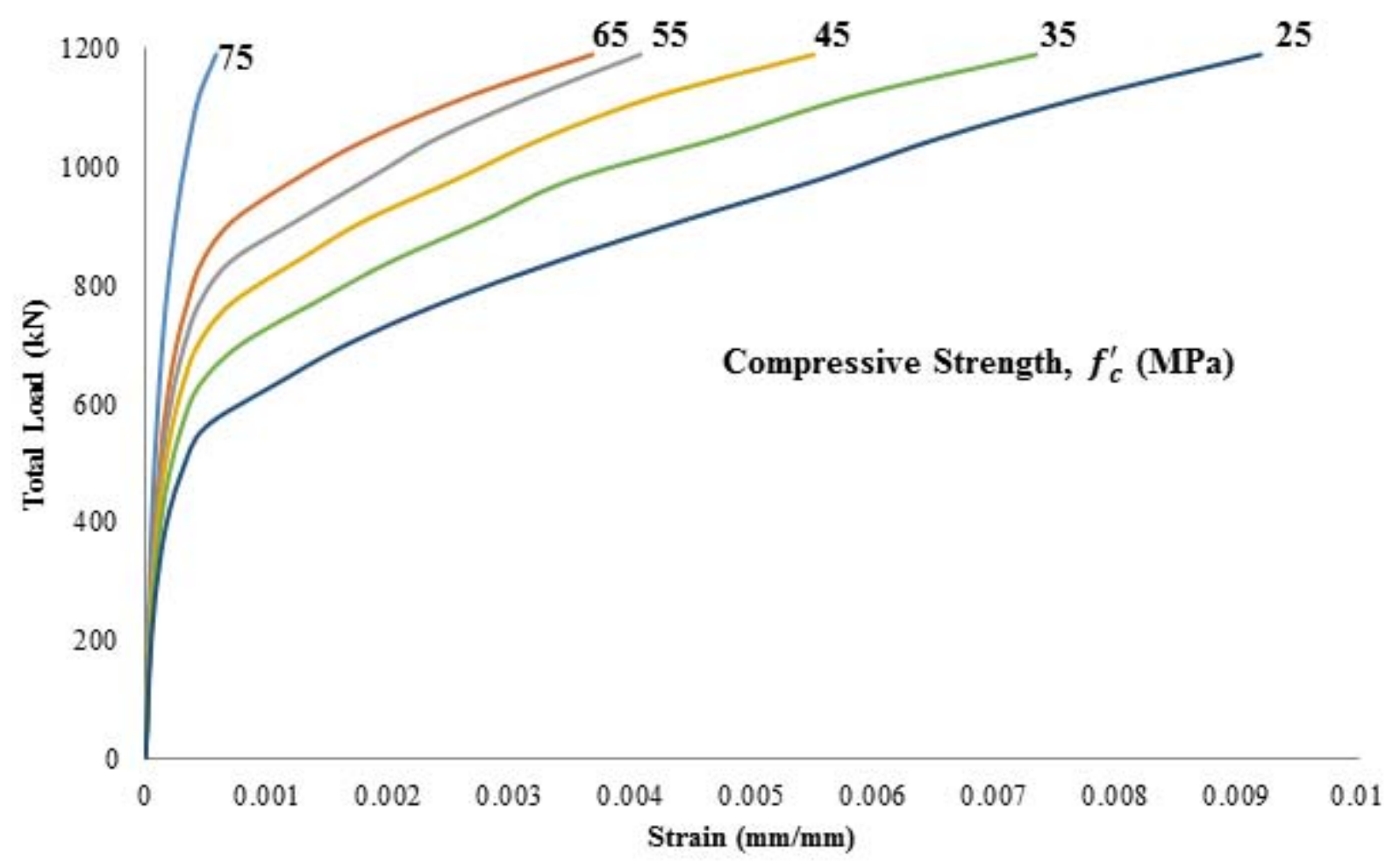

Figure 4.12: Effect of increasing compressive strength of concrete on load-strain relationship of the GFRP reinforcement

\subsubsection{Reinforcement Type}

In reinforced concrete structures, reinforcement has a significant role in carrying tensile loads due to flexure, shear, and other loads, due to the limited ability of concrete to sustain tensile stresses. Once concrete has cracked, it is assumed that the tensile stresses between cracks are transmitted through the bond between reinforcing bars and concrete. The amount of load being transmitted through the reinforcing bars depends mostly on the mechanical properties of the reinforcement. Obviously, using a reinforcing bar, which can carry higher levels of stress with lower strain, would result in better control of cracking, deformation, and crack requirements.

This section presents the effect of reinforcement type on concrete chamber performance. In the model, dimension, concrete properties, boundary and load conditions were kept unchanged. The only parameter was the type of reinforcement. Three different reinforcing bars were employed in this study, as listed in Table 4.2 . 
Table 4.2: Properties of GFRP, CFRP and steel bars

\begin{tabular}{|l|l|l|l|l|}
\hline Bar type & Diameter, $\mathrm{mm}$ & Area, $\mathrm{mm}^{2}$ & Tensile strength, MPa & Tensile modulus, GPa \\
\hline Carbon FRP & 16 & 197 & 1648 & 140 \\
\hline Glass FRP & 16 & 197 & 1312 & 65 \\
Steel & 15 & 200 & $f_{y}=460$ & \multirow{2}{*}{200} \\
\cline { 3 - 4 } & & & $f_{u}=610$ & \\
\hline
\end{tabular}

\section{Load-Deflection Response}

Figure 4.13 presents the load-deflection relationships for the chambers with different types of reinforcement. Figure 4.13 indicates that the chamber reinforced with GFRP bars exhibited a significant reduction of stiffness after the initiation of first crack, compared to the chambers reinforced with CFRP and steel. This response is due to the low elastic modulus of GFRP bars, which decreased their capability to control concrete cracks. In addition, Figure 4.13 indicates that the chamber reinforced with GFRP exhibited greater deflection than the ones reinforced with steel and CFRP due to the low elastic modulus of GFRP bars.

Figure 4.13 shows a linear response of the chambers from before cracking up to their cracking loads. The slope of this portion illustrates the un-cracked stiffness of the chambers, which is similar for all chambers reinforced with GFRP, CFRP and steel rebar. After cracking, the slope of the curve was substantially reduced due to the cracking, which resulted in reduction of stiffness. After cracking, the response of the chamber reinforced with GFRP bars was found to be almost linear compared with the dashed line in Figure 4.13. It can be noted from Figure 4.13 that the model showed considerable nonlinearity in the load-deflection relationship compared to the chamber reinforced with steel bars, which may be due to the considered elastic-plastic behaviour of steel reinforcements. 


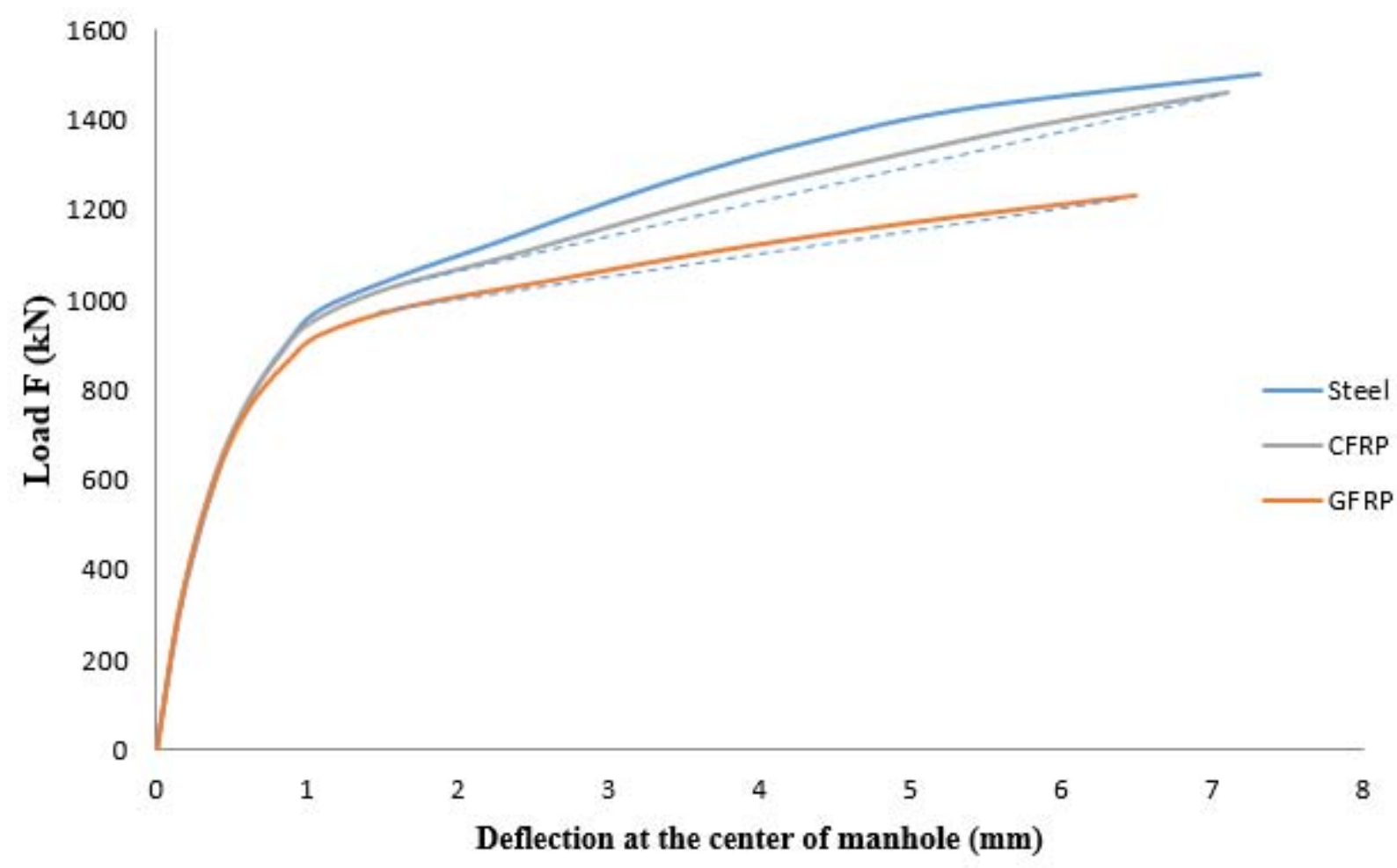

Figure 4.13: Effect of different types of reinforcement on the load-deflection relationship of the concrete chamber

\section{Stress Distribution}

The yield and failure surface used with the concrete damage plasticity model are expressed in terms of hydrostatic pressure stress and von Mises equivalent stress. Figure 4.14 shows the stress distribution in terms of von Mises equivalent stress for the chambers reinforced with GFRP and steel bars. Both chambers were loaded until their ultimate loads, which were 1230 $\mathrm{kN}$ and $1500 \mathrm{kN}$, respectively. As shown in Figure 4.14, stress distribution patterns in GFRPand steel-reinforced concrete chambers were similar. Therefore, when the chambers were loaded up to their ultimate loads, similar modes of failure were expected for both GFRP- and steelreinforced concrete chambers. 


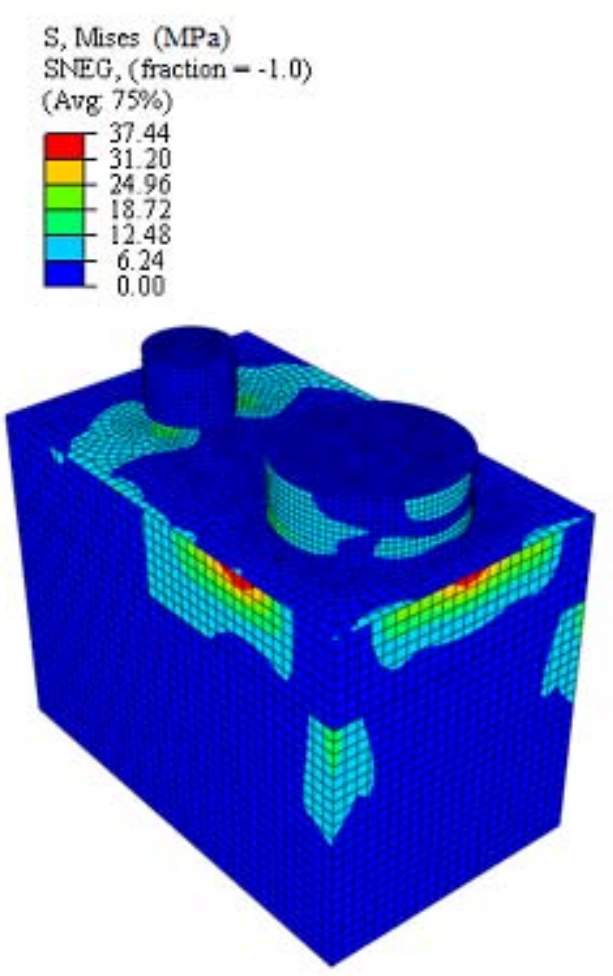

(a) Steel

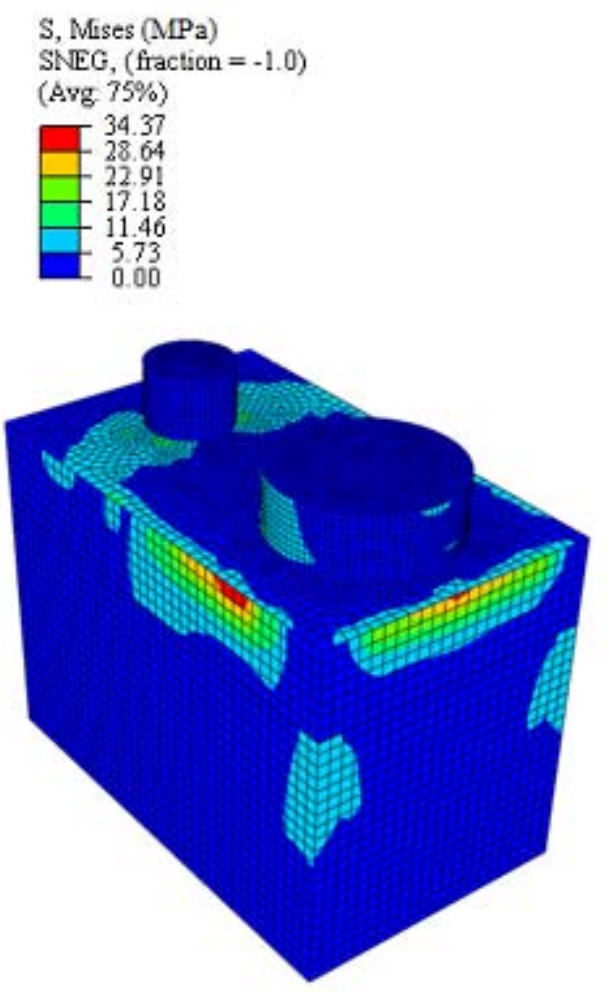

(b) GFRP

Figure 4.14: Von Mises equivalent stress in the chamber reinforced with steel and GFRP bars loaded up to their ultimate loads

Although stress distribution in both types of concrete chambers is similar, it should be noted that the chambers were loaded differently up to their ultimate loads. If the chambers had been loaded similarly, their stress distributions would have been different, and the steel-reinforced concrete chamber would have exhibited lower values of stress distribution than the chamber reinforced with GFRP bars.

\section{Reinforcement Strain}

The reinforcement strains developed for the particular reinforcing bar (shown in Figure 4.11) were plotted against the total applied load. Figure 4.15 illustrates the load-strain response of the different reinforcements (steel, CFRP and GFRP). In this section, all chambers were loaded up to $1200 \mathrm{kN}$. Figure 4.15 indicates that higher amounts of reinforcement strain were generated in GFRP bars, which may be attributed to the fact that the chamber reinforced with GFRP bars exhibited larger deflection than those reinforced with steel and CFRP. Hence, larger deflection 
can generate a higher amount of reinforcement strain in rebar.

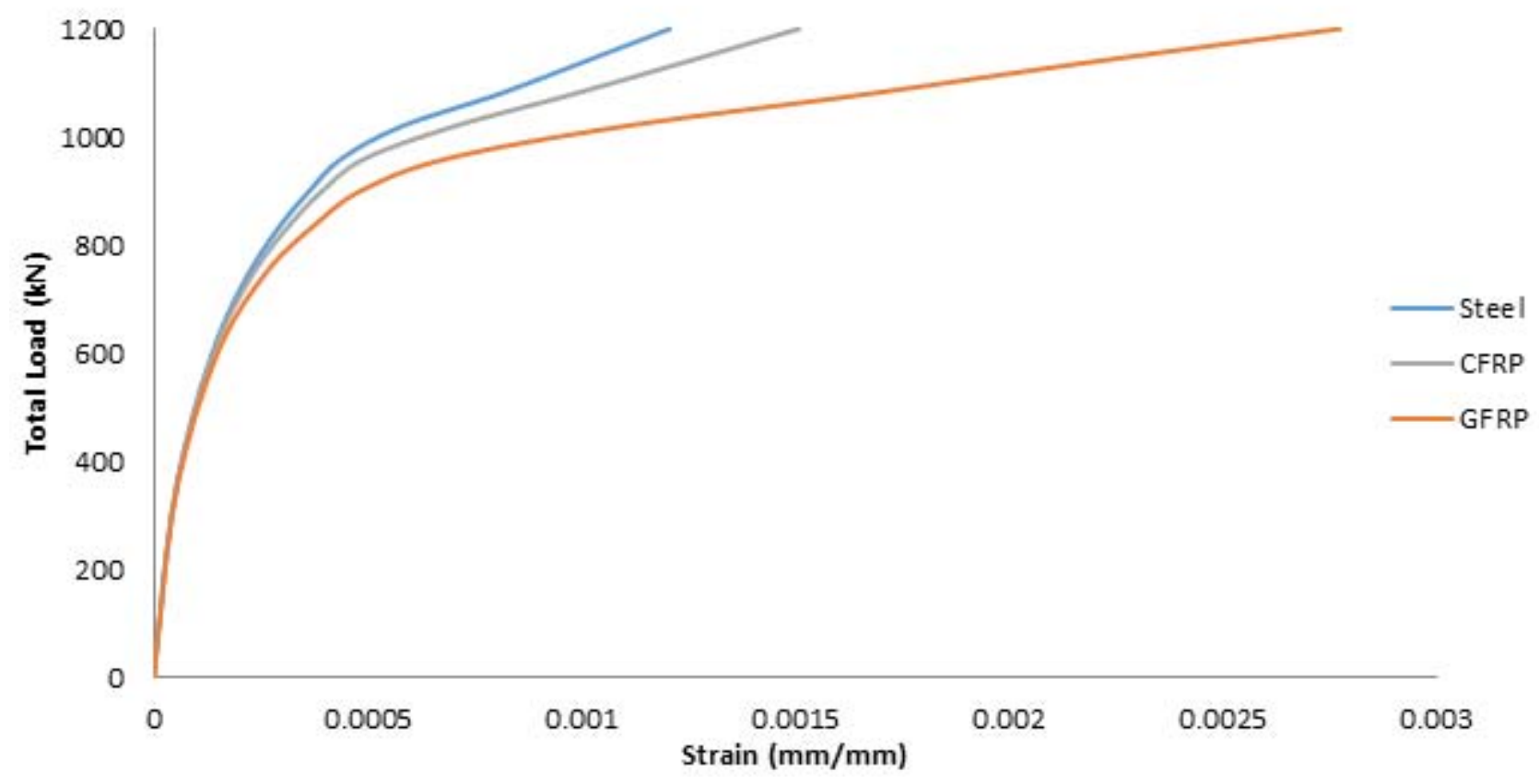

Figure 4.15: Effect of different types of reinforcement on load-strain relationship of reinforcement

\subsubsection{Reinforcement Ratio}

In this section, the effect of reinforcement ratio on the overall behaviour of the GFRP-reinforced chamber is investigated. The reinforcement ratio of a section usually governs the failure mode of concrete structures. As recommended by current design codes and guidelines, the most desirable failure mode is the crushing of concrete rather than the rupture of FRP bars; increasing levels of flexural reinforcement could prevent that rupture. To evaluate the effects of reinforcement ratios on the performance of concrete chambers, three different reinforcement configurations were considered, as listed in Table 4.3. The dimensions, concrete properties and boundary and loading conditions were not changed. Table 4.3 shows that the area of reinforcement in the model was increased by using GFRP bars No. 10, 16 and $20\left(A_{b}=71,198\right.$, and $\left.378 \mathrm{~mm}^{2}\right)$, and the spacing between reinforcing bars was kept constant, based on construction industry standards. 
Table 4.3: Summary of different reinforcement configuration

\begin{tabular}{|l|l|l|l|l|}
\hline \multirow{2}{*}{ Case No. } & \multicolumn{3}{|c|}{ Reinforcement in both perpendicular directions } \\
\cline { 2 - 5 } & chamber & base slab & cover & cap slab \\
\hline 1 & No. $10 @ 125 \mathrm{~mm}$ & No. $10 @ 200 \mathrm{~mm}$ & No.10@200mm & No.10@ 200mm \\
\hline 2 & No.16@125mm & No.16@200mm & No.16@200mm & No.16@200mm \\
\hline 3 & No. 20@125mm & No. 20@200mm & No. 20@200mm & No. 20@200mm \\
\hline
\end{tabular}

\section{Load-Deflection Response}

Figure 4.16 shows the load-deflection relationships for the chamber reinforced with a different reinforcement ratio. It can be seen that the model with lower reinforcement ratio results has the lowest stiffness after cracking, as well as the lowest ultimate load capacity. This may be attributed to the fact that the flexural capacity of the concrete sections increased with greater reinforcement ratio. Consequently, an increase in flexural capacity of the sections could improve the load capacity of the structure. However, as is evident in Figure 4.16, a fourfold increase in reinforcement ratio only increased the ultimate load of the chamber by $20 \%$. Therefore, increasing reinforcement ratio may not be a good idea for improving load capacity of the chamber.

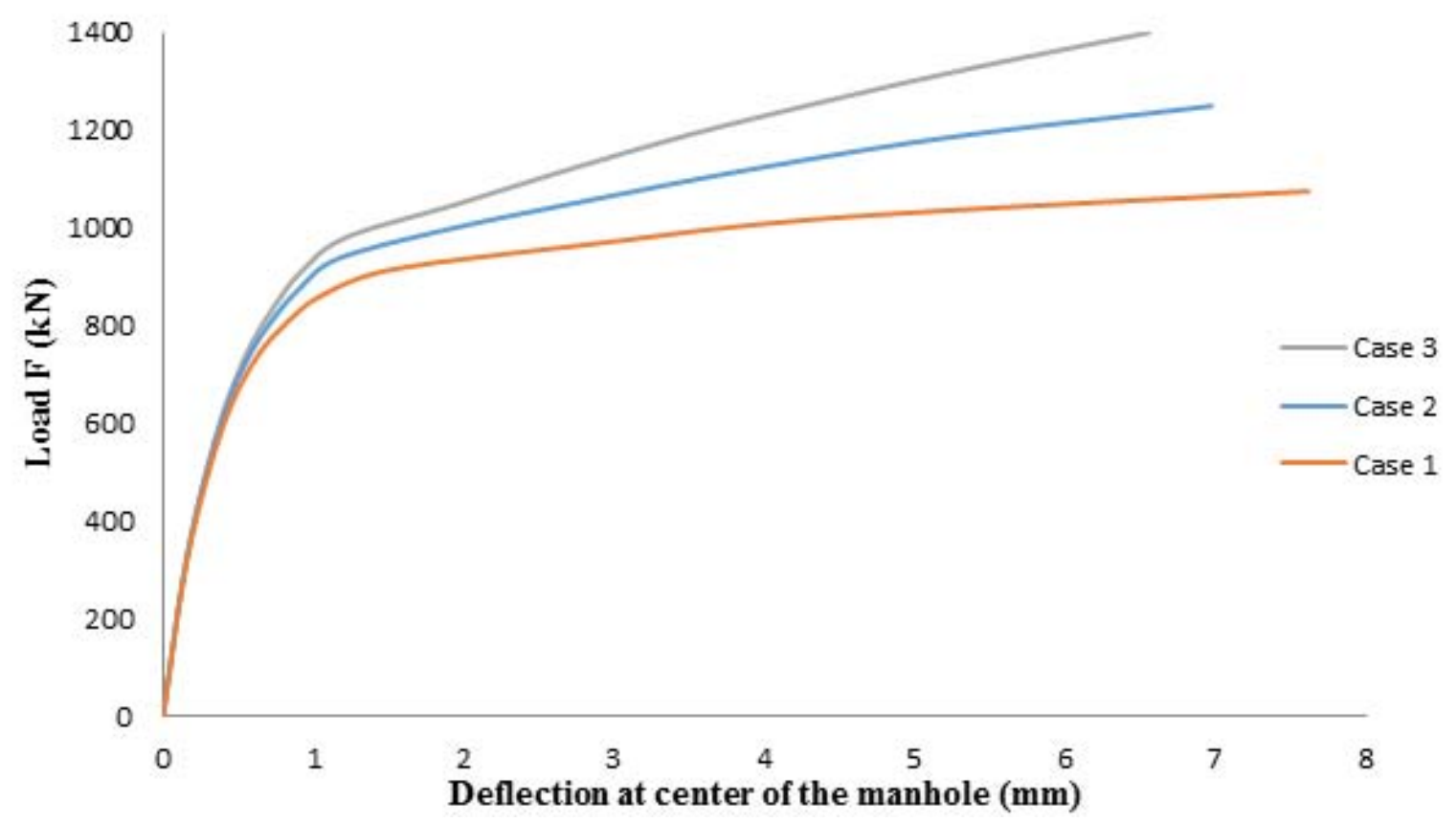

Figure 4.16: Effect of reinforcement ratio on load-deflection relationships of concrete chamber reinforced with GFRP (Table 4.3) 


\subsubsection{Thermal Analysis of the Chamber}

Three-dimensional finite element models were prepared to study the thermal analysis of the concrete chamber. 3-D shell elements with material nonlinearity and thermal properties were used to model the chamber. The chamber was assumed to be placed in different soil depths, with corresponding temperatures for each specific depth assigned to the chamber. The results were prepared based on predicted cracking patterns and stress distributions of the chamber due to the temperature variations throughout its depth.

\section{Material Model}

As required for thermal analysis, the values for thermal properties of concrete, steel and GFRP were considered. The thermal properties, including the thermal coefficient of expansion (or contraction), thermal conductivity and specific heat, are listed in Table 4.4 (ACI 122R-02, 2002).

Table 4.4: Thermal properties of steel and GFRP reinforced concrete chamber

\begin{tabular}{|l|l|l|}
\hline \multirow{3}{*}{ Steel } & Thermal coefficient of expansion $\left(\alpha_{s}\right)$ & $11.6 \times 10^{-6}\left(1 /{ }^{o} \mathrm{C}\right)$ \\
\cline { 2 - 3 } & Thermal conductivity $\left.\left(K_{s}\right)\right)$ & $43.0\left(\mathrm{~J} / \mathrm{ms}^{\circ} \mathrm{C}\right)$ \\
\cline { 2 - 3 } & Specific heat $\left(C_{s}\right)$ & $1.0\left(\mathrm{KJ} / \mathrm{Kg}^{o} \mathrm{C}\right)$ \\
\hline \multirow{3}{*}{ GFRP } & Thermal coefficient of expansion $\left(\alpha_{f r p}\right)$ & $10.0 \times 10^{-6}\left(1 /{ }^{\circ} \mathrm{C}\right)$ \\
\cline { 2 - 3 } & Thermal conductivity $\left.\left(K_{f r p}\right)\right)$ & $0.7\left(\mathrm{~J} / \mathrm{ms}^{\circ} \mathrm{C}\right)$ \\
\cline { 2 - 3 } & Specific heat $\left(C_{f r p}\right)$ & $0.8\left(K J / K g^{o} \mathrm{C}\right)$ \\
\hline \multirow{3}{*}{ Concrete } & Thermal coefficient of expansion $\left(\alpha_{c}\right)$ & $9.9 \times 10^{-6}\left(1 /{ }^{o} \mathrm{C}\right)$ \\
\cline { 2 - 3 } & Thermal conductivity $\left.\left(K_{c}\right)\right)$ & $1.3\left(\mathrm{~J} / \mathrm{ms}^{\circ} \mathrm{C}\right)$ \\
\cline { 2 - 3 } & Specific heat $\left(C_{c}\right)$ & $0.96\left(K J / K g^{o} \mathrm{C}\right)$ \\
\hline
\end{tabular}

\section{Temperature Distributions}

Temperature distributions that develop in the concrete chamber depend on soil temperature, which is governed by many factors. As mentioned in Chapter two (Section 2.2.1), the graphical approach was employed as an approximate approach to determining soil temperature. This approach may not be adequate for all situations involving layered soil systems, snow covers, considerable freezing water and other features (Williams and Gold, 1976). However, for many cases, such details are not necessary and this simple graphical method is quite adequate (Brown, 1963). Along with the graphical approach, the graph shown in Figure 4.17 (provided by the Ontario Ministry of the Environment (Fielding, 1976) for Canadian regions) can be used as an approximate guide to determining soil temperature for the given freezing index degree days. 


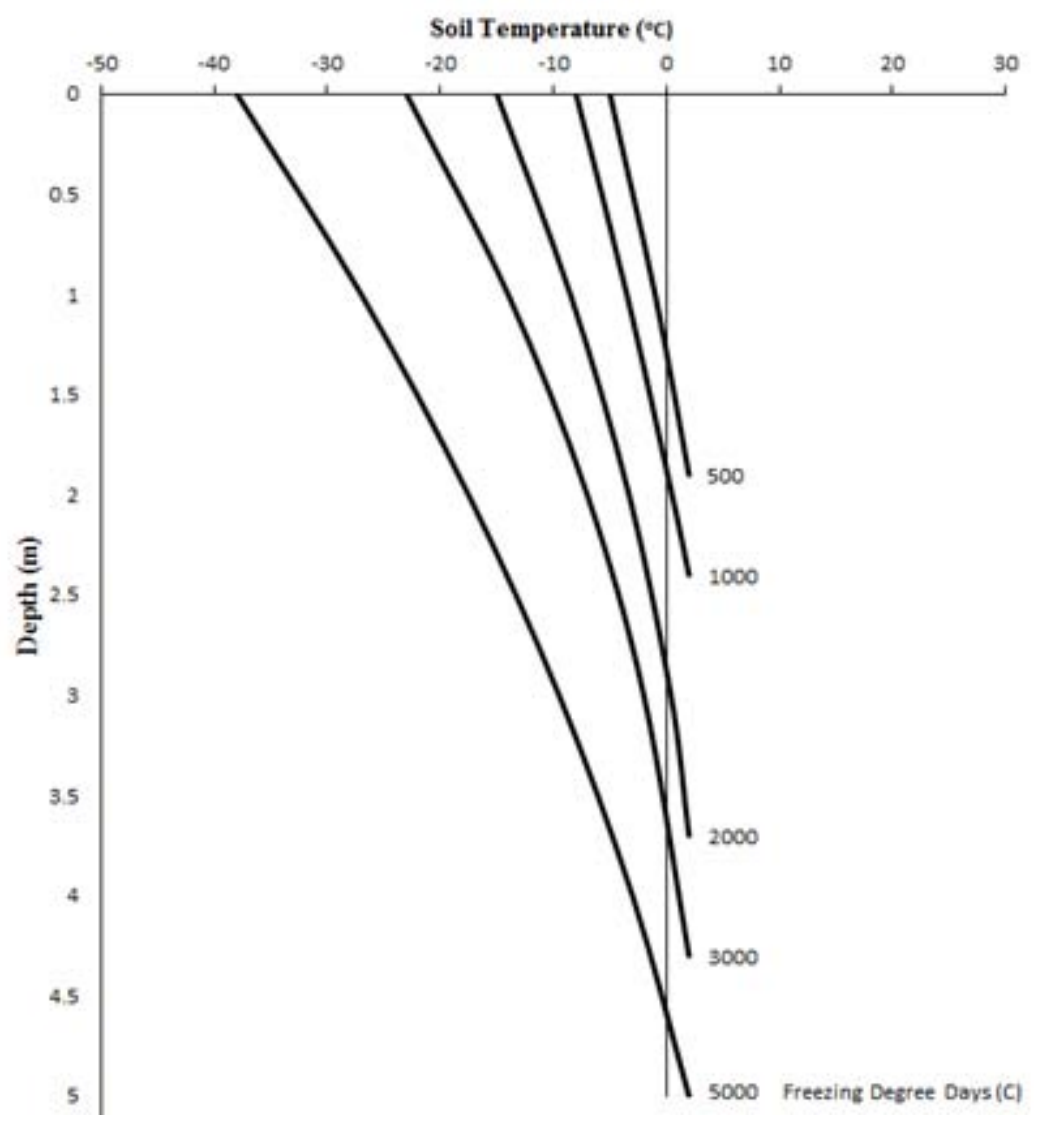

Figure 4.17: Soil temperature versus Depth (Fielding, 1976)

The freezing index is based on the total number of degree-days of freezing for a given winter (Zhang, 1998). The map in Figure 4.18 shows the the number of freezing degree days in Canada by zone. This thesis focuses on locations in Ontario and Quebec, their freezing indices vary from 500 to 4000 freezing degree days $\left({ }^{\circ} \mathrm{C}\right.$ ) (see Figure 4.18). 3000 and 2000 freezing degree days $\left({ }^{\circ} \mathrm{C}\right)$ were taken for Ontario and Quebec, respectively.

To examine the effects of temperature variation on the concrete chamber, it was placed in different soil depths. It was assumed that soil depths over the chamber vary between $0.5 \mathrm{~m}$ to $3.5 \mathrm{~m}$, as shown in Figure 4.19. The initial temperature was assumed to be zero for the entire concrete chamber. The temperature of the outer surface was assumed to change according to temperature distribution (see Figure 4.17). Linear temperature variations were produced through the thickness of the chamber, which changed from zero to the value of the temperature at the specific depth. 


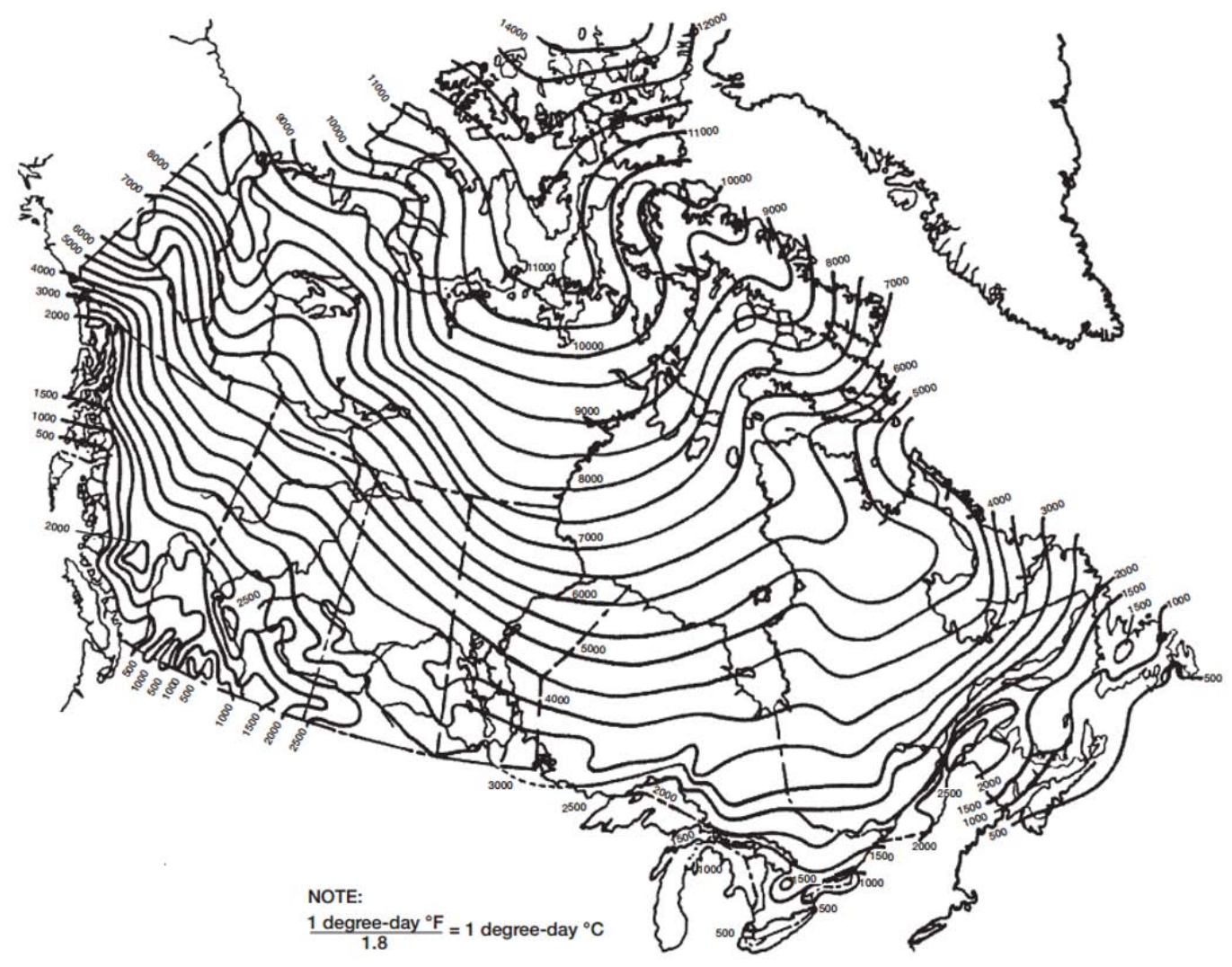

Figure 4.18: Normal freezing index in degree days based on the period 1931 to 1960 for Canada (Boyd, 1973)

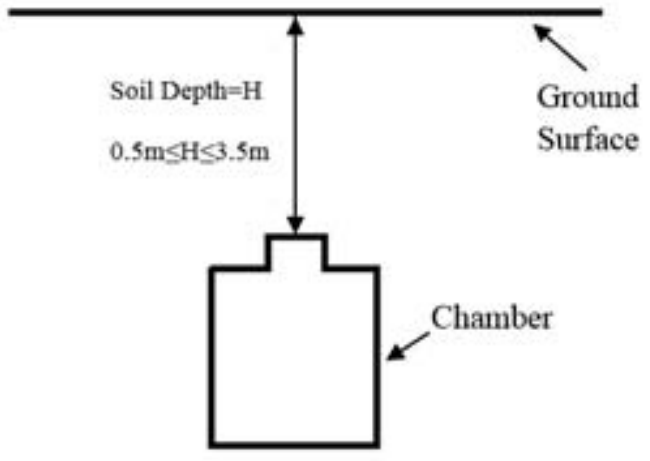

Figure 4.19: Schematic front view of the chamber 


\section{Cracking Patterns}

The crack patterns for steel-reinforced concrete chambers buried in different soil depths were compared, and fewer cracks were observed for higher soil depth values, as seen in Figures 4.20 and 4.21. This is attributed to the fact that when the soil depth over the chamber was increased, the chamber was subjected to more uniform temperature distribution through its depth, thereby reducing the effect of temperature changes. Figures 4.20 and 4.21 show the predicted crack pattern due to temperature changes for Quebec and Ontario regions.

The cracked and intact portions are shown in grey and red, respectively. As shown in Figures 4.20 and 4.21 . crack patterns were strongly influenced by thermal loadings. The effects of temperature variation became negligible after $2.5 \mathrm{~m}$ and $1.5 \mathrm{~m}$ for Quebec and Ontario, respectively. Therefore, to reduce the effect of soil temperature on concrete chambers in those regions, the soil depth should be greater than $2.5 \mathrm{~m}$ and $1.5 \mathrm{~m}$.

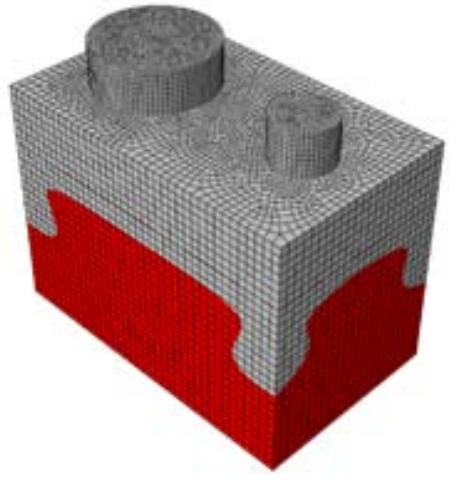

(a) Soil Depth $=0.5 \mathrm{~m}$

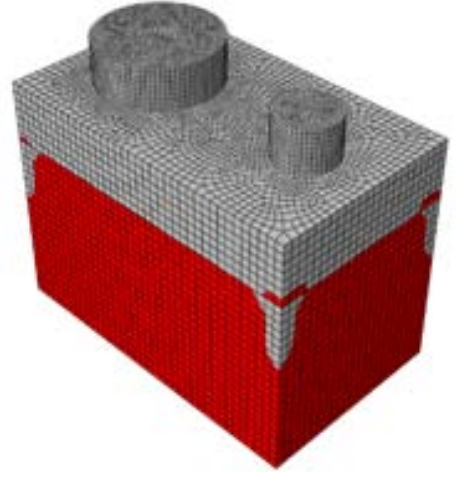

(b) Soil Depth $=1 \mathrm{~m}$

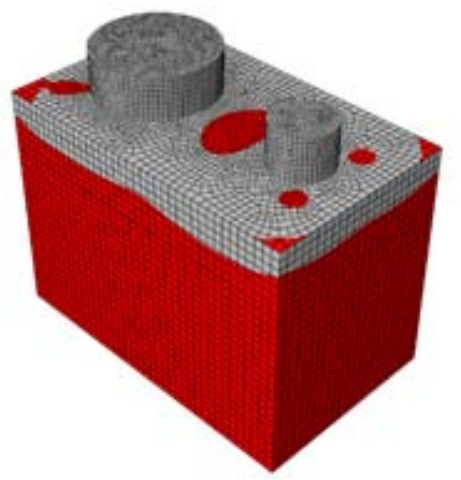

(c) Soil Depth $=1.5 \mathrm{~m}$

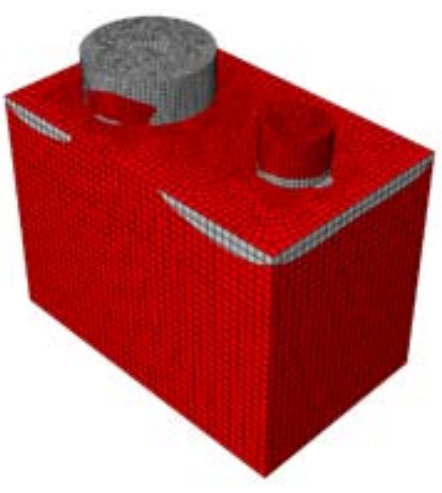

(d) Soil Depth $=2 \mathrm{~m}$

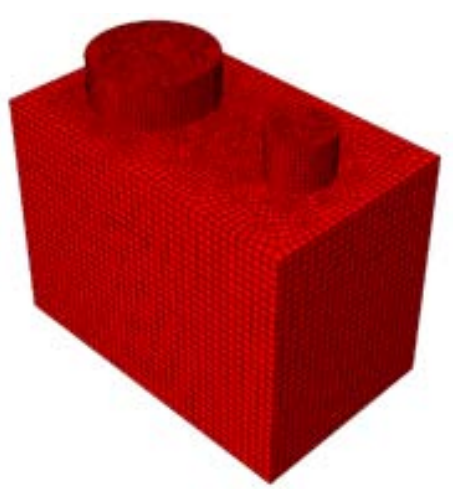

(e) Soil Depth $=2.5 \mathrm{~m}$

Figure 4.20: Predicted crack patterns due to temperature changes for Quebec (cracked elements $=$ grey, intact elements $=$ red) 


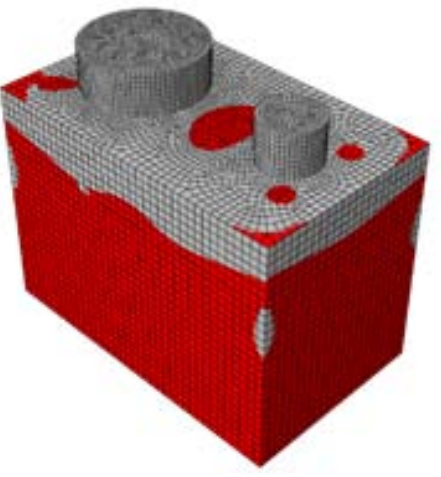

(a) Soil Depth $=0.5 \mathrm{~m}$

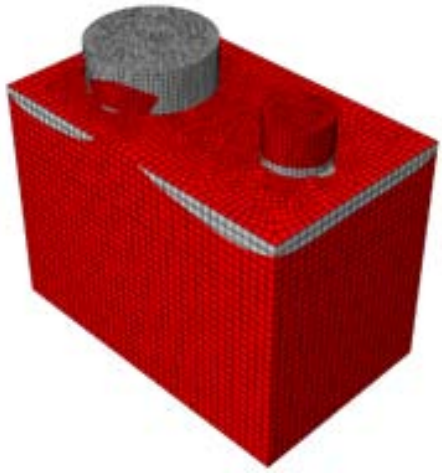

(b) Soil Depth $=1 \mathrm{~m}$

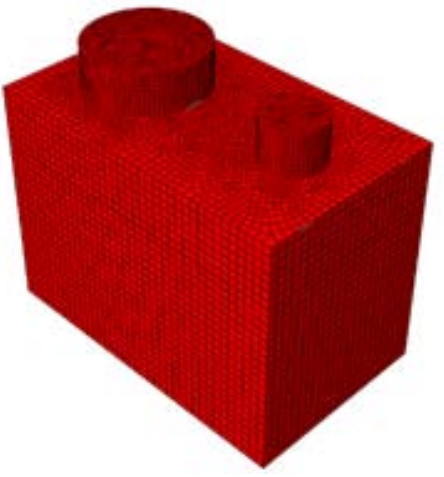

(c) Soil Depth $=1.5 \mathrm{~m}$

Figure 4.21: Predicted crack patterns due to temperature changes for Ontario (cracked elements $=$ grey, intact elements $=$ red)

\section{Stress Distributions}

The distribution of equivalent stress in the steel-reinforced chamber due to the action of the changing temperature was prepared for different soil depth values. Based on distortion energy theory (Yang, 2004), equivalent stress $\left(\sigma_{e}\right)$ is the combination of the three principal stresses and can be obtained by the following equation:

$$
\sigma_{e}=\frac{1}{\sqrt{2}}\left[\left(\sigma_{1}-\sigma_{2}\right)^{2}+\left(\sigma_{2}-\sigma_{3}\right)^{2}+\left(\sigma_{3}-\sigma_{1}\right)^{2}\right]^{1 / 2}
$$

Or it can be expressed with respect to direct stress components as follows:

$$
\sigma_{e}=\frac{1}{\sqrt{2}}\left[\left(\sigma_{x}-\sigma_{y}\right)^{2}+\left(\sigma_{y}-\sigma_{z}\right)^{2}+\left(\sigma_{z}-\sigma_{x}\right)^{2}+6\left(\tau_{x y}^{2}+\tau_{y z}^{2}+\tau_{z x}^{2}\right)\right]^{1 / 2}
$$

Therefore, if the equivalent stress is close to zero in a particular area, the effect of changing temperature on that area is negligible. Figures 4.22 to 4.24 show the distribution of equivalent stress in the steel- and GFRP-reinforced chamber placed in different soil depth values for Quebec and Ontario.

It can be concluded that increasing the soil depth decreases the areas affected by temperature change; if the chamber is placed lower than $2.0 \mathrm{~m}$ or $2.5 \mathrm{~m}$ in Ontario and Quebec regions, the effect of temperature change will be negligible. In addition, as is obvious from the figures, changing the type of reinforcement also has a negligible impact on the response of the chamber under thermal loads. 

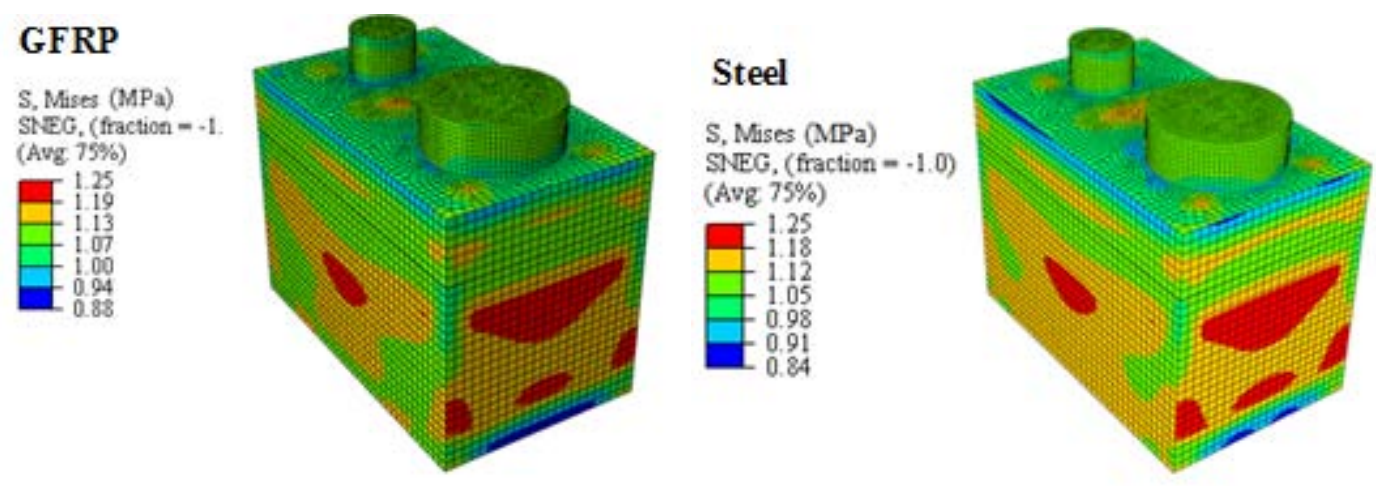

(a) Soil Depth $=0.5 \mathrm{~m}$
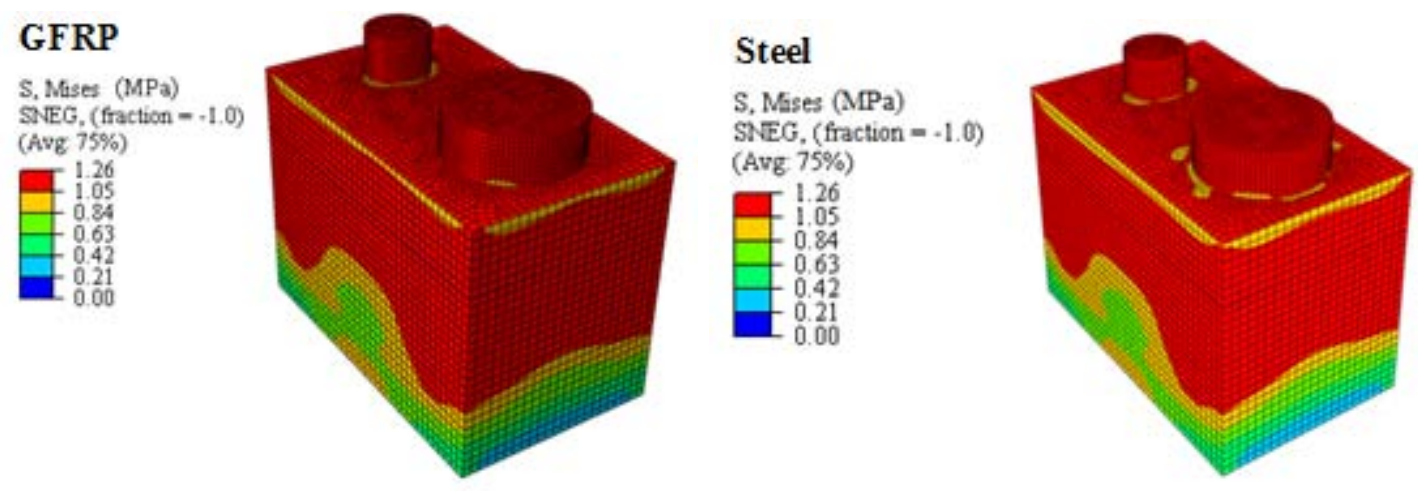

(b) Soil Depth $=1.0 \mathrm{~m}$
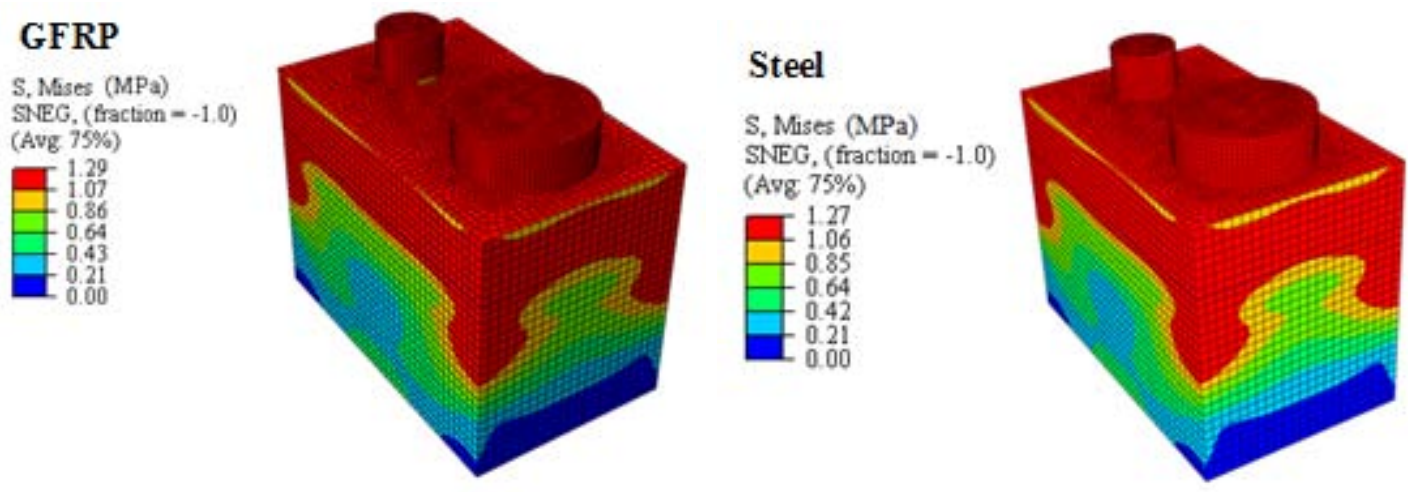

(c) Soil Depth $=1.5 \mathrm{~m}$

Figure 4.22: Distribution of equivalent stress of chamber reinforced with steel and GFRP bars due to the action of temperature changes for Quebec (Soil depth $=0.5$ to1.5 m) 

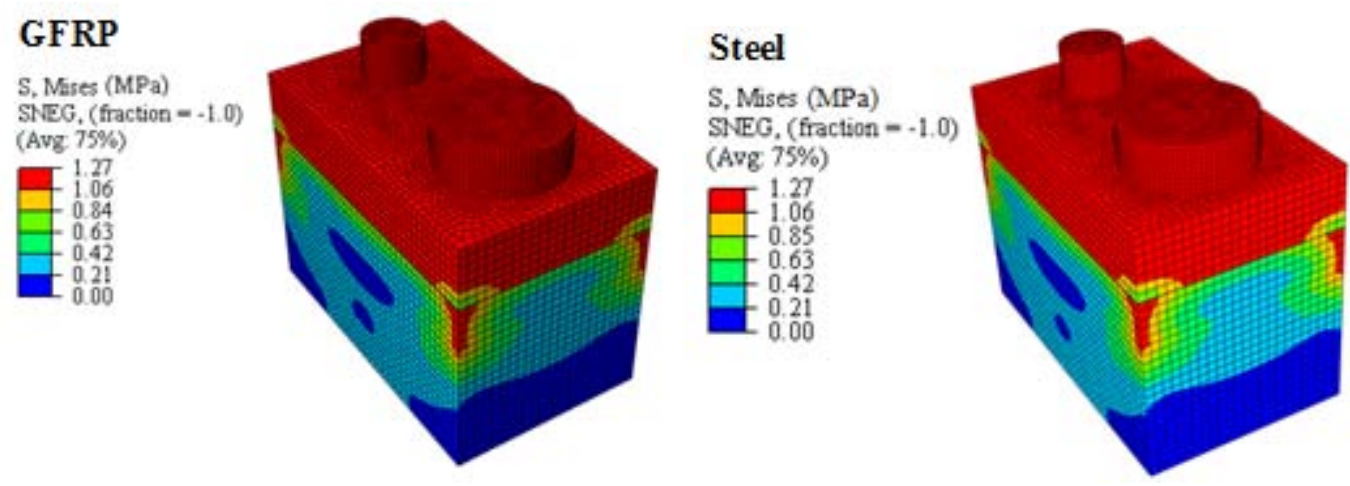

(a) Soil Depth $=2.0 \mathrm{~m}$
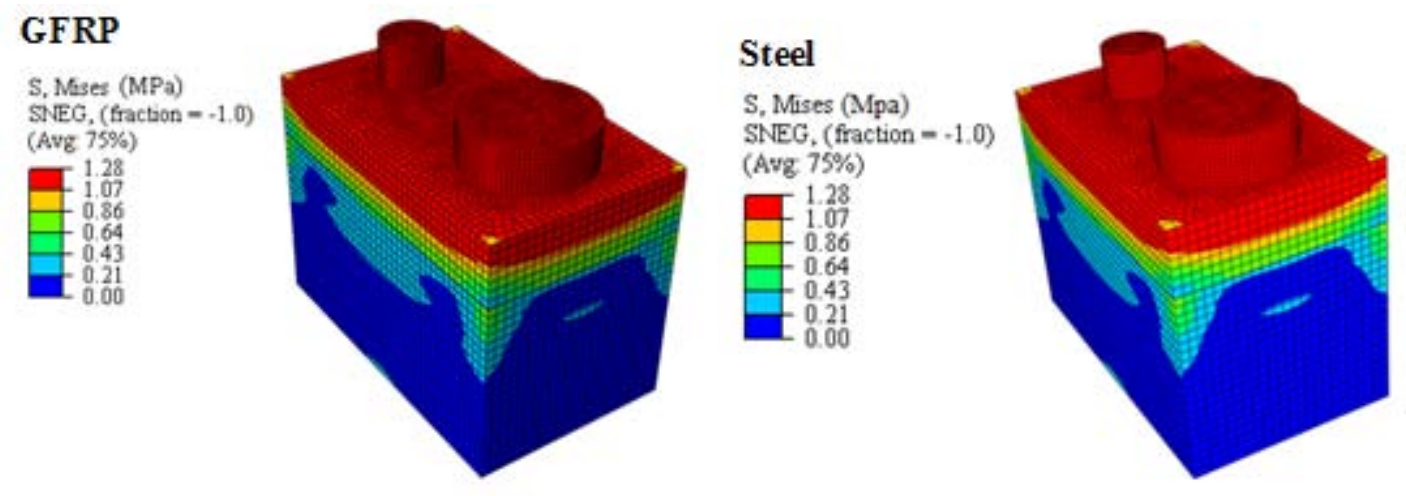

(b) Soil Depth $=2.5 \mathrm{~m}$
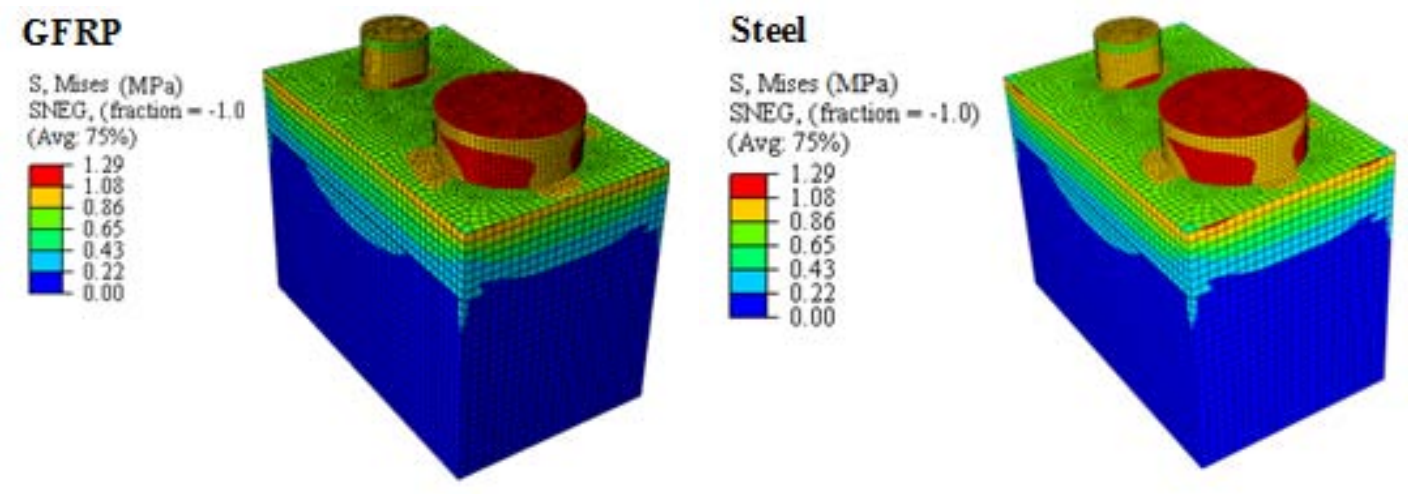

(c) Soil Depth $=3.0 \mathrm{~m}$

Figure 4.23: Distribution of equivalent stress of chamber reinforced with steel and GFRP bars due to the action of temperature changes for Quebec (Soil depth=2.0 to $3.0 \mathrm{~m}$ ) 


\section{GFRP \\ S, Mises (MPa) SNEG, (fraction $=-1.09$ (Aug 75\%)

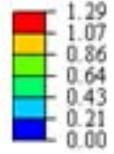

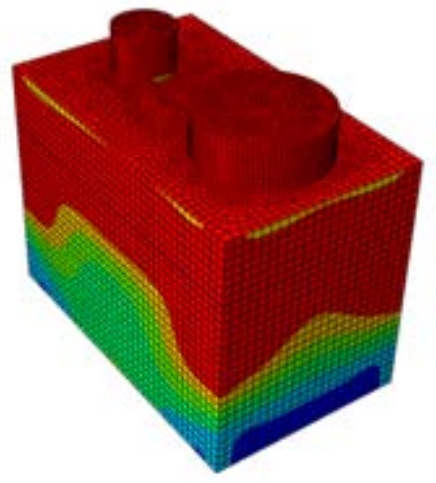
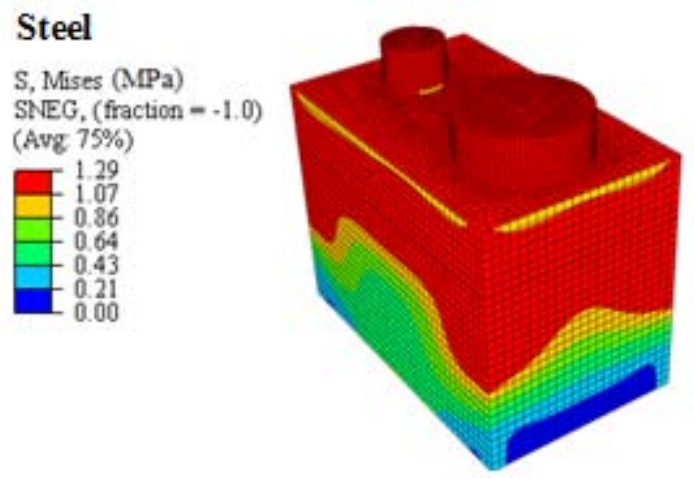

(a) Soil Depth $=0.5 \mathrm{~m}$
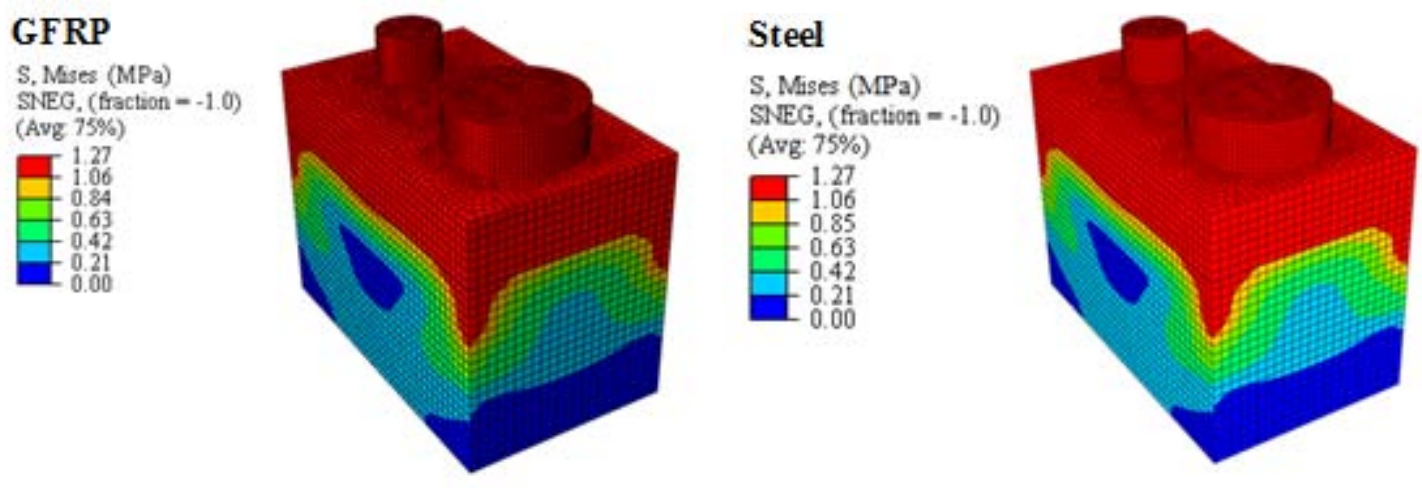

(b) Soil Depth $=1.0 \mathrm{~m}$
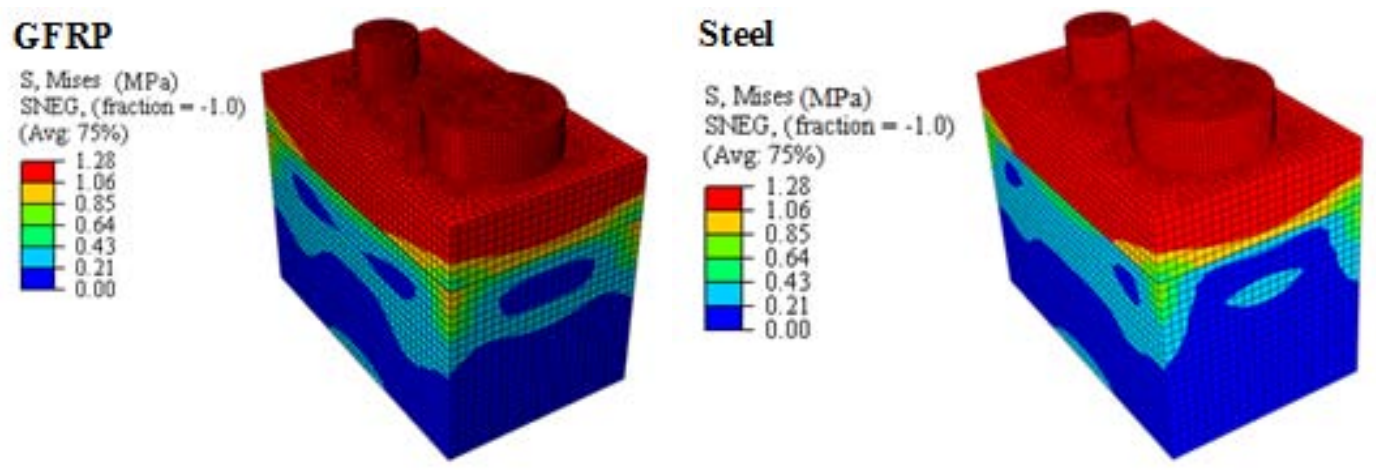

(c) Soil Depth $=1.5 \mathrm{~m}$

Figure 4.24: Distribution of equivalent stress of the chamber reinforced with steel and GFRP bars due to the action of temperature changes for Ontario 


\section{Chapter 5}

\section{Cold Weather Soil Chamber Interaction}

\subsection{General}

Buried concrete chambers can be subjected to complex vertical and lateral loads during their construction and service life. The effect of these loads on the chambers depends mostly on soil structure interaction factors, which include (Selvadurai, et al., 1983):

- Movement of the surrounding soil, including fault displacement, frost heave, thawing settlement, soil consolidation, soil creep, ground subsidence due to underground mining, tunneling, excavation or dewatering, landslides

- Deformation and movement of the buried structure, which could include expansion or contraction due to temperature changes

- External loading such as earthquakes, weight of earth embankments, traffic loads and overburden

Consequently, a more realistic evaluation can be achieved if the mutual interaction between the chamber and surrounding soil is taken into consideration. This interaction can be affected by several factors, such as soil and structure properties or environmental conditions.

In cold regions, buried structures exhibit damage mainly because of frost heave or thaw settlement of the soil. These changing soil phases can produce differential ground movements, which can induce high levels of stress and strain in a buried structure. In this study, several regions of Canada were considered as a case study. Canada is categorized as a cold region with seasonally frozen ground, with almost half the country having permanently frozen ground. To 
ensure the safety and durability of buried structures in Canadian regions, it is necessary to consider the effect of freeze-thaw conditions on soil structure interaction.

As mentioned earlier, FRP bars have emerged as a practical alternative material for reinforcing concrete chambers due to their high strength and noncorrosive nature. However, they have a lower modulus of elasticity than steel bars. Consequently, the stiffness of a concrete chamber reinforced with FRP bars would be lower than one reinforced with steel. As discussed in Chapter 4 (Section 4.3.2), a chamber reinforced with FRP bars may experience large deformations under static loads, which may affect soil structure interaction. In the overall study of soil structure interaction problems, several computational methods have been carried out by a number of researchers. In this study, numerical simulation models were developed to investigate the effect of the aforementioned factors on soil chamber interaction.

\subsection{Soil Structure Interaction Concept}

The soil structure interaction concept and its advantages have been well-known since the earliest days of underground construction. In the construction of the Chicago subway, Terzaghi (1943) recommended thinner, more flexible tunnel linings to take advantage of their interaction with the surrounding soil. He recognized that active ground loads caused by earth pressure produce inward deflections, while the structure deflects outwardly against the ground at the same time. Consequently, the ground resists against the movement, developing additional passive ground pressure, which is more favorable than active load. His consideration of both active and passive pressure systems helped determine the benefit of using thinner linings.

The load exerted on buried structures depends on several factors. The proportions of the load that reaches the buried structure were first studied by Anson Marston. The Marston theory (Spangler and Handy, 1982) deals mainly with the effects of installation conditions on load intensity around the buried structure. Spangler and Handy found that the load intensity on the structure is modified by the arching action of the soil. This type of action is the result of the differential settlement of soil above the buried structure, which can be classified as positive and negative arching actions.

Spangler and Handy (1982) classified the construction installation into two parts: trench and embankment conditions. Trench conditions are defined as the installation of structures in a relatively narrow trench excavated in passive or undisturbed soil, with the trench occupied with backfill. Embankment conditions occur when the structure is placed above natural ground level and covered with embankment. In trench installations, the relative settlement of the backfill material is greater than the adjacent soil due to the higher compressibility of the backfill material compared to the adjacent soil. The soil layers in the central prism are deformed as a 
reverse arch shape, causing relative downward movements within the trench. These movements induce upward shearing stresses within the central soil prism, and create a positive arching action that reduces the earth pressure on top of the structure. Likewise, when the relative settlement of backfill material is less than adjacent soil, the layers of the soil in the central prism are deformed into an arch shape, creating a negative arching action that increases the earth pressure on the structure. Figure 5.1 shows the soil arching mechanism in both trench and embankment installations.

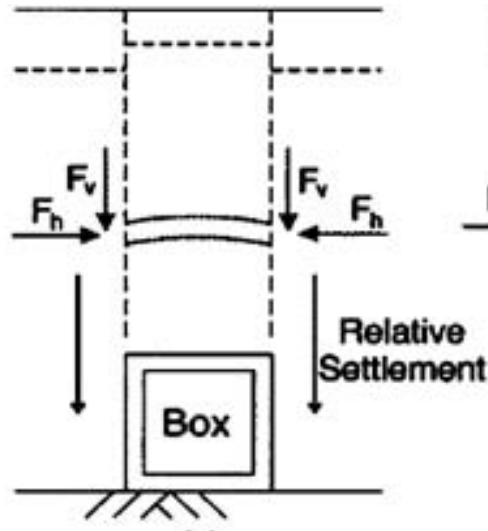

(a)

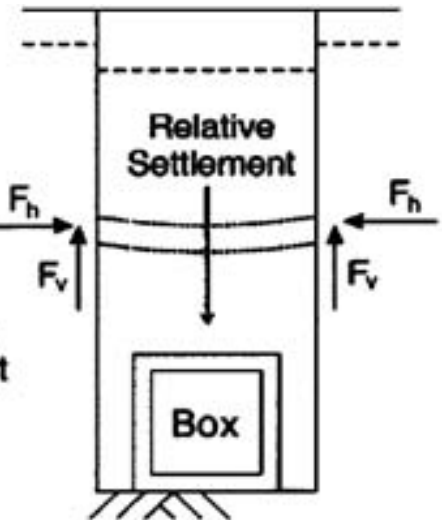

(b)

Figure 5.1: Mechanisms of soil arching over a buried structure (a) embankment installation (b) trench installation (Kim and Yoo, 2005)

In addition to construction installations, load distributions exerted on the structure depend on the overall relative stiffness of both structure and soil. If the structure has a lower stiffness than the soil, as is usually found in flexible structures, it will deform more than the soil. Such deformations result in an arching effect, which reduces the vertical loading acting on the structure. Otherwise, if the structure is stiffer than the soil, as in a rigid culvert, the structure will not deform as much as the soil, causing a negative arching action that increases the load on the structure. It can therefore be concluded that according to Marston theory, the magnitude of the vertical load exerted on the top of a buried structure is governed by the installation method, the soil and structure stiffness, the geometry of the structure, and the boundary conditions with the natural ground.

\subsubsection{Finite Element Codes}

Since the early 1950s, finite element analysis has been a powerful tool for solving complex engineering problems. In the late 1960s, it was introduced as a useful tool in geotechnical engi- 
neering. In a study done by Ozawa and Duncan (1973), a finite element program called ISBILD was developed to analyze stress and movement in dams. This program takes construction sequences into account through incremental analysis procedures. Allen and Meade (1984) used ISBILD to determine loads and settlements of concrete culverts. Their study indicates that ISBILD results were more accurate than any other analytical methods available at the time.

In another study sponsored by FHWA, Katona et al. (1976) developed a computer program called CANDE for analysis of buried pipe structures. The CANDE program has the capability of including nonlinear behaviour of soil and construction sequences. The interface behaviour of soil and structure is characterized by frictional sliding during loading; the ability of the CANDE program to perform soil structure analysis of buried box structures has been proven by many researchers, including Chang et al. (1981), Katona and Vittes (1982), and Tadros and Benak (1989).

The general-purpose finite element program ABAQUS has been widely used by researchers to solve geotechnical problems. Yang et al. (1997) used it to model and predict loads on double-cell concrete box culverts. In that study, the Drucker-Prager elasto-plastic model was used to model the backfill and adjacent soil. The soil structure interface was defined using a contact pair, which allows sliding and loss of contact during loading.

Another numerical study was carried out by Yang (2000) to evaluate factors affecting earth pressures on buried box culverts. ABAQUS software was used to create a two-dimensional finite element model of the soil and culvert. The elastic-plastic Drucker-Prager and the elastic models were used to represent the soil and culvert, respectively. The contact pair was used to model the contact between soil and culvert. The study investigated the effects of height of embankment, compaction effort, overburden pressure and dynamic lateral pressures on buried culverts.

In another study done by Kim and Yoo (2005), the ABAQUS program was used to investigate the soil structure interaction of deeply buried concrete box culverts. In this study, linear and nonlinear models were considered for modelling the soil, and the soil-structure interface was defined by contact pairs. The results indicated that the vertical pressure on the box culvert is not dependent on the possibility of slip at the interface between soil and culvert.

As mentioned previously, earth pressure on box-shaped structures may be affected by many factors, e.g. soil properties, environmental conditions, type of installation, and the relative stiffness of box structure and soil. ABAQUS was used to investigate these effects on box structures because it is the most powerful and well-known software available. 


\subsection{Finite Element Model}

As stated above, the commercial finite element program ABAQUS was used to analyze the performance of buried concrete chambers. The chamber was modelled with linear 3-D shell elements, and the soil was characterized with elasto-plastic 3-D solid elements. The DruckerPrager yield criterion was taken for plastic behaviour of soil. Reinforcing bars were defined as a smeared layer in shell elements. Due to the symmetry of the concrete chamber and soil, only half of the chamber and the surrounding soil were considered. The contact pair option in ABAQUS was used to simulate the contact between the soil and the outer surface of the chamber. All outer surfaces of the model (except the top surface) were restrained from moving in a direction perpendicular to the surface.

\subsubsection{Constitutive Model of Concrete Chamber}

Elastic behaviour was considered as a material property of the concrete chamber, and the elastic characteristics of concrete and reinforcements were defined using modulus of elasticity and Poissons ratio. With concrete compressive strength at $75 \mathrm{MPa}$, the modulus of elasticity of concrete was obtained by Equation 3.1

The modulus of elasticity of the steel and FRP bars was adopted from manufacturing data. Table 5.1 lists the elastic properties of chamber materials.

Table 5.1: Elastic properties of concrete chamber reinforced with FRP and Steel bars

\begin{tabular}{|l|l|l|}
\hline Type & Modulus of Elasticity (MPa) & Poisson's Ratio \\
\hline Concrete & 35470 & 0.2 \\
\hline Steel & 200000 & 0.3 \\
\hline FRP & 65000 & 0.25 \\
\hline
\end{tabular}

\subsubsection{Constitutive Model for Backfill Material}

The elastic plastic Drucker-Prager model was used to simulate backfill material. The DruckerPrager model is classified into three groups according to the shape of the yield surface: linear form, hyperbolic form and general exponent form. For cases where the experimental data (e.g. triaxial test data) has already been calibrated in terms of a cohesion and friction angle, the linear model can be used (ABAQUS/Standard User's Manual, 2010). In this study, the soil properties were adopted from literature in terms of cohesion and friction angles, and the linear Drucker-Prager was used to model the yield criteria. The linear Drucker-Prager criterion is 
defined as (Figure 5.2):

$$
F=t-p \tan \beta-d=0
$$

Where,

$\beta=$ the slope of the linear yield surface in the $p-t$ plane is referringed to the friction angle of the material (Figure 5.2

$d=$ hardening parameter and is related to the cohesion of the material

$t$ and $p$ are stress invariants and are given by the following equations (ABAQUS/Standard User's Manual, 2010):

$$
\begin{gathered}
p=-\frac{1}{3} \operatorname{trace}(\sigma) \\
t=\frac{1}{2} q\left[1+\frac{1}{K}-\left(1-\frac{1}{K}\right)\left(\frac{r}{q}\right)^{3}\right]
\end{gathered}
$$

Where,

$K=$ the ratio of the yield stress in triaxial tension to the yield stress in triaxial compression.

To simplify the problem in this study, $\mathrm{K}$ was assumed to be 1.0, which implies that the yield stresses in triaxial tension and compression are the same values.

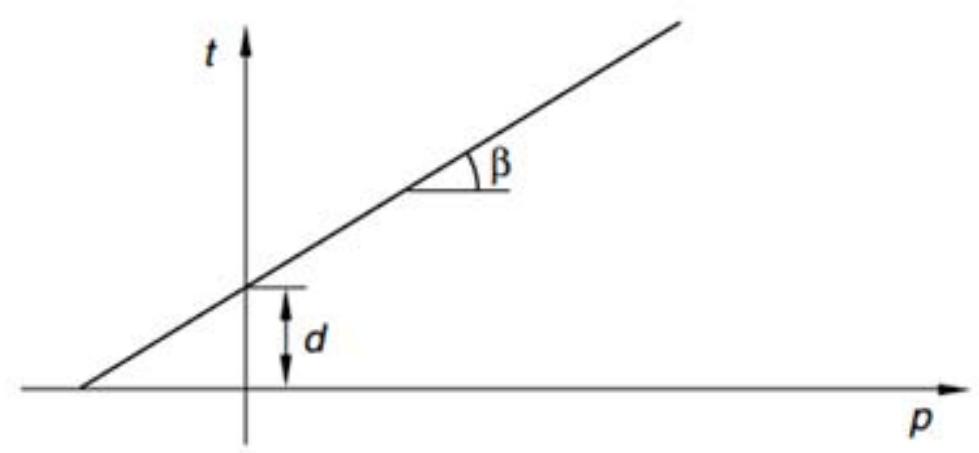

Figure 5.2: Linear Drucker-Prager model: Yielding surface (ABAQUS/Standard User's Manual, 2010) 


\section{Soil Condition}

Two basic installation techniques are typically used for buried concrete box sections: embankment installation and trench installation (CHBDC 2000). Due to the size of the concrete chamber, the embankment installation technique was selected for this study. CHBDC specifies backfill material as sand and gravel, sandy silt, and silty clay for box concrete sections. Sandy silt and silty clay were considered for the backfill material in this study. Water table was assumed to be at ground surface.

\section{Effect of Freezing and Thawing on Material Properties}

Soil temperature gradually decreases as winter approaches, and the moist ground is subjected to freezing when the water in the soil pores changes into ice. The formation of the ice lens may increase the volume of soil by about 9\% (Andersland and Ladanyi, 2004). When the ice lens melts as spring approaches, the soil layer becomes wet and soft, and this loss of soil strength may cause thaw settlement in soil layers. Obviously, changing temperature in soil layers has a significant impact on soil properties. In this study, it was assumed that soil and pore fluid flow properties are dependent on whether the soil is frozen or thawed. The soil properties in the frozen state and the thawed state are shown in Table 5.2 for clay and sand. These data are based on published literature, e.g. Selig, (1990), McGrath (1998) and Yang et al. (2007). The symbols $E, v, \gamma, \phi, \psi, e$ and $K$ represent the Young's modulus, Poison's Ratio, density, friction angle, dilation angle, void ratio, and permeability, respectively.

Table 5.2: Recommended properties for backfill soils

\begin{tabular}{|l|l|l|l|}
\hline \multicolumn{2}{|l|}{ Material Properties } & Silty Sand (ML95) & Silty Clay (CL95) \\
\hline \multirow{2}{*}{$E(M P a)$} & Frozen & 1800 & 600 \\
\cline { 2 - 4 } & Thawed & 18 & 6 \\
\hline$v$ & 0.3 & 0.29 \\
\hline$\gamma\left(k N / m^{3}\right)$ & 17.7 & 15.4 \\
\hline$c\left(k N / m^{3}\right)$ & 28 & 48 \\
\hline$\Phi, d e g$ & 34 & 17 \\
\hline$\Psi, d e g$ & 0 & 7 \\
\hline$e$ & 0.4 & 0.5 \\
\hline \multirow{2}{*}{$K$} & Frozen & $6 \times 10^{-13}$ & $5 \times 10^{-16}$ \\
\cline { 2 - 4 } & Thawed & $3 \times 10^{-7}$ & $5 \times 10^{-10}$ \\
\hline
\end{tabular}




\section{Thermal Properties}

In addition to physical properties, thermal properties are required to model freezing and thawing. To account for the volumetric expansion of pore water during the phase change, different values of thermal expansion were adopted for different temperatures, as listed in Table 5.3 . Two thermal properties were considered for modelling of the heat transfer process in the soil media, as shown in Table 5.3 .

Table 5.3: Thermal properties for soil and water

\begin{tabular}{|l|l|l|}
\hline Thermal properties & Water & Soil \\
\hline Thermal conductivity $\left(\mathrm{J} / \mathrm{secm}^{\circ} \mathrm{C}\right)$ & 0.58 & 2.0 \\
\hline Specific heat $\left(\mathrm{kJ} / \mathrm{kg}^{\circ} \mathrm{C}\right)$ & 4.2 & 1.4 \\
\hline \multirow{5}{*}{ Thermal coefficient of expansion $\left(1 /{ }^{\circ} \mathrm{C}\right)$} & $51 \times 10^{-6}\left(\right.$ at $\left.\left.-5{ }^{\circ} \mathrm{C}\right)\right)$ & \multirow{2}{*}{$9.67 \times 10^{-6}$ (for Clay) } \\
\cline { 2 - 2 } & $51 \times 10^{-6}\left(\right.$ at $\left.\left.0{ }^{\circ} \mathrm{C}\right)\right)$ & \\
\cline { 2 - 2 } & $-16.67 \times 10^{-6}\left(\right.$ at $\left.\left.1^{\circ} \mathrm{C}\right)\right)$ & \multirow{3}{*}{$5.6 \times 10^{-6}$ (for Sand) } \\
\cline { 2 - 2 } & $0.0\left(\right.$ at $\left.\left.4^{\circ} \mathrm{C}\right)\right)$ & \\
\cline { 2 - 3 } & $29.33 \times 10^{-6}\left(\right.$ at $\left.\left.10^{\circ} \mathrm{C}\right)\right)$ & \\
\hline
\end{tabular}

\subsubsection{Selection of Elements}

A finite element analysis of a buried structure has to incorporate different element types for the structure and soil (Watkins and Anderson, 1999). Moreover, to allow movement between structure and soil, use of interface elements is required. A three-dimensional four-node shell element (S4R) with six degree of freedom at each node was used to model the reinforced concrete chamber. The layers of reinforcement were accommodated into shell elements as smeared layers.

The elements used for the soil were three-dimensional eight-node pore fluid/stress (C3D8RP) elements with displacement and pore pressure degrees of freedom. The continuum of pore pressure elements has the capability to model a porous medium as a multiphase material. The porous medium modeled by these elements provides two fluids in the medium: wetting liquid and gas. Accordingly, the element volume is made up of a volume of solid material, a volume of voids, and a volume of wetting liquids which can flow through the elements. Soil as a multiphase material is a good example of such a system. When soil is partially saturated, both fluids exist in the medium; when it is fully saturated, the volume of voids is completely occupied by the wetting liquid or water.

The material property of pore pressure element has to be defined with the associated properties of pore fluid flow and porous solid material. Any available mechanical properties can be used for porous solid material. However, an enhanced procedure would result if the model contains the elastic, porous elastic, extended Cam-clay plasticity, and Mohr-Coulomb placidity 
models (ABAQUS/Standard User's Manual, 2010). Pore fluid flow properties are characterized with specific weight of the wetting liquid, permeability, void ratio, and the percentage of saturation.

\section{Interface Behaviour}

Contact interactions for two bodies are characterized by the relative movement along the contact surface, which starts when the shear stress tangent to the interface is larger than the frictional resistance of the corresponding interface. To account for the movement between a buried structure and its surrounding soil, the ABAQUS User's Manual (2010) offers the following approaches: general contact and contact pairs. The general procedure for defining contact simulation is to first define surfaces for bodies that are potentially in contact, and then define mechanical contact property.

As indicated in the literature review (Section 5.2.1), the most popular approach for modeling soil structure interface is the contact pair, and it is therefore the option chosen for modelling contact behaviour in this study. The outer surface of the chamber and the inner surface of the soil, which were in contact with each other, were defined in the model, and the Mohr-Coulomb constitutive model was used to characterize the contact property. According to the MohrCoulomb model, two contacting surfaces can carry shear stresses up to critical shear stress $\left(\tau_{c r i t}\right)$ which is given by the following equation:

$$
\tau_{\text {crit }}=\mu p
$$

Where

$$
\begin{aligned}
& \mu=\text { coefficient of friction } \\
& p=\text { contact pressure }
\end{aligned}
$$

The contact pressure is equal to the ratio of the normal contact force and cross-sectional area at the contact nodes. The coefficient of friction was considered as $2 / 3$ of the tangent of the angle of friction of the soil, as recommended by Yang (2000).

\subsubsection{Boundary and Load Conditions}

\section{Boundary Conditions}

As mentioned previously, the finite element method was used to analyze soil-chamber interaction. This analysis treated the soil masses as a continuum and required the specification of boundary conditions around the soil masses. These boundaries were carefully defined because the displacement on wall boundaries can have a considerable impact on results (Potts and 
Zdravkovic, 1999). To eliminate the boundary effect in this study, the finite element mesh was extended to a depth two times that of the chamber height and laterally four times its width. Examples of the soil and chamber meshes used in the finite element analysis are shown in Figure 5.3 .

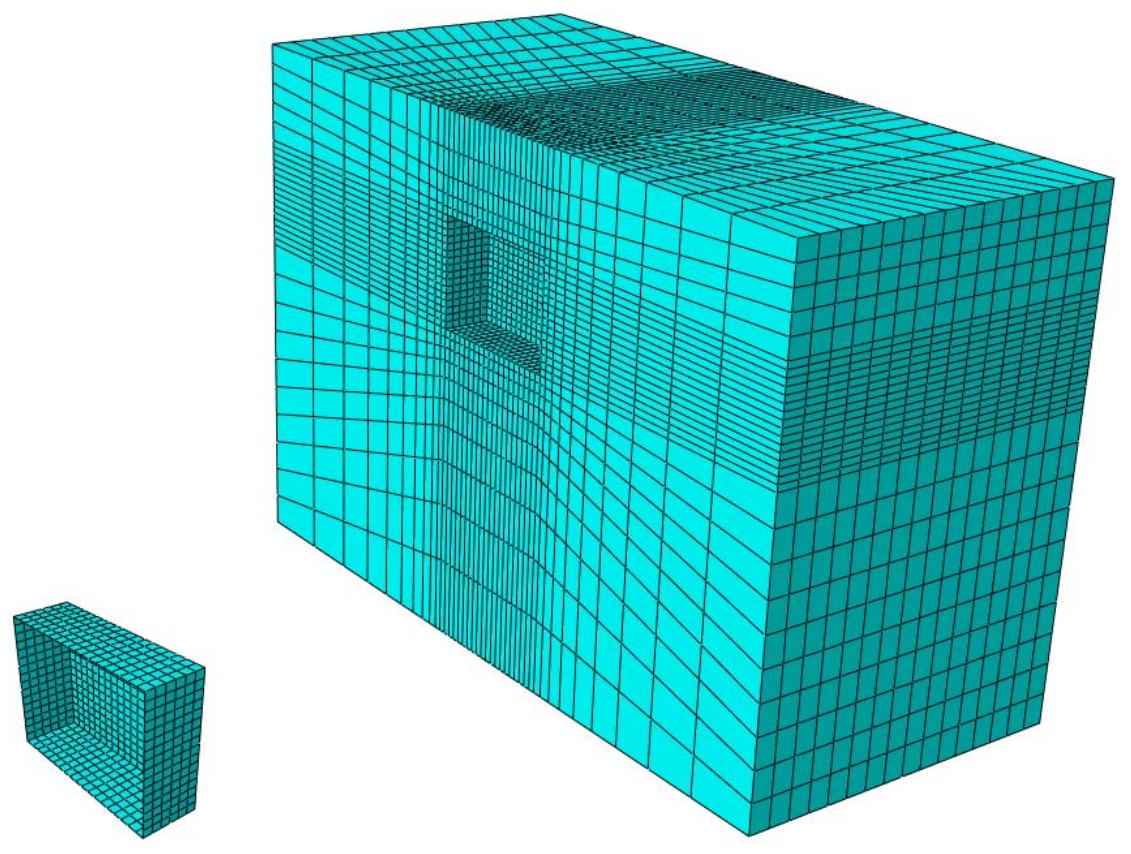

Figure 5.3: Finite element mesh in for soil and chamber in three dimensional view

All outer surfaces of the soil elements (except the top surface) were restrained from movement in the perpendicular direction. Zero pore pressure was assumed for the top surface, which allowed water to drain through and into soil beneath.

\section{Load Conditions}

The freezing and thawing process occurs mainly in the top layers of ground, where the temperature fluctuates above and below $0{ }^{\circ} \mathrm{C}$ during the year. These layers are known as active layers; their thickness varies between $15 \mathrm{~cm}$ and $3 \mathrm{~m}$ and depends mainly on local air temperature. The number of freezing degree days can be used as an approximate guide for estimating the thickness of active layers. Table 5.4 provided courtesy of Environment Canada, shows the average freezing depth for any given number of freezing degree days. The number of freezing days can be seen in Figure 4.18 .

For this thesis, the locations studied were Ontario and Quebec. Their corresponding freezing 
indices vary from 1000 to 3000 freezing degree days $\left({ }^{\circ} \mathrm{C}\right)$. therefore the freezing depth for these two regions was assumed to be $2.5 \mathrm{~m}$ for Ontario and Quebec. The temperature changes in this depth were assumed to be 5 to $-10\left({ }^{\circ} \mathrm{C}\right)$ for freezing and -10 to $5\left({ }^{\circ} \mathrm{C}\right)$ for thawing. 
Table 5.4: Aaverage freezing depth for any number of freezing degree days ${ }^{1}$

\begin{tabular}{|c|c|c|c|}
\hline $\begin{array}{l}\text { Freezing Index } \\
\text { Degree days }\end{array}$ & $\begin{array}{l}\text { Estimated Frost } \\
\text { Depth in meters }\end{array}$ & $\begin{array}{l}\text { Freezing Index } \\
\text { Degree days }\end{array}$ & $\begin{array}{l}\text { Estimated Frost } \\
\text { Depth in meters }\end{array}$ \\
\hline 400 & 0.66 & 2000 & 1.98 \\
\hline 450 & 0.71 & 2050 & 2.01 \\
\hline 500 & 0.76 & 2100 & 2.04 \\
\hline 550 & 0.81 & 2150 & 2.07 \\
\hline 600 & 0.86 & 2200 & 2.10 \\
\hline 650 & 0.91 & 2250 & 2.13 \\
\hline 700 & 0.96 & 2300 & 2.16 \\
\hline 750 & 1.00 & 2350 & 2.19 \\
\hline 800 & 1.05 & 2400 & 2.22 \\
\hline 850 & 1.09 & 2450 & 2.25 \\
\hline 900 & 1.14 & 2500 & 2.28 \\
\hline 950 & 1.18 & 2550 & 2.31 \\
\hline 1000 & 1.21 & 2600 & 2.34 \\
\hline 1050 & 1.25 & 2650 & 2.36 \\
\hline 1100 & 1.29 & 2700 & 2.39 \\
\hline 1150 & 1.32 & 2750 & 2.42 \\
\hline 1200 & 1.36 & 2800 & 2.45 \\
\hline 1250 & 1.39 & 2850 & 2.48 \\
\hline 1300 & 1.43 & 2900 & 2.51 \\
\hline 1350 & 1.47 & 2950 & 2.52 \\
\hline 1400 & 1.50 & 3000 & 2.54 \\
\hline 1450 & 1.54 & 3050 & 2.56 \\
\hline 1500 & 1.57 & 3100 & 2.59 \\
\hline 1550 & 1.62 & 3150 & 2.62 \\
\hline 1600 & 1.66 & 3200 & 2.64 \\
\hline 1650 & 1.70 & 3250 & 2.67 \\
\hline 1700 & 1.74 & 3300 & 2.69 \\
\hline 1750 & 1.78 & 3350 & 2.72 \\
\hline 1800 & 1.82 & 3400 & 2.74 \\
\hline 1850 & 1.86 & 3450 & 2.77 \\
\hline 1900 & 1.90 & 3500 & 2.79 \\
\hline 1950 & 1.94 & and more & 2.80 \\
\hline
\end{tabular}

\footnotetext{
${ }^{1}$ http://www.urecon.com/main/home.html
} 


\subsubsection{Solution Procedure}

Analysis consisted of three steps: initial stress condition, geostatic state and loading step. Each step was broken into smaller increments, and at each increment, a number of iterations were employed to find an equilibrium solution. ABAQUS uses the Newton-Raphson method to find equilibrium solutions for each iteration; all increment sizes and number of iterations are specified automatically. The initial condition is the first step in which the first guess for stresses is specified in the soil. The initial vertical stress was assumed to vary linearly with depth, and the horizontal stress was calculated by multiplying vertical stress by the coefficient of earth pressure at rest. Afterwards, the geostatic step was used to verify whether the initial stresses were in equilibrium with external loading and boundary conditions. Equilibrium is achieved if the effective stresses calculated by ABAQUS are equal to initial stresses; several iterations may be required to achieve this equilibrium state. After finding the correct initial stress with proper boundary conditions, the loading step could proceed.

\subsection{Results and Discussion}

The FE model was developed for the buried chambers, as described in the previous section. Section 5.4.1 presents the effects of soil and reinforcement type on stress distributions in the buried concrete chamber, followed by the results of the parametric study of the effects of freezing and thawing.

\subsubsection{Stress Distributions in the Buried Chamber}

The behaviour of buried chambers was studied in terms of equivalent stress, which represents an envelope of direct and shear stress components (Equations 4.4 and 4.5 . This section presents the effects of reinforcement and backfill type on equivalent stress distribution on the buried chamber, followed by an investigation into the effects of freezing and thawing.

\section{Effect of Different Type of Reinforcement and Backfills}

Figures 5.4 to 5.6 show the equivalent stress in the chamber reinforced with FRP and steel bars. The chamber was placed at soil depths of $1.5 \mathrm{~m}, 2 \mathrm{~m}$ and $2.5 \mathrm{~m}$. By referring to these figures, it can be concluded that the type of reinforcement has an insignificant effect on stress

distributions. In addition, two different backfill materials were taken into consideration: silty clay and silty sand. Figures 5.4 to 5.6 show that changing the backfill had a negligible impact on the equivalent stress distribution in the concrete chambers. However, changing the soil depth has an impact on stress distributions. As illustrated in Figures 5.4 to 5.6, increasing the soil 
depth from $1.5 \mathrm{~m}$ to $2.5 \mathrm{~m}$ increased the maximum equivalent stresses by $28 \%$ and $29.4 \%$ for silty clay and silty sand, respectively.
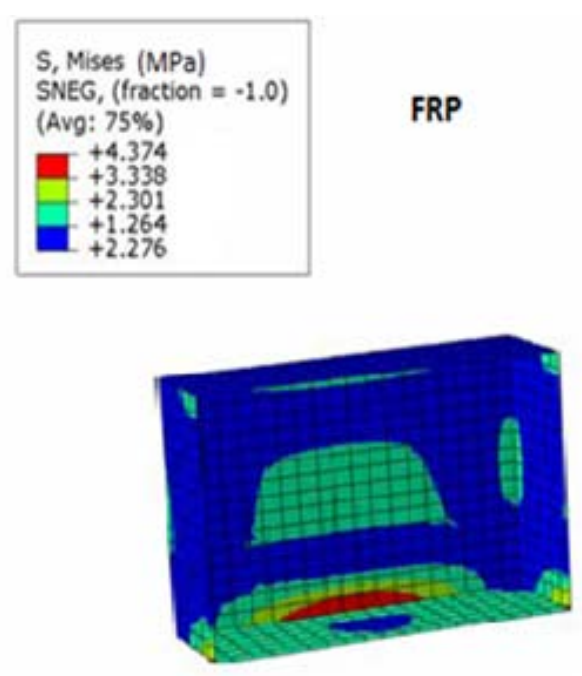

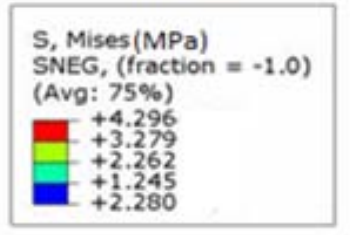

Steel

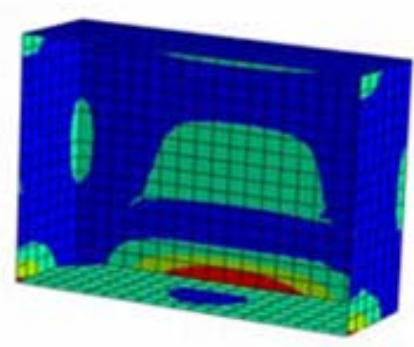

(a) Silty-Clay
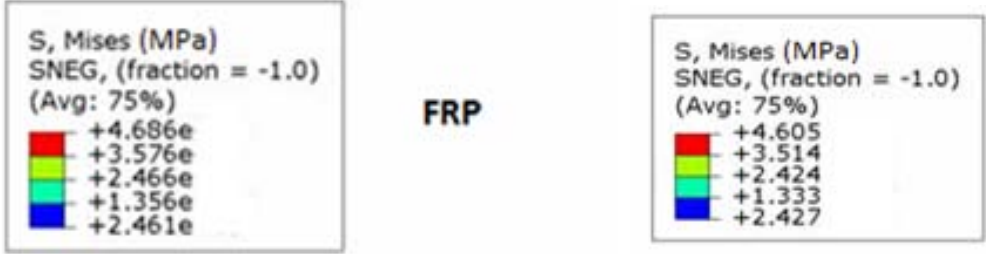

Steel

FRP
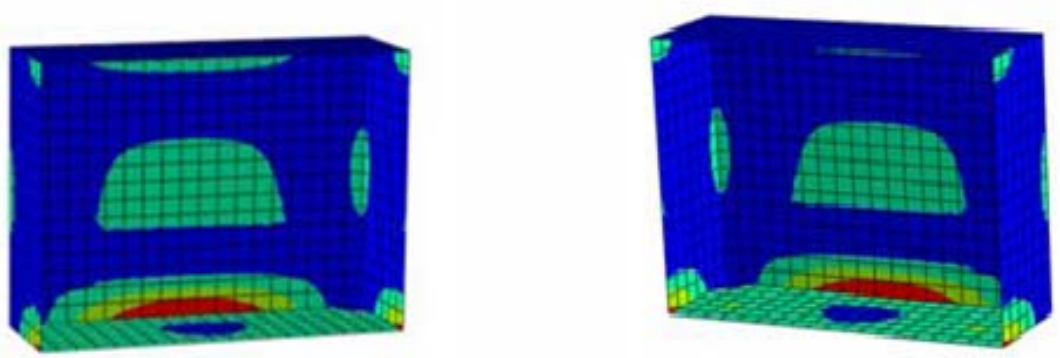

(b) Silty- Sand

Figure 5.4: Equivalent stress distributions in the concrete chamber reinforced with FRP and steel bars (backfill height $=1.5 \mathrm{~m}$ ) 


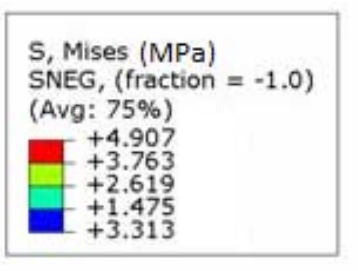

\begin{tabular}{l|l|}
\multicolumn{1}{c|}{ S, Mises (MPa) } \\
SNPEG, (fraction $=-1.0$ ) \\
(Avg: $75 \%$ ) \\
+4.996 \\
+3.831 \\
+2.666 \\
+1.502 \\
+3.368 \\
\hline
\end{tabular}

\section{Steel}
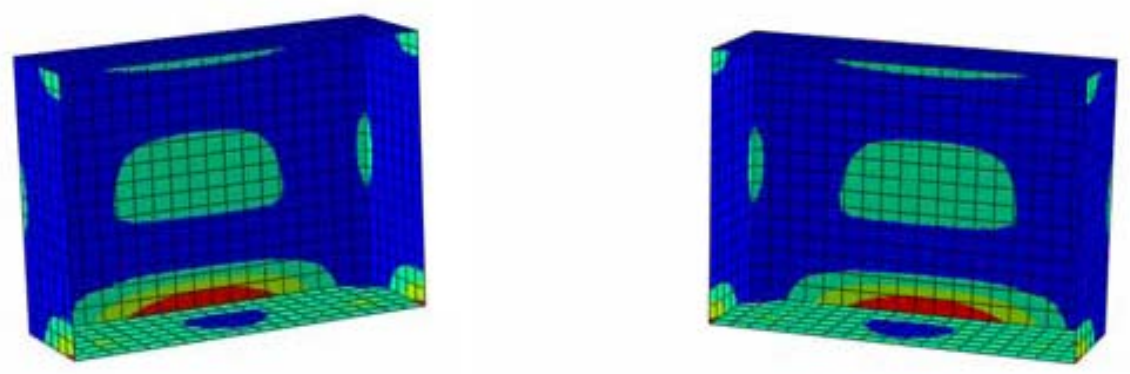

(a) Silty-Clay

\begin{tabular}{|l|}
\hline S, Mises (MPa) \\
SNEG, (fraction $=-1.0$ ) \\
(Avg: $75 \%$ ) \\
+5.73 \\
+4.39 \\
+3.05 \\
+1.71 \\
+3.74 \\
\hline
\end{tabular}

\begin{tabular}{|l|} 
S, Mises (MPa) \\
SNEG, (fraction = $=-1.0$ ) \\
(Avg: $75 \%$ ) \\
+5.628 \\
+4.313 \\
+2.998 \\
+1.683 \\
+3.683
\end{tabular}

Steel

FRP
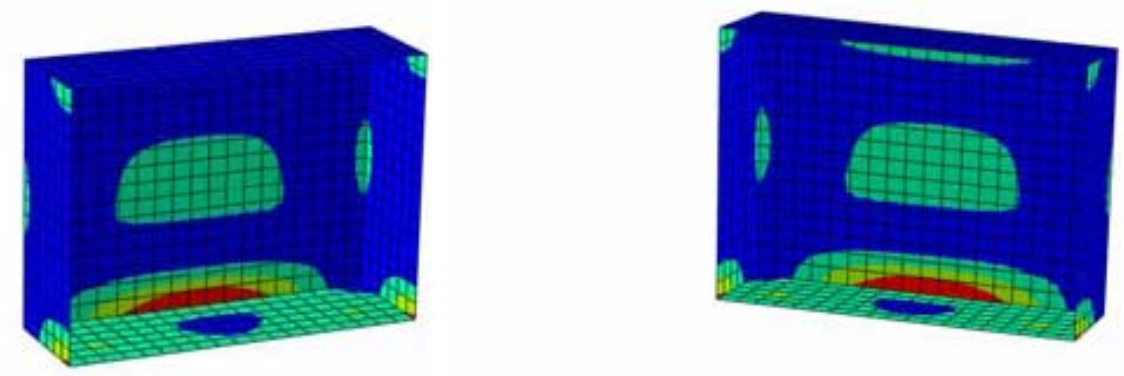

(b) Silty- Sand

Figure 5.5: Equivalent stress distributions in the concrete chamber reinforced with FRP and steel bars (backfill height $=2 \mathrm{~m}$ ) 

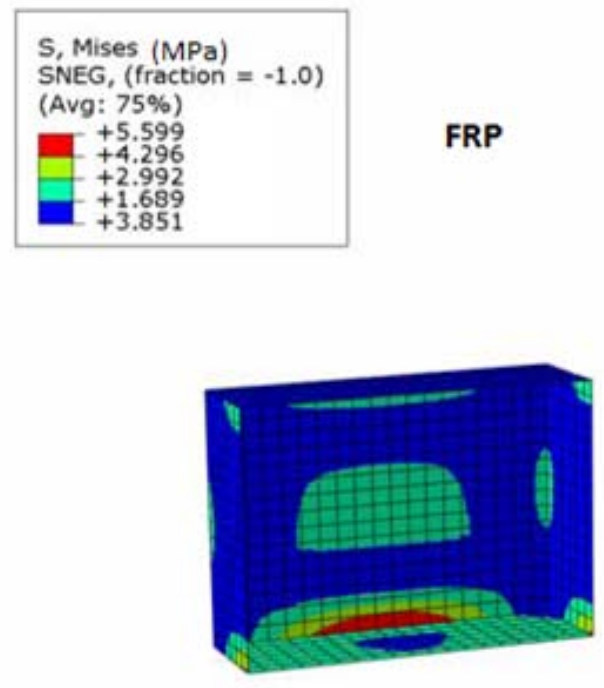

\begin{tabular}{l} 
S, Mises (MPa) \\
SNEG, (fraction = -1.0) \\
(Avg: $75 \%$ ) \\
+5.499 \\
+4.219 \\
+2.939 \\
+1.659 \\
+3.788 \\
\hline
\end{tabular}

\section{Steel}

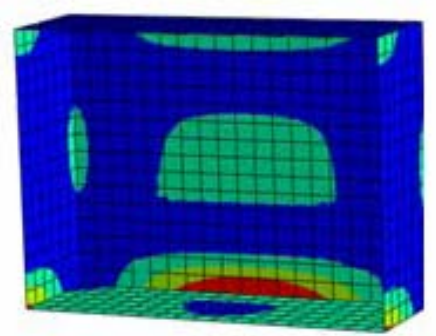

(a) Silty-Clay

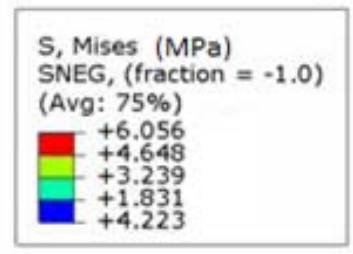

\begin{tabular}{l|l|}
\hline & \\
& S, Mises (MPa) \\
SNEG, (fraction $=-1.0)$ \\
(Avg: $75 \%$ ) \\
\\
+5.951 \\
+4.567 \\
+3.183 \\
+1.799 \\
+7.155 \\
\hline
\end{tabular}

\section{Steel}
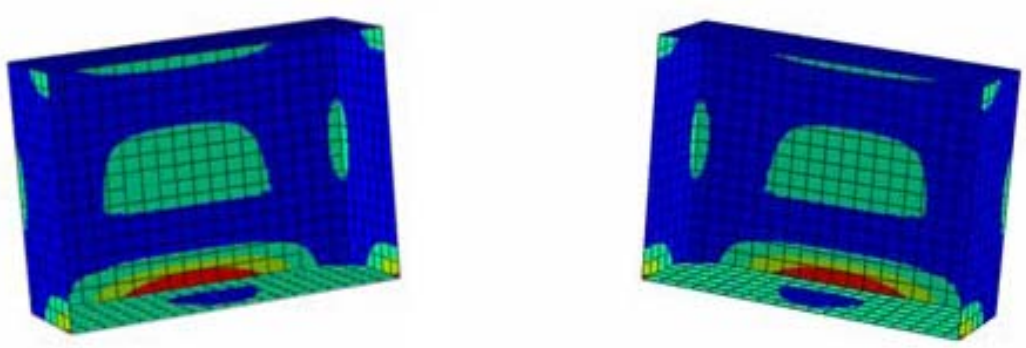

(b) Silty- Sand

Figure 5.6: Equivalent stress distributions in the concrete chamber reinforced with FRP and steel bars (backfill height $=2.5 \mathrm{~m}$ ) 


\section{Effect of Freezing and Thawing}

To determine the effects of freezing and thawing on the equivalent stresses in the chambers, the factors considered in this study were soil type and the soil depth over the chamber. Figures 5.7 to 5.9 present the differences in equivalent stress distribution for three possible soil conditions: thawing, freezing and normal (without freezing and thawing). When the soil depth over the chamber was $1.5 \mathrm{~m}$ (Figure 5.7), the stress distribution was significantly changed by freezing. Figure 5.7 indicates that the freezing increases the maximum equivalent stresses by $40 \%$ and $32 \%$ for silty clay and silty sand, respectively. Silty sand had a less obvious effect on stress distribution. This may be attributed to the fact that the silty clay backfill has tiny voids and silty sand does not. Thus, the growth of the ice lens in silty clay backfill generated more pressure than it did in the silty sand.

Increasing the soil depth decreases the effect of freezing on the chamber. When the soil depth over the chamber was $2.5 \mathrm{~m}$ (Figure 5.9), the stress distribution was not changed significantly by freezing. Figure 5.9 shows that the freezing process only increased the maximum equivalent stresses by $2 \%$ and $1.8 \%$ for silty clay and silty sand, respectively. It can therefore be concluded that increasing the soil depth decreases the effect of freezing on stress distribution. Thus, because the chamber was placed lower than the freezing depth of the soil, it was less affected by freezing.

Figures 5.7 to Figure 5.9 indicate that increasing the soil depth increases the effect of thawing on the chamber. this is due to the nature of thawing process in soil, which is related to the weight of the soil. As thawing occurs, the soil will consolidate under its weight or external load. Thus, if the weight of the soil is increased, the consolidation of soil under its weight will be increased and consequently the effect of thawing is more sensible. 

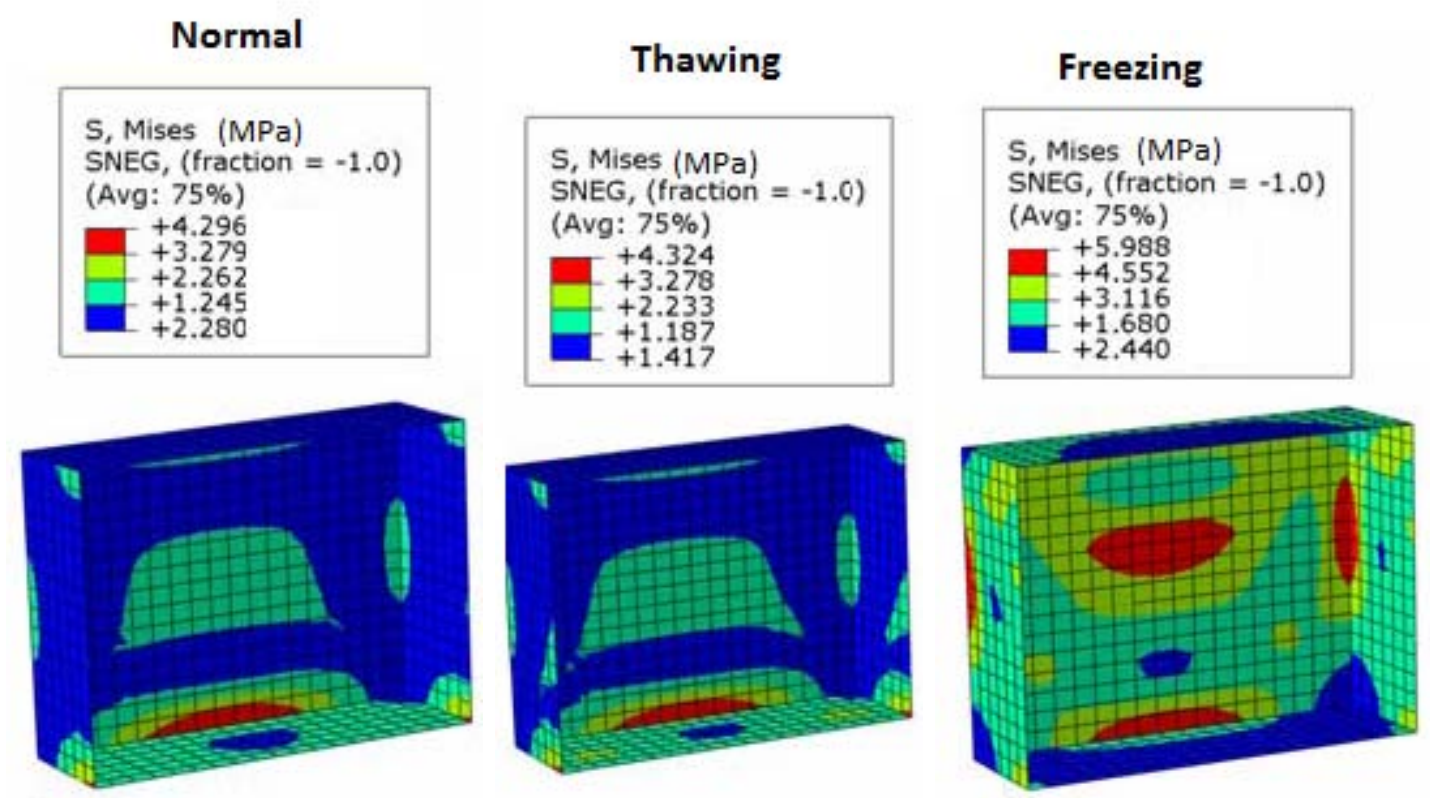

(a) Silty-Clay

\section{Normal}

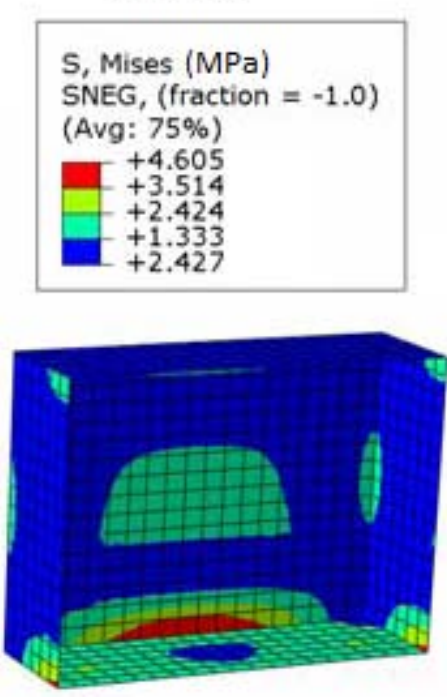

Thawing
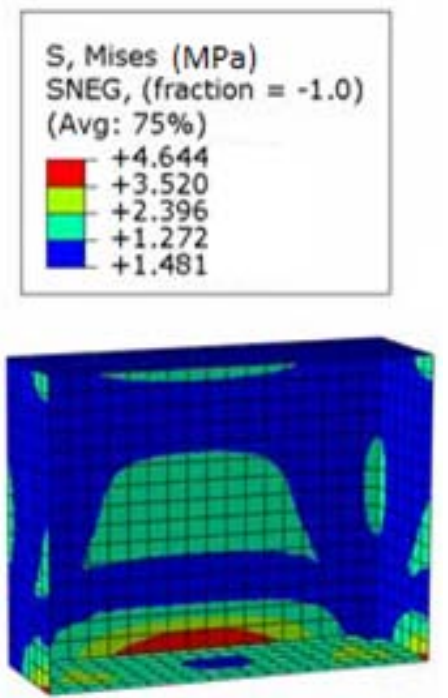

(b) Silty- Sand

\section{Freezing}

S, Mises (MPa)
SNEG, (fraction = -1.0)
(Avg: $75 \%$ )
+6.069
+4.583
+3.098
+1.612
+1.270

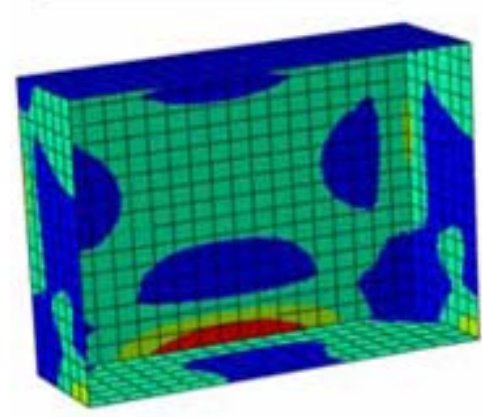

Figure 5.7: Effect of freezing/thawing on Equivalent stress distributions in steel reinforced concrete chamber (backfill material: Silty-Clay and Silty-Sand; backfill height $=1.5 \mathrm{~m}$ ) 


\section{Normal}

\begin{tabular}{|l|}
\hline S, Mises (MPa) \\
SNEG, (fraction = $=1.0$ ) \\
(Avg: $75 \%$ ) \\
+4.996 \\
+3.831 \\
+2.666 \\
+1.502 \\
+3.368
\end{tabular}
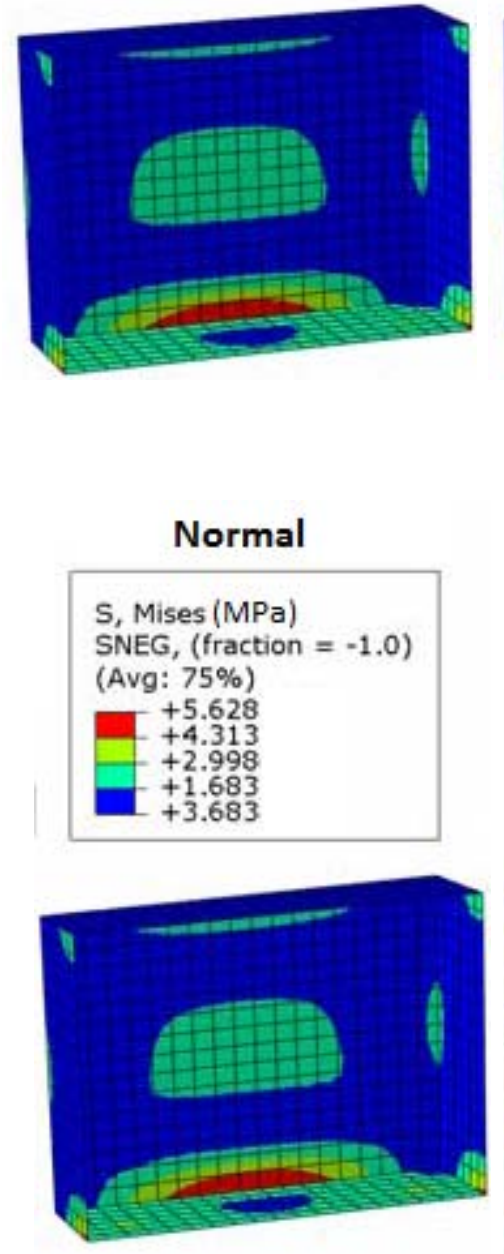

\section{Thawing}

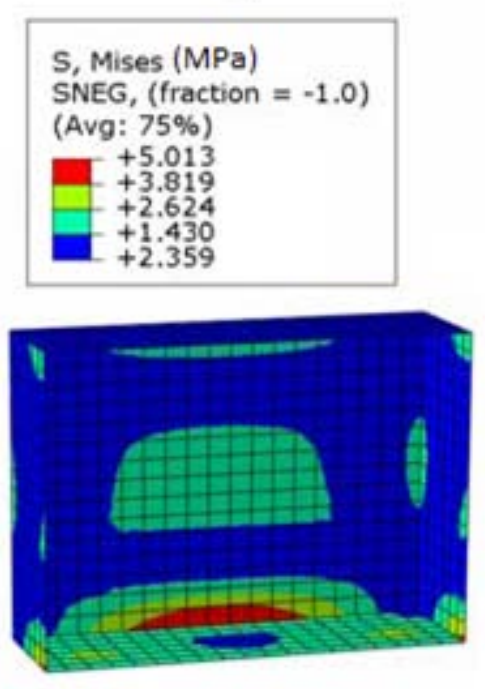

(a) Silty-Clay

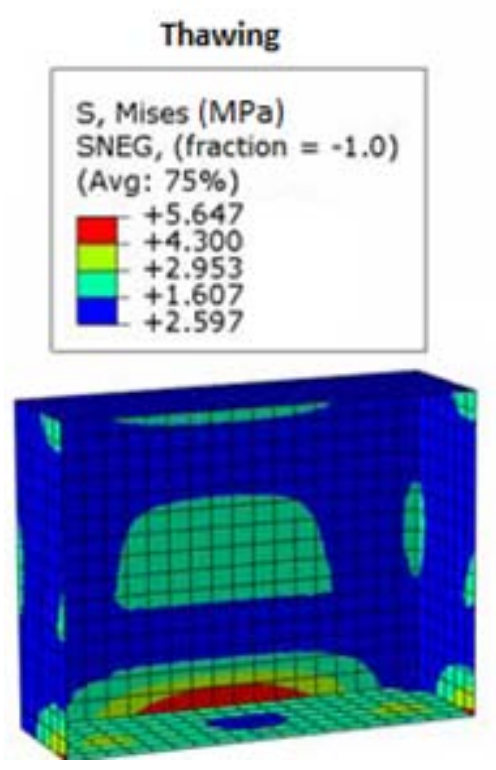

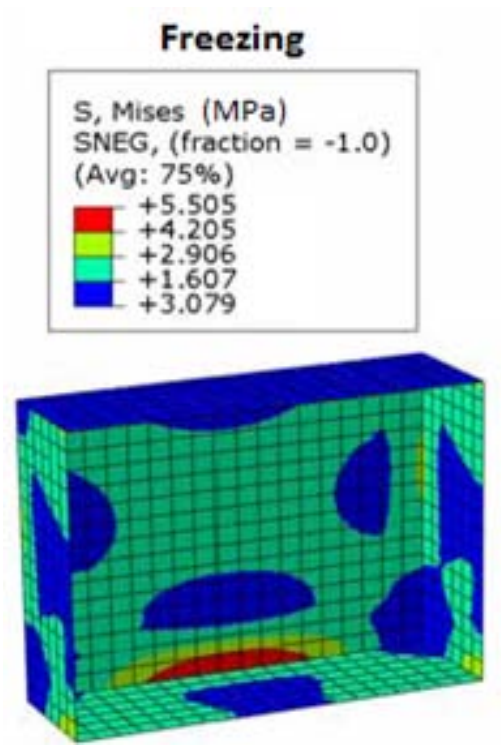



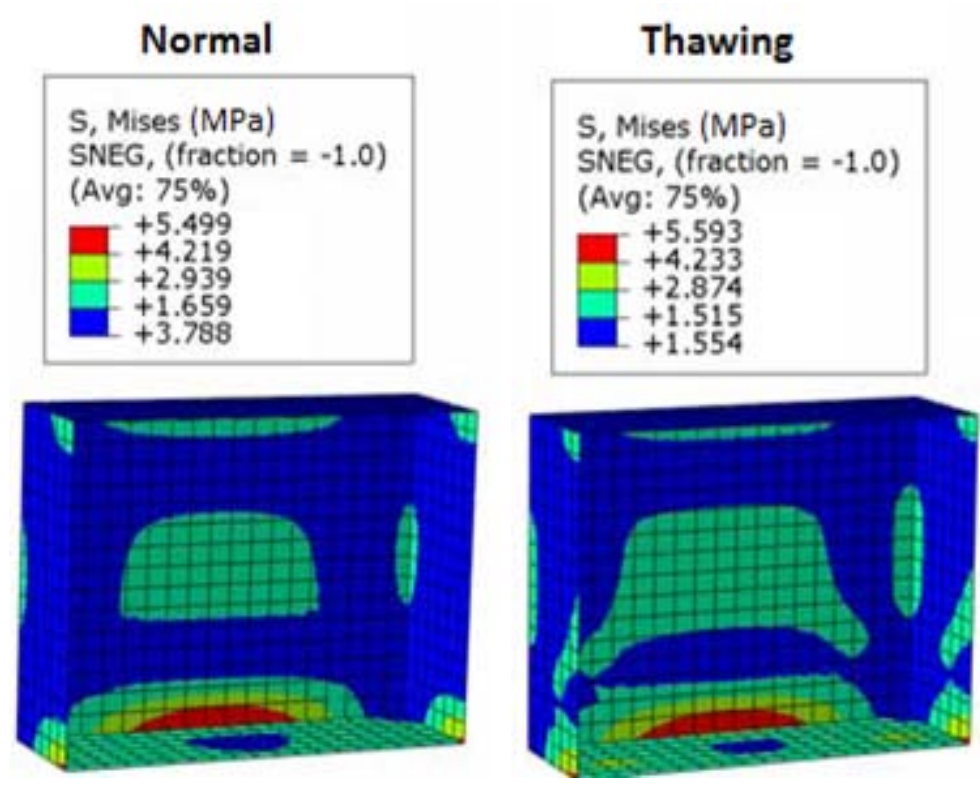

(a) Silty-Clay

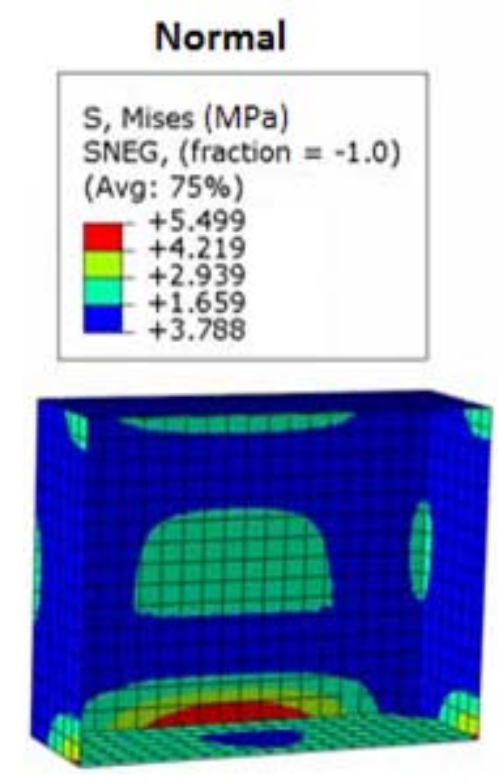

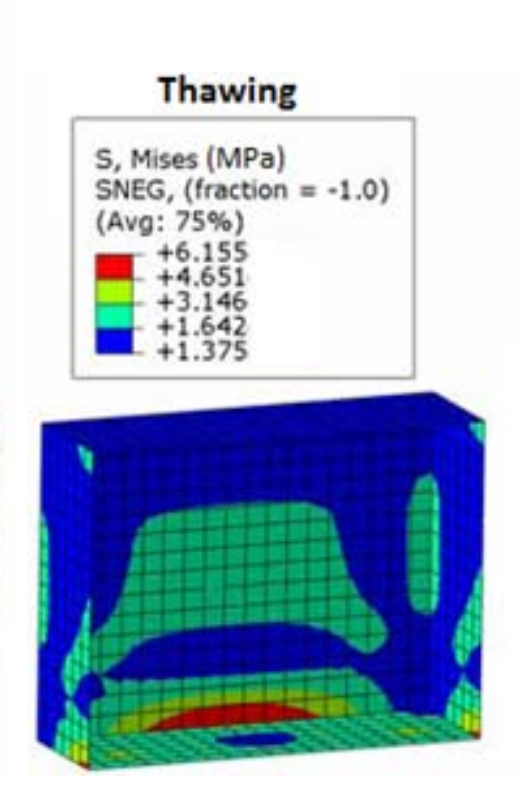
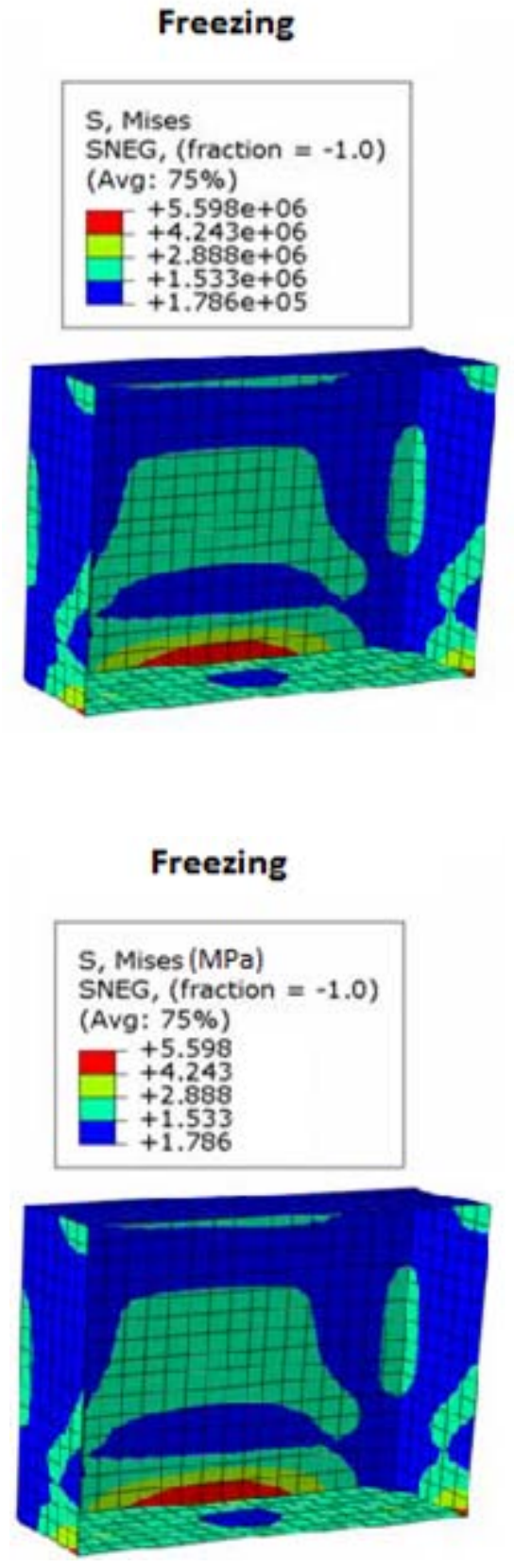

\section{Freezing}

(b) Silty- Sand

Figure 5.9: Effect of freezing/thawing on Equivalent stress distributions in steel reinforced concrete chamber (backfill material: Silty-Clay and Silty-Sand; backfill height $=2.5 \mathrm{~m}$ ) 


\section{Chapter 6}

\section{Conclusions and Future Work}

\subsection{Summary}

In the current study, numerical simulation models were developed to predict the performance of buried concrete chambers under thermo-mechanical loads. For this purpose, the response of the chamber under static load was investigated using the finite element method (FEM). The model was developed using ABAQUS commercial finite element software. A nonlinear FE model incorporating the damaged plasticity model for concrete and the explicit solution technique was validated using experimental results of full-scale chambers tested at the University of Sherbrooke (D'Amours, et al., 2013).A parametric study was then conducted using the verified model to investigate the effects of concrete compressive strength, reinforcement type and reinforcement ratio on the performance of the concrete chambers. The developed model was also used to study the response of the chamber to temperature fluctuations in terms of cracking patterns and distribution of stresses.

In the final phase of the study, a finite element model was prepared to analyze the buried chamber in a realistic fashion. The numerical analysis was conducted using ABAQUS software. Studying the mutual interaction between the chamber and soil was the main objective of this phase, which involved an investigation into the influence of backfill properties, backfill height and type of reinforcement. Pressure distribution and chamber stress contours were also evaluated for various types of soil and concrete reinforcement. The soil was subjected to freezing and thawing loading profiles to account for cold weather and severe environmental conditions. 


\subsection{Conclusions}

Numerical analysis was conducted to investigate the response of the chambers reinforced with FRP and steel under different loading conditions. As a result, this study achieved several improvements in the understanding of the behaviour of buried concrete structures reinforced with FRP. The main contributions of this research can be highlighted as follows:

1. The created finite element model using ABAQUS program was able to predict the behaviour of FRP- and steel- reinforced concrete chambers under thermo-mechanical loads.

2. Taking post-failure behaviour for concrete into account provided adequate predictions for concrete chamber behaviour in terms of crack formations.

3. ABAQUS software is a powerful program used to solve geotechnical engineering problems. It has the capability to model coupling between mechanical deformations, pore fluid flow and heat transfer, which is essential for modelling the freeze-thaw process in the soil.

4. Although the stiffness of the GFRP bars are only $1 / 3$ that of the steel bars, the behaviour of chambers reinforced with GFRP bars, subjected to thermal and static loads, was very similar to that of the identical chambers reinforced with conventional steel.

5. Increasing concrete compressive strength and reinforcement ratio reduced deflection and increased load carrying capacity of chambers reinforced with GFRP bars.

6. Increasing the soil depth over the chamber substantially decreased the effect of temperature gradients on the formation of cracks due to thermal stresses. When the chamber was embedded at a depth of $1.5 \mathrm{~m}$ (Ontario) and $2.5 \mathrm{~m}$ (Quebec) below ground level, the effect of temperature gradients was negligible.

7. Changing backfill material and type of reinforcement (GFRP and steel) had a minor impact on stress distributions in the chambers.

8. Increasing the soil depth over the chamber decreased the effect of freezing on the stress distribution in the chamber. When the chamber was placed lower than the freezing depth of the soil, it was less affected by freezing.

\subsection{Recommendations for Future research}

The finite element analysis of buried structures is a complicated area involving a wide range of parameters. The current study not only provides a series of advancements in the understanding 
the behaviour of a buried structure (chamber) subjected to different loading conditions, but also presents a parametric study that illustrates how the various factors can affect the behaviour of the structure. However, there are still a number of gaps that should be filled with further research as follows:

1. Further experimental and analytical research is required to investigate the behaviour of FRP-reinforced chambers with a wide range of reinforcement ratios and different concrete strengths.

2. Geometric dimensions of the chamber, reinforcement spacing and ratios using FRP and steel bars is another domain of research that needs to be tackled.

3. The bond between reinforcing bars and concrete plays a key role in transferring stress from reinforcing bars to the surrounding bars. At higher load levels, bond-slip may occur in the reinforced concrete structure. The bond-slip behaviour of FRP-reinforced concrete is different from that of steel-reinforced concrete, and there appears to be a lack of study into the effects of different bond-slip models of FRP and steel bars on the overall behaviour of concrete chambers.

4. Further study is also needed into the effects of different types of reinforcement, reinforcement ratios and depths reinforced with reinforcing bars on the development of thermal stresses and on the control of thermal cracking in concrete chambers.

5. In the current study, it was assumed that the FRP bars have the same thermal coefficient expansion in longitudinal and transverse directions. The effect of different thermal coefficient expansion of FRP bars in different directions needs to be investigated.

6. More experimental and analytical research may be needed to investigate the behaviour of concrete chambers in terms of crack distribution, spacing and width under temperature variations and mechanical loads.

7. Ground level loading surcharge and buried chamber depth can have a significant impact on the soil pressure acting on the chamber as well as on stresses due to F/T cycles. This is also something that merits investigation.

8. In the current study, the effect of stiffness changes due to cracking of the concrete was not considered for the soil pressure acting on the buried chamber. Thus, there is a need to study the effect of cracking and stiffness reduction of concrete buried chambers on global structural behaviour. 
9. Accurate measurements and procedures for determining temperature distribution in soil will greatly enhance the modelling of frost heave actions. 


\section{Appendix A}

\section{Specimen Geometry}

The process of manufacturing and shop drawings for the concrete chamber are provided in Figures A.1 to A.2.

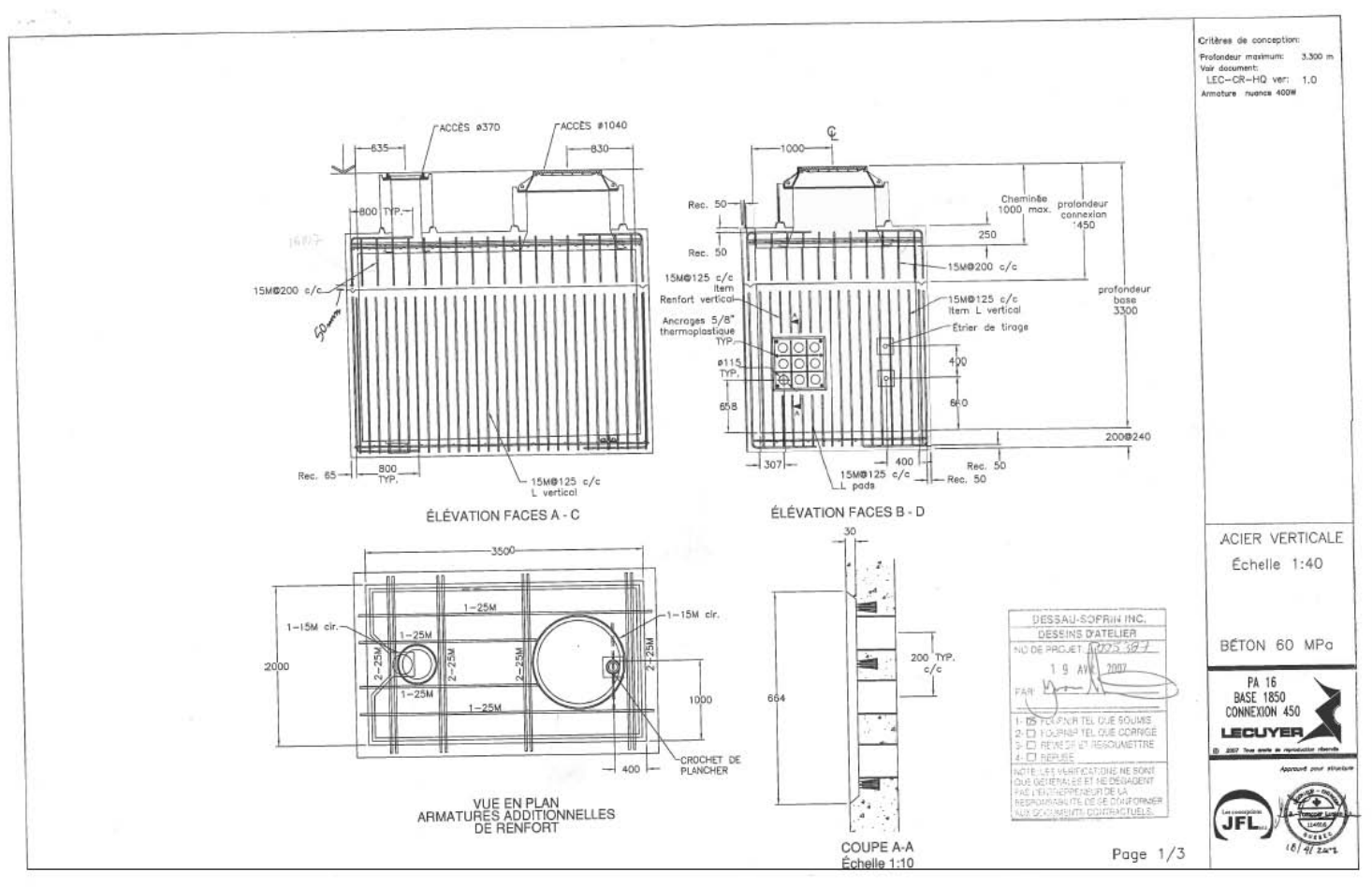

Figure A.1: Shop drawing for the concrete chamber(Elevation faces A-C) 


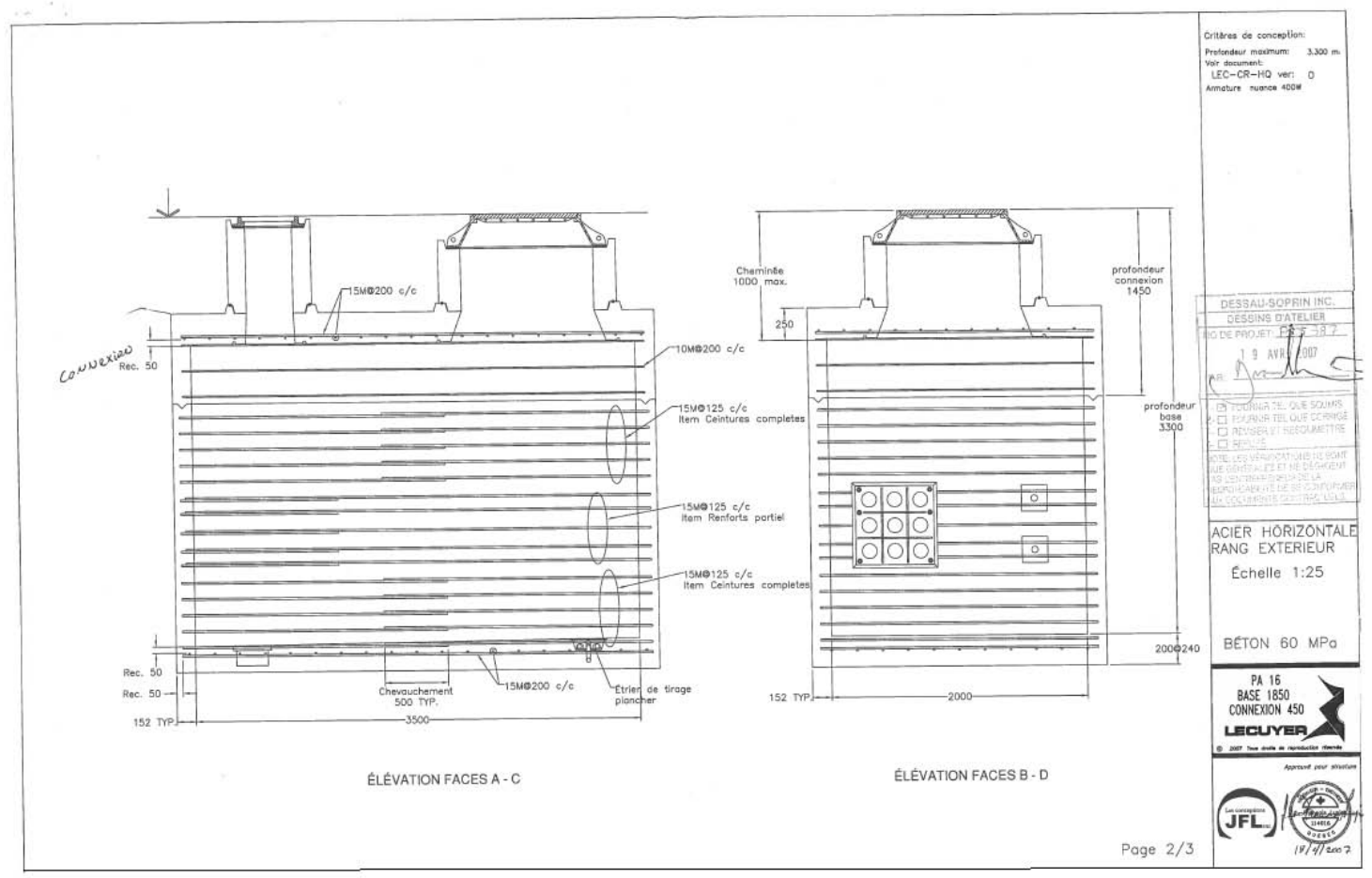

Figure A.2: Shop drawing for the concrete chamber(Elevation faces B-D) 


\section{Appendix B}

\section{Finite Element Results}

Appendix B lists all the FE results of the GFRP reinforced concrete chambers loaded up to ultimate load in terms of compressive plastic strain(PEEQ) and GFRP reinforcement stresses (RBFOR) as reported in Section 4.3.1. Figures B.1 to B.6 to show the results for the chambers with different concrete compressive strength (25 to $75 \mathrm{MPa}$ ). 

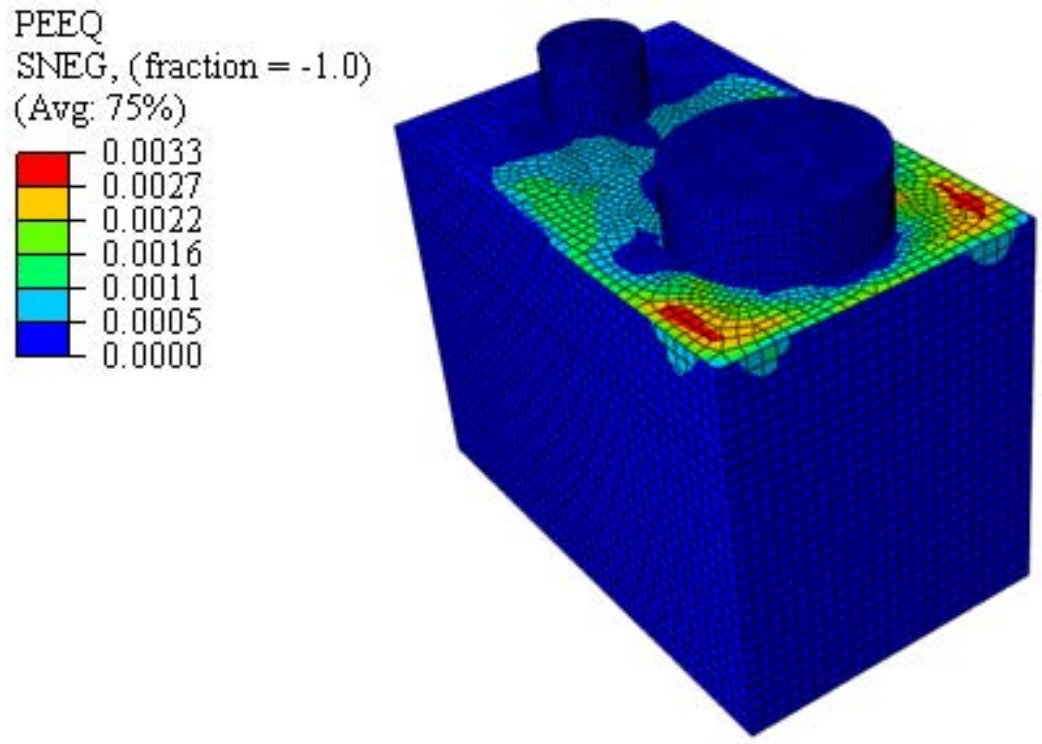

RBFOR (MPa)

Multiple section points (Avg: 75\%)
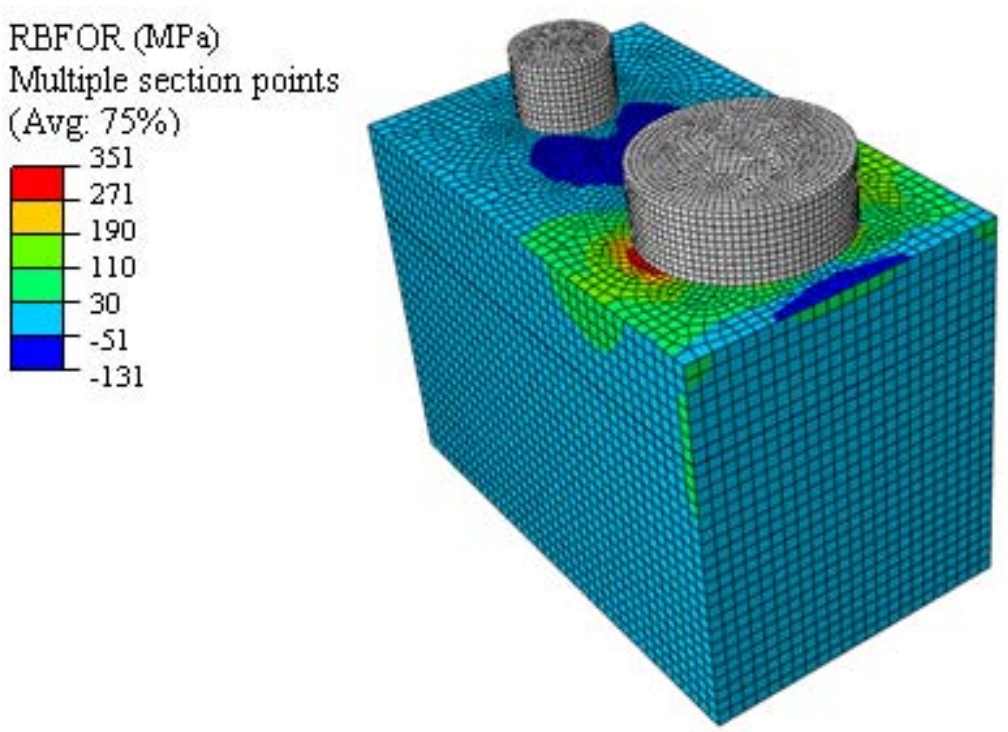

Figure B.1: Compressive equivalent plastic strain (PEEQ) contours and GFRP reinforcement stresses (RBFOR) for the chamber reinforced with GFRP bars

$$
\left(f_{c}^{\prime}=25 \mathrm{MPa} \text {, Ultimate Load }=900 \mathrm{kN}\right)
$$



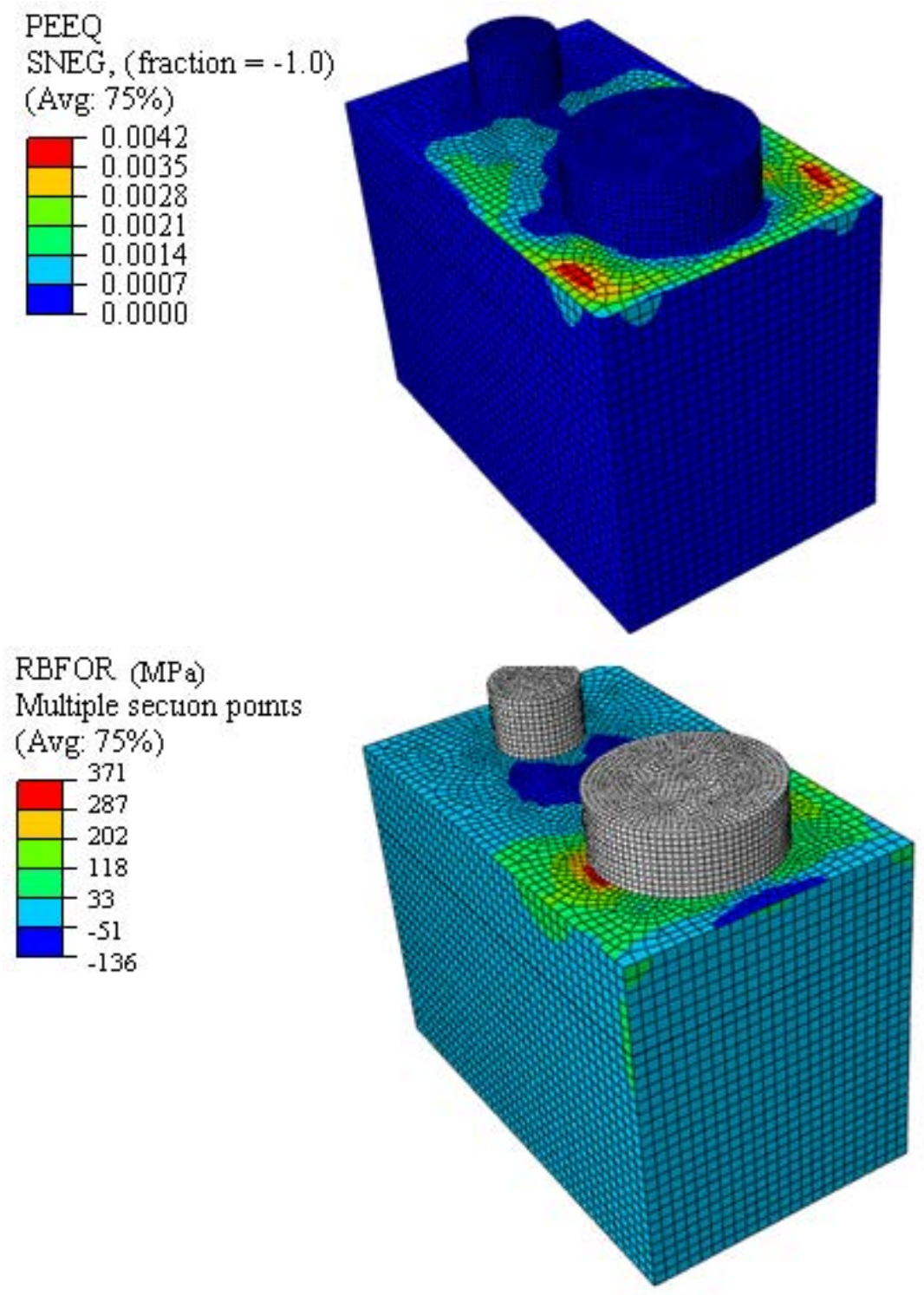

Figure B.2: Compressive equivalent plastic strain (PEEQ) contours and GFRP reinforcement stresses (RBFOR) for the chamber reinforced with GFRP bars

$$
\left(f_{c}^{\prime}=35 \mathrm{MPa} \text {, Ultimate Load }=1000 \mathrm{kN}\right)
$$



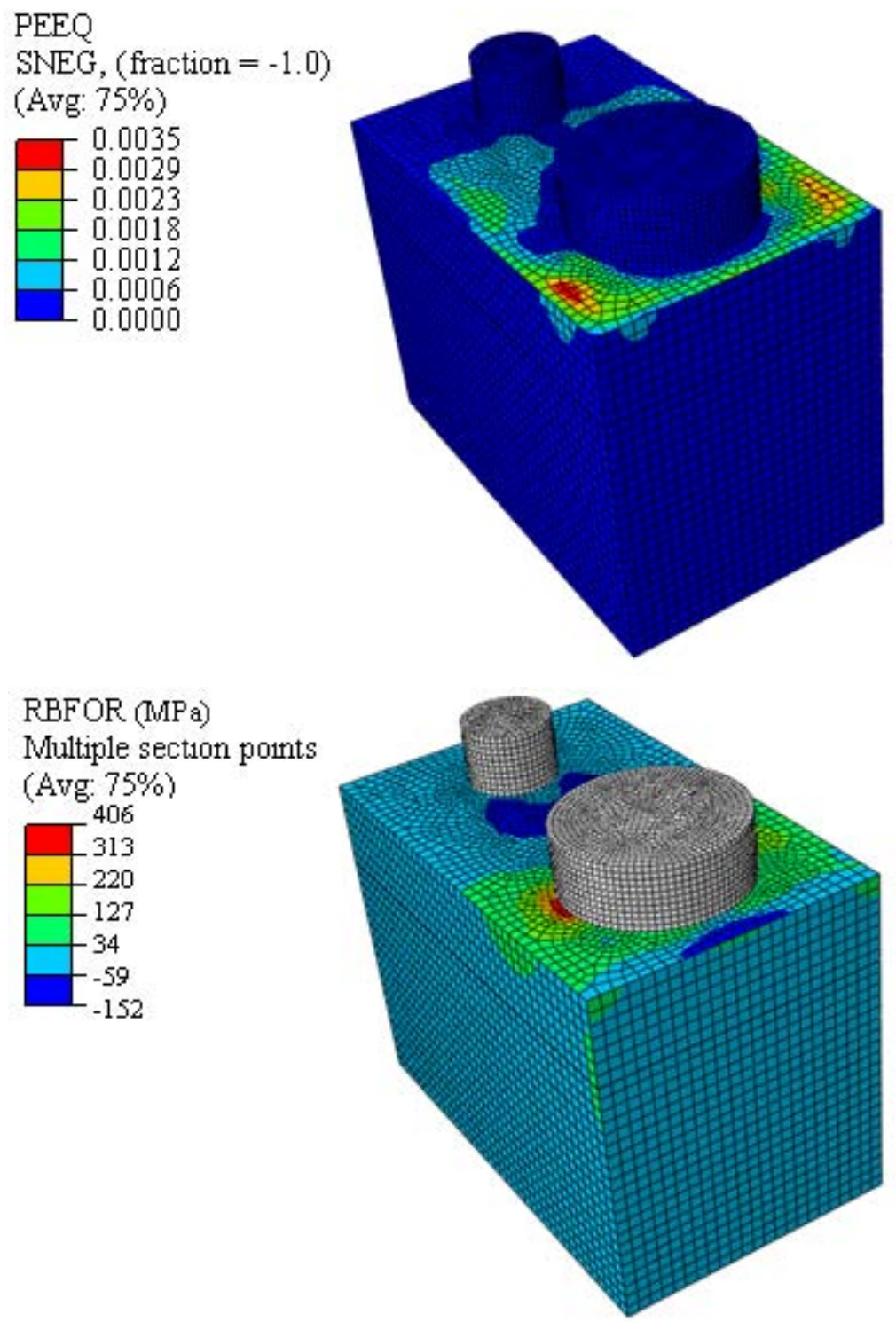

Figure B.3: Compressive equivalent plastic strain (PEEQ) contours and GFRP reinforcement stresses (RBFOR) for the chamber reinforced with GFRP bars

$$
\left(f_{c}^{\prime}=45 \mathrm{MPa} \text {, Ultimate Load= } 1100 \mathrm{kN}\right)
$$


PEEQ

SNEG, $($ fraction $=-1.0$ )

(Avg: 75\%)
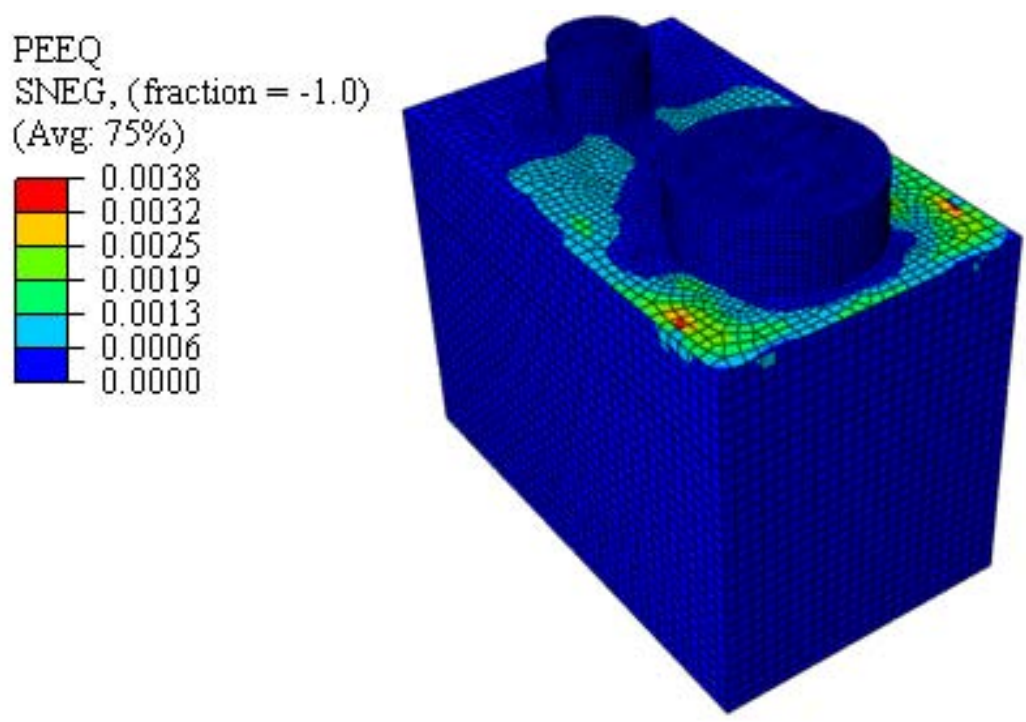

RBFOR (MPa)

Multiple section points

(Avg: $75 \%$ )
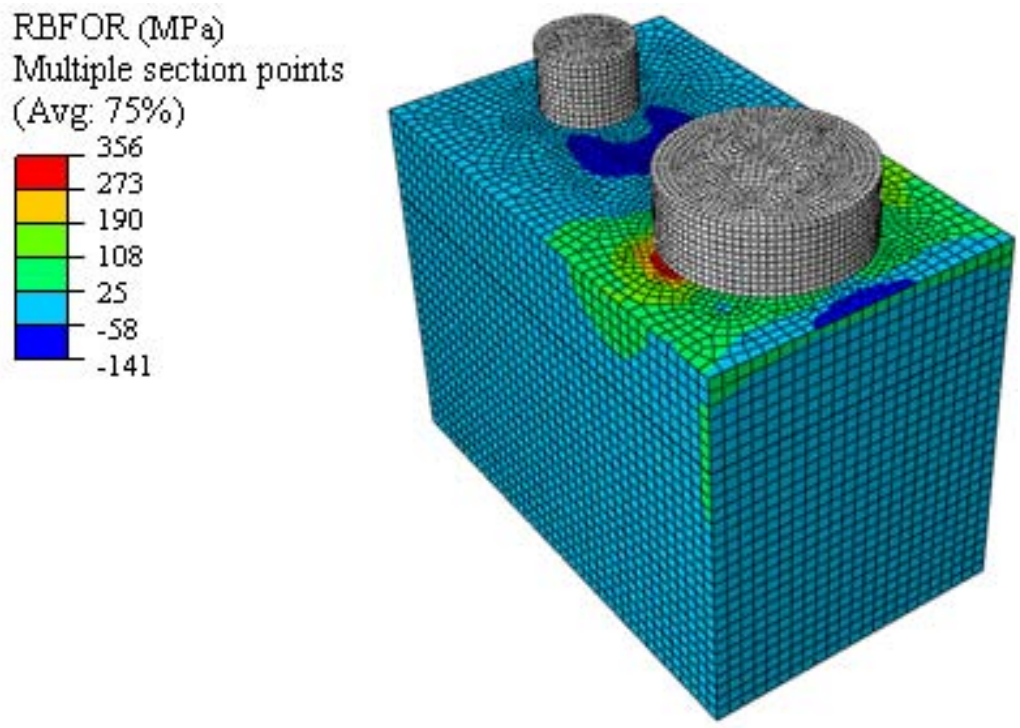

Figure B.4: Compressive equivalent plastic strain (PEEQ) contours and GFRP reinforcement stresses (RBFOR) for the chamber reinforced with GFRP bars

$$
\left(f_{c}^{\prime}=55 \mathrm{MPa} \text {, Ultimate Load }=1140 \mathrm{kN}\right)
$$



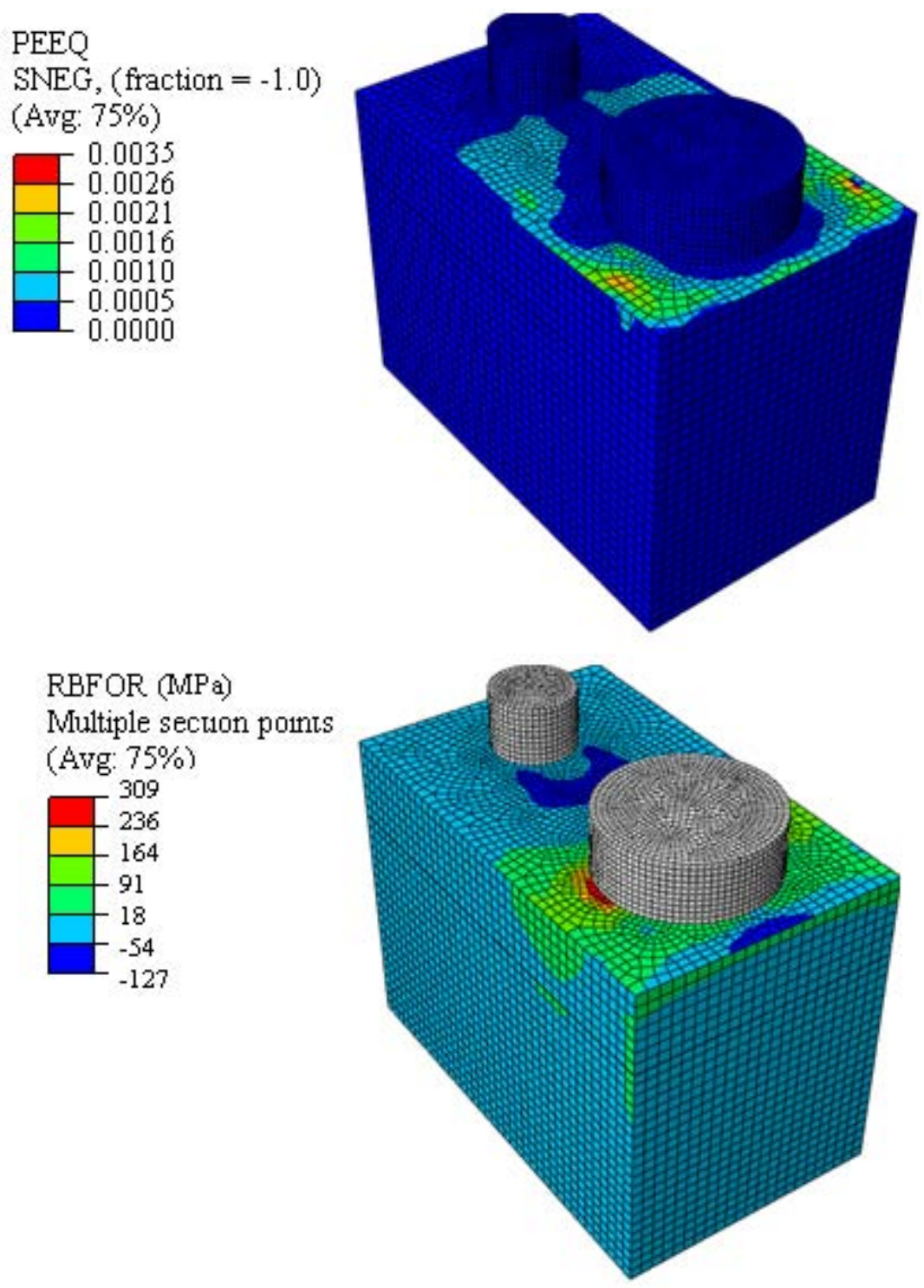

Figure B.5: Compressive equivalent plastic strain (PEEQ) contours and GFRP reinforcement stresses (RBFOR) for the chamber reinforced with GFRP bars

$$
\left(f_{c}^{\prime}=65 \mathrm{MPa} \text {, Ultimate Load }=1175 \mathrm{kN}\right)
$$



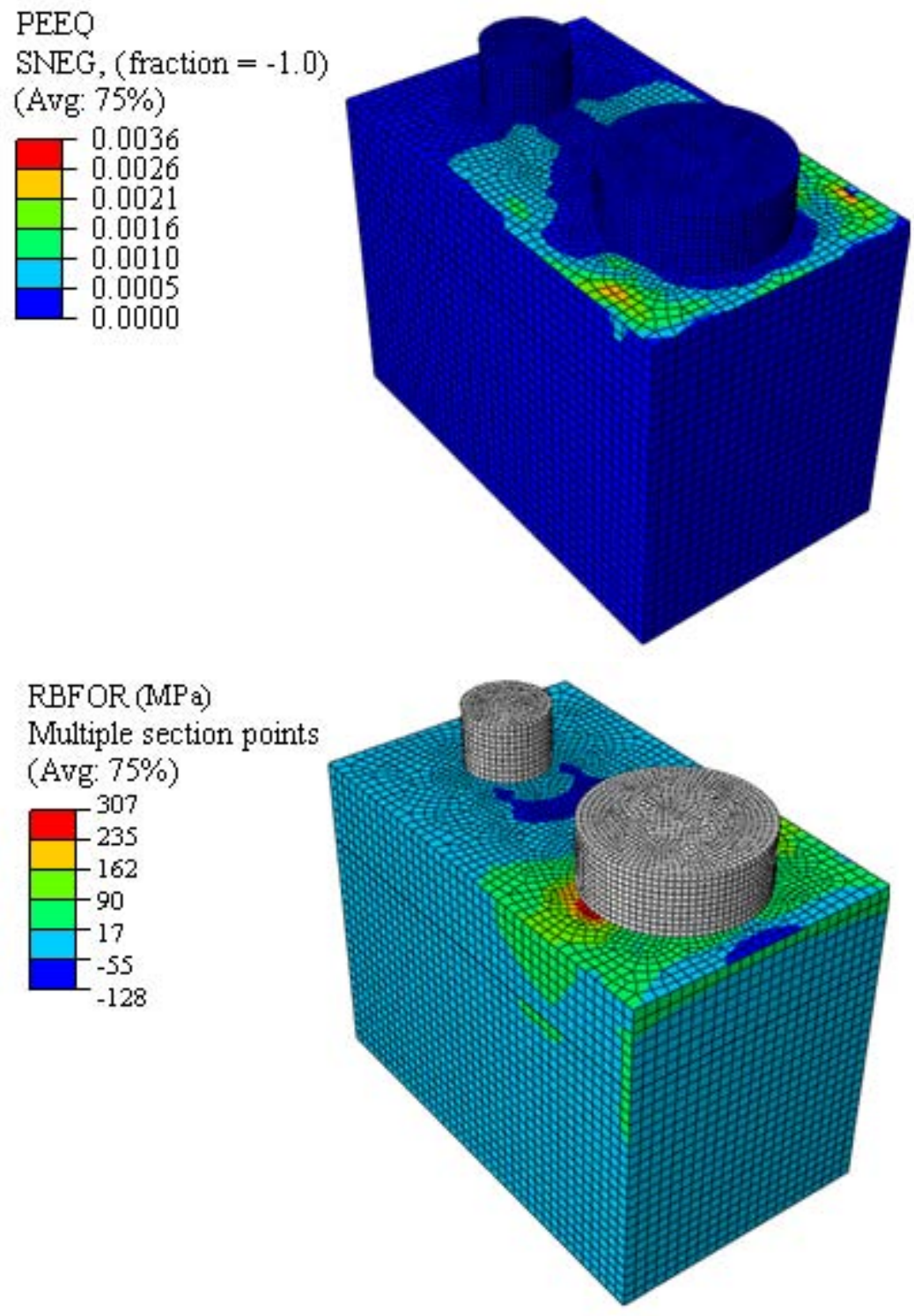

Figure B.6: Compressive equivalent plastic strain (PEEQ) contours and GFRP reinforcement stresses (RBFOR) for the chamber reinforced with GFRP bars $\left(f_{c}^{\prime}=75 \mathrm{MPa}\right.$, Ultimate Load $\left.=1230 \mathrm{kN}\right)$ 


\section{Appendix $\mathrm{C}$}

\section{Input File}

The ABAQUS input fie for the steel-reinforced concrete chamber under a static load of 1200 $\mathrm{kN}$ is given below as a sample:

*Heading

** Job name: Final Model name: Steel

** Generated by: Abaqus/CAE 6.13-3

$*$ Preprint, $\mathrm{echo}=\mathrm{NO}$, model $=\mathrm{NO}$, history $=\mathrm{NO}$, contact $=\mathrm{NO}$

$* *$

** PARTS

$* *$

$*$ Part, name $=$ CHAMBER

*End Part

$* *$

$*$ Part, name $=$ COVER

*End Part

$* *$

$* *$

** ASSEMBLY

$* *$

*Assembly, name=Assembly

$* *$

$*$ Instance, name $=$ CHAMBER -1 , part $=$ CHAMBER

*End Instance

$* *$

$*$ Instance, name=COVER -1 , part $=$ COVER 
*End Instance

$* *$

** Constraint: CONSTRAINT-1-1

${ }^{*}$ Tie, name $=$ CONSTRAINT-1 -1 , adjust=yes

COVER-1.COVER, CHAMBER-1.CHAMBER

** Constraint: CONSTRAINT-2

$*$ Coupling, constraint name=CONSTRAINT-2

*Kinematic

*End Assembly

*Amplitude, name=LOAD 0., 0., 0.05, 0.05, 0.1, 0.1, 0.15, 0.15

$0.2,0.2,0.25,0.25,0.3,0.3,0.35,0.35$

$0.4,0.4,0.45,0.45,0.5,0.5,0.55,0.55$

$0.6,0.6,0.65,0.65,0.7,0.7,0.75,0.75$

$0.8,0.8,0.85,0.85,0.9,0.9,0.95,0.95$

1., 1.

**

** MATERIALS

$* *$

$*$ Material, name $=$ CONCRETE

*Density

2.3e-09,

*Elastic

35480., 0.2

*Concrete Damaged Plasticity

34., 0.1, 1.16, 0.666, 0.

*Concrete Compression Hardening

26.6, 0 .

$31.9,1 \mathrm{e}-06$

$37.18,2 \mathrm{e}-06$

$42.4,5 \mathrm{e}-06$

$47.54,1 \mathrm{e}-05$

$52.53,1.9 \mathrm{e}-05$

$57.31,3.5 \mathrm{e}-05$

$61.77,5.9 \mathrm{e}-05$

$65.8,9.5 \mathrm{e}-05$

$69.27,0.000148$ 
$72.03,0.00022$

73.94, 0.000316

$74.9,0.000439$

$72.36,0.00066$

$65.24,0.001011$

$55.76,0.001428$

45.32, 0.001873

$35.35,0.002304$

26.76, 0.002696

$19.89,0.003039$

14.64, 0.003337

$10.74,0.003597$

*Concrete Tension Stiffening

1.30106, 0 .

1.07776, 0.000261607

$0.979609,0.000514373$

$0.914247,0.000766216$

$0.865121,0.0010176$

$0.825821,0.00126871$

$0.793139,0.00151963$

$0.765225,0.00177042$

$0.740914,0.0020211$

$0.719419,0.00227171$

0.700186, 0.00252225

$0.68281,0.002772740 .666983,0.00302318$

$0.65247,0.00327359$

$0.639082,0.00352397$

$0.62667,0.00377432$

$0.615111,0.00402465$

$0.604305,0.00427495$

$0.594166,0.00452524$

*Concrete Compression Damage

$0 ., 0$.

$0 ., 2 \mathrm{e}-06$

$0 ., 5 \mathrm{e}-06$

$0 ., 1.2 \mathrm{e}-05$ 

$0 ., 2.2 \mathrm{e}-05$
$0 ., 4 \mathrm{e}-05$
$0 ., 6.7 \mathrm{e}-05$
$0 ., 0.000107$
0., 0.000164
$0 ., 0.00024$
$0 ., 0.000339$
$0 ., 0.000463$
$0.0242844,0.00066$
$0.100737,0.000958$
$0.202646,0.001306$
$0.317902,0.001679$
$0.43383,0.002053$
$0.540744,0.002411$
$0.633322,0.00274$
$0.710029,0.003038$
$0.77175,0.003308$
$0.820509,0.003552$

*Concrete Tension Damage

$0 ., 0$.

$0.171626,0.000261607$

$0.247067,0.000514373$

$0.297305,0.000766216$

$0.335063,0.0010176$

$0.365269,0.00126871$

$0.390389,0.00151963$

$0.411843,0.00177042$

$0.43053,0.0020211$

$0.447051,0.00227171$

$0.461833,0.00252225$

$0.475189,0.00277274$

$0.487353,0.00302318$

$0.498508,0.00327359$

$0.508798,0.00352397$

$0.518338,0.00377432$

$0.527222,0.00402465$ 
$0.535528,0.00427495$

$0.54332,0.00452524$

$*$ Material, name $=$ STEEL

*Density

7.849e-09,

*Elastic

200000., 0.25

*Plastic

400.,0.

$* *$

** BOUNDARY CONDITIONS

$* *$

** Name: Disp-BC-1 Type: Symmetry/Antisymmetry/Encastre

*Boundary

SET-42, ENCASTRE

**

$* *$

** STEP: Step-1

$* *$

*Step, name=Step-1, nlgeom $=$ YES

*Dynamic, Explicit

, 1 .

*Bulk Viscosity

$0.06,1.2$

**

$* *$ LOADS

$* *$

** Name: CFORCE-1 Type: Concentrated force

${ }^{*}$ Cload, amplitude $=\mathrm{LOAD}$

SET-2, 3, -1.2e+06

**

** OUTPUT REQUESTS

$* *$

$*$ Restart, write, number interval $=1$, time marks $=\mathrm{NO}$

$* *$

** FIELD OUTPUT: F-Output-1 
$* *$

*Output, field

*Node Output

$* *$

** FIELD OUTPUT: F-Output-1

$* *$

** HISTORY OUTPUT: H-Output-1

**

*Output, history

*Energy Output

*End Step 


\section{References}

AASHTO, 1996. Standard specifications for highway bridges. American Association of State Highway and Transportation Officials Washington, DC.

Abdelrahman, A.A., 1996. Serviceability of concrete beams prestressed by fibre reinforced plastic tendons. University of Manitoba.

ACI Committee, 2001. Guide for the design and construction of concrete reinforced with FRP bars. American Concrete Institute.

Ahmed, E.A., El-Salakawy, E.F., and Benmokrane, B., 2010. Performance evaluation of glass fiber-reinforced polymer shear reinforcement for concrete beams. ACI structural Journal, 107 (01).

Allen, D.L. and Meade, B.W., 1984. Analysis of loads and settlements for reinforced concrete culverts. .

Almusallam, T., et al., 1997. Behavior of concrete beams doubly reinforced by FRP bars. In: Proceedings of the Thrd International Symposium, Vol. 2.

Alsayed, S.H. and Alhozaimy, A.M., 1999. Ductility of concrete beams reinforced with FRP bars and steel fibers. Journal of composite materials, 33 (19), 1792-1806.

Andersland, O.B. and Ladanyi, B., 2004. Frozen ground engineering. John Wiley \& Sons.

Ashour, A., 2006. Flexural and shear capacities of concrete beams reinforced with GFRP bars. Construction and Building Materials, 20 (10), 1005-1015.

Benmokrane, B., 1996. Flexural response of concrete beams reinforced with FRP reinforcing bars. ACI Structural Journal, 93 (1).

Benmokrane, B. and Masmoudi, R., 1996. FRP C-bar as reinforcing rod for concrete structures. In: Proceedings of the 2nd International Conference on Advanced Composite Materials in Bridges and Structures, Acmbs-Ii, Montreal 1996.

Benmokrane, B., Tighiouart, B., and Thériault, M., 1997. Bond strength of FRP rebar splices. In: Proceedings of the Third International Symposium on Non-Metallic (FRP) 
Reinforcement for Concrete Structures (FRPRCS-3), Japan Concrete Institute, Sapporo, Japan, Vol. 2, 405-412.

Boyd, D.W., 1973. Normal freezing and thawing degree-days for Canada, 1931-1960. Downsview: Environment Canada, Atmospheric Environment.

Brown, W.G., 1963. The temperature under heated or cooled areas on the ground surface. Transactions of the Engineering Institute of Canada, 6 (B-14), 1-14.

Buyle-Bodin, F., Benhouna, M., and Convain, M., 1995. 28 Flexural Behaviour of JITEC Frp Reinforced Beams. In: Non-Metallic (FRP) Reinforcement for Concrete Structures: Proceedings of the Second International RILEM Symposium, Vol. 29, p. 235.

Chaallal, O. and Lachemi, M., 2011. Reinforced Concrete Structures: Design according to CSA A23. 3-04. .

Chang, C.S., Espinoza, J.M., and Selig, E.T., 1981. Computer analysis of Newton creek culvert: J Geotech Engng Div ASCE, V106, NGT5, May 1980, P531-556. In: International Journal of Rock Mechanics and Mining Sciences $\&$ Geomechanics Abstracts, Vol. 18, p. 9 .

CHBDC, 1996. Section 16. Fibre-Reinforced Structures, final draft.

CHBDC, 2000. Canadian Standards Association-International. Toronto, Canada.

CHBDC, 2006. Canadian Highway Bridge Design Code (CHBDC). A National Standard of Canada, CAN/CSA Standard S6-06, CSA International, Rexdale, Ontario.

Clear, K.C., 1995. Performance of Epoxy-Coated Reinforcing Steel in Highway Bridges. Vol. 370. Transportation Research Board.

Collins, M.P. and Mitchell, D., 1997. Prestressed concrete structures. Response Publications.

Collins, M. and Vecchio, F., 1982. The Response of Reinforced Concrete to Inplane Shear and Normal Stresses. ISBN Pub, (82-03).

Crisfield, M.A., 1981. A fast incremental/iterative solution procedure that handles snapthrough. Computers \& Structures, 13 (1), 55-62.

CSA, 2002. Design and construction of building components with fibre-reinforced polymers. Canadian Standards Association.

CSA, 2004. Design of concrete structures, CSA A23. 3-04. CSA, Rexdale, Ontario.

D'Amours, A., Mohamed, H., and Benmokrane, B., 2013. Preliminary draft report of the test results of the first steel and GFRP reinfoced concrete chamber under static load. 
University of Sherbrooke.

De Borst, R. and Nauta, P., 1984. Smeared crack analysis of reinforced concrete beams and slabs failing in shear. In: Proceedings International Conference on Computer Aided Analysis and Design of Concrete Structures, Part, Vol. 1, 261-273.

Deitz, D., Harik, I., and Gesund, H., 1999. One-way slabs reinforced with glass fiber reinforced polymer reinforcing bars. ACI Special Publication, 188.

Deitz, D., Harik, I., and Gesund, H., 2003. Physical properties of glass fiber reinforced polymer rebars in compression. Journal of Composites for Construction, 7 (4), 363366.

El-Salakawy, E. and Benmokrane, B., 2004. Serviceability of concrete bridge deck slabs reinforced with fiber-reinforced polymer composite bars. ACI Structural Journal, 101 (5).

Fico, R., Prota, A., and Manfredi, G., 2008. Assessment of Eurocode-like design equations for the shear capacity of FRP RC members. Composites Part B: Engineering, 39 (5), 792-806.

Fielding, M., 1976. Temperature Monitoring of an Insulated Watermain. Report.

Fields, K. and Bischoff, P.H., 2004. Tension stiffening and cracking of high-strength reinforced concrete tension members. ACI Structural Journal, 101 (4).

Gálvez, J., et al., 2002. A discrete crack approach to normal/shear cracking of concrete. Cement and concrete research, 32 (10), 1567-1585.

GangaRao, H. and Vijay, P., 1997. Design of concrete members reinforced with GFRP bars. In: Proc., 3rd Int. Symposium, Fiber Reinforced Polymer Reinforcement for Reinforced Concrete Structures, Vol. 1, 143-150.

Gdoutos, E.E., Pilakoutas, K., and Rodopoulos, C., 2000. Failure analysis of industrial composite materials. McGraw-Hill New York.

Gold, L.W., 1967. Influence of surface conditions on ground temperature. Canadian Journal of Earth Sciences, 4 (2), 199-208.

Gutiérrez, E., Dimova, S., and Pinto, A., 2007. Purpose and justification for new design standards regarding the use of fibre-reinforced polymer composites in civil engineering.

Harris, H.G., Somboonsong, W., and Ko, F.K., 1998. New ductile hybrid FRP reinforcing bar for concrete structures. Journal of composites for construction, 2 (1), 28-37. 
Hibbett, Karlsson, and Sorensen, 1998. ABAQUS/standard: User's Manual. Vol. 1. Hibbitt, Karlsson \& Sorensen.

Huang, S.L., Bray, M.T., and Akagawa, S., 2004. Field investigation of soil heave by a large diameter chilled gas pipeline experiment, Fairbanks, Alaska. Journal of cold regions engineering, 18 (1), 2-34.

Hwang, L. and Rizkalla, S., 1983. Effective tensile stress-strain characteristics for reinforced concrete. Proceedings of the Canadian Society of Civil Engineering, 129-147.

Iserles, A., 2008. A First Course in the Numerical Analysis of Differential Equations. Cambridge University Press.

IsgorA, O.B. and RazaqpurB, A.G., 2002. Predicting the Initiation and Propagation of Corrosion in Reinforced Concrete Structures. .

ISIS Canada, 2007. Reinforcing Concrete Structures with Fibre Reinforced Polymers. Winnipeg, Manitoba, Canada.

Jaejer, L., Mufti, A., and Tadros, G., 1997. The concept of the overall performance factor in rectangular-section reinforced concrete beams. In: Proceedings of the 3rd International Symposium on Non-Metallic (FRP) Reinforcement for Concrete Structures, Vol. 2, 551-558.

Jeong, S.M., 1994. Evaluation of ductility in prestressed concrete beams using fiber reinforced plastic tendons. University of Michigan.

Joint ACI-ASCE Committee 445, 1998. Recent Approaches to Shear Design of Structural Concrete. In: .

Kara, I.F., 2011. Prediction of shear strength of FRP-reinforced concrete beams without stirrups based on genetic programming. Advances in Engineering Software, 42 (6), 295-304.

Kara, I.F. and Ashour, A.F., 2012. Flexural performance of FRP reinforced concrete beams. Composite Structures, 94 (5), 1616-1625.

Katona, M.G., Smith, J., and Odello, R., CANDE-A Modern Approach for the Structural Design and Analysis of Buried Culverts. , 1976. , Technical report.

Katona, M.G. and Vittes, P., 1982. Soil-structure analysis and evaluation of buried boxculvert designs. Transportation Research Record, (878).

Kim, K. and Yoo, C.H., 2005. Design loading on deeply buried box culverts. Journal of Geotechnical and Geoenvironmental Engineering, 131 (1), 20-27. 
Kim, Y.J., Shi, C., and Green, M.F., 2008. Ductility and cracking behavior of prestressed concrete beams strengthened with prestressed CFRP sheets. Journal of composites for construction, 12 (3), 274-283.

Kmiecik, P. and Kamiński, M., 2011. Modelling of reinforced concrete structures and composite structures with concrete strength degradation taken into consideration. Archives of civil and mechanical engineering, 11 (3), 623-636.

Kobayashi, K. and Fujisaki, T., 1995. Compressive Behavior of FRP Reinforcement in Non-Prestressed Concrete Members. In: Non-Metallic (FRP) Reinforcement for Concrete Structures: Proceedings of the Second International RILEM Symposium, Vol. 29, p. 267.

Lee, J. and Fenves, G.L., 1998. Plastic-damage model for cyclic loading of concrete structures. Journal of engineering mechanics, 124 (8), 892-900.

Leung, H. and Balendran, R., 2003. Flexural behaviour of concrete beams internally reinforced with GFRP rods and steel rebars. Structural Survey, 21 (4), 146-157.

Liu, H., 2003. Pipeline engineering. CRC Press.

Lubliner, J., et al., 1989. Shear strength of FRP-reinforced concrete beams without transverse reinforcement. International Journal of Solids and Structures, 25 (3).

Marzouk, H. and Chen, Z., 1993. Nonlinear analysis of normal-and high-strength concrete slabs. Canadian Journal of Civil Engineering, 20 (4), 696-707.

Masmoudi, R., Theriault, M., and Benmokrane, B., 1998. Flexural behavior of concrete beams reinforced with deformed fiber reinforced plastic reinforcing rods. ACI Structural Journal, 95 (6).

McGrath, T.J., 1998. Pipe-soil interactions during backfill placement. University of Massachusetts.

Mettemeyer, M. and Nanni, A., 1999. Guidelines for rapid load testing of concrete structural members. Rep. No. 99, 5.

Michalowski, R.L. and Zhu, M., 2005. Frost heave: the cause of damage to transportation infrastructure. In: Proc. X X II Conference on Civil Engineering Failures.

Michaluk, C.R., et al., 1998. Flexural behavior of one-way concrete slabs reinforced by fiber reinforced plastic reinforcements. ACI structural Journal, 95 (3).

Mindess, S. and Young, J.F., 1981. Concrete. .

Mufti, A.A., Newhook, J.P., and Tadros, G., 1996. Deformability versus ductility in concrete beams with FRP reinforcement. In: Proceedings of the 2nd International 
Conference on Advanced Composite Materials in Bridges and Structures, Acmbs-Ii, Montreal 1996.

Naaman, A., 2003. FRP reinforcements in structural concrete: assessment, progress and prospects. Tan K H. Fiber-Reinforced Polymer Reinforcement for Concrete Structures, FRPRCS-6, World Scientific, Singapore, 3-24.

Nanni, A. and Faza, S., 2002. Design and Construction of Concrete Reinforced with FRP Bars: An Emerging Technology. Concrete international, 24 (11), 53-58.

Nanni, A., 1993. Flexural behavior and design of RC members using FRP reinforcement. Journal of Structural Engineering, 119 (11), 3344-3359.

Nanni, A., et al., 1997. Experimental bond behavior of hybrid rods for concrete reinforcement. Structural Engineering and Mechanics, 5 (4), 339-353.

Naus, D.J., Primer on durability of nuclear power plant reinforced concrete structures-A review of pertinent factors. , 2007. , Technical report, Oak Ridge National Laboratory (United States). Funding organisation: ORNL work for others (United States).

Nielsen, M.P. and Hoang, L.C., 2010. Limit analysis and concrete plasticity. CRC press.

Nixon, J. and Burgess, M., 1999. Norman Wells pipeline settlement and uplift movements. Canadian geotechnical journal, 36 (1), 119-135.

Nkurunziza, G., et al., 2005. Durability of GFRP bars: A critical review of the literature. Progress in Structural Engineering and Materials, 7 (4), 194-209.

Ozawa, Y. and Duncan, J.M., 1973. ISBILD: A computer program for analysis of static stresses and movements in embankments. University of California.

Pecce, M., Manfredi, G., and Cosenza, E., 2000. Experimental Response and Code Modelsof GFRP RC Beams in Bending. Journal of Composites for Construction, 4 (4), $182-190$.

Phukan, A., 1985. Frozen ground engineering. .

Porter, M.L. and Harries, K., 2007. Future directions for research in FRP composites in concrete construction. Journal of Composites for Construction, 11 (3), 252-257.

Potts, D. and Zdravkovic, L., 1999. Finite Element Analysis in Geotechnical Engineering: Theory and Application. Thomas Telford Ltd.

Powell, G. and Simons, J., 1981. Improved iteration strategy for nonlinear structures. International Journal for Numerical Methods in Engineering, 17 (10), 1455-1467. 
Qu, W., Zhang, X., and Huang, H., 2009. Flexural behavior of concrete beams reinforced with hybrid (GFRP and steel) bars. Journal of Composites for Construction, 13 (5), 350-359.

Ramirez, J.A., French, C., and Adebar, P., 1998. Recent approaches to shear design of structural concrete. Journal of structural engineering, 124 (12), 1374.

Ramm, E., 1981. Strategies for tracing the nonlinear response near limit points. Springer.

Razaqpur, A.G., Isgor, B.O., and Greenaway, S., 2004. Concrete contribution to the shear resistance of fiber reinforced polymer reinforced concrete members. Journal of Composites for Construction, 8 (5), 452-460.

Rosenboom, O. and Rizkalla, S., 2006. Behavior of prestressed concrete strengthened with various CFRP systems subjected to fatigue loading. Journal of Composites for Construction, 10 (6), 492-502.

Rots, J., Nauta, P., and Kuster, G., 1985. Smeared crack approach and fracture localization in concrete. Delft University of Technology.

Roy, S., 2005. Nonlinear finite element analysis of reinforced concrete bridge deck/bridge approach slab using ABAQUS. Thesis (PhD). School of Computing and Engineering. University of Missouri-Kansas City.

Selig, E.T., 1990. Soil properties for plastic pipe installations. Buried plastic pipe technology, 141-158.

Selvadurai, A., Lee, J., and Todeschini, R., 1983. Lateral resistance in soil-pipeline interaction. Pipelines in Adverse Environments II, 259-283.

Sharbatdar, M.K., 2003. Concrete columns and beams reinforced with FRP bars and grids under monotonic and reversed cyclic loading. Thesis (PhD). University of Ottawa.

Shima, H., Chou, L.L., and Okamura, H., 1987. Micro and macro models for bond in reinforced concrete. Journal of the Faculty of Engineering, 39 (2), 133-194.

Simonsen, E. and Isacsson, U., 1999. Thaw weakening of pavement structures in cold regions. Cold regions science and technology, 29 (2), 135-151.

Spangler, M.G. and Handy, R.L., 1982. Soil engineering. Harper \& Row New York.

Tadros, M.K. and Benak, J.V., 1989. Soil pressure on box culverts. ACI Structural Journal, 86 (4).

Terzaghi, K., 1943. Earth Pressure and Shearing Resistance of Plastic Clay: A Symposium: Liner-Plate Tunnels on the Chicago (IL) Subway. Transactions of the American Society of Civil Engineers, 108 (1), 970-1007. 
Theriault, M. and Benmokrane, B., 1998. Effects of FRP reinforcement ratio and concrete strength on flexural behavior of concrete beams. Journal of composites for construction, 2 (1), 7-16.

Tottori, S. and Wakui, H., 1993. Shear capacity of RC and PC beams using FRP reinforcement. ACI Special Publication, 138.

Toutanji, H.A. and Saafi, M., 2000. Flexural behavior of concrete beams reinforced with glass fiber-reinforced polymer (GFRP) bars. ACI Structural Journal, 97 (5).

Vecchio, F. and Collins, M., 1982. The response of reinforced concrete to in-plane shear and normal stresses. University of Toronto, Department of Civil Engineering.

Vijay, P. and GangaRao, H.V., 2001. Bending behavior and deformability of glass fiberreinforced polymer reinforced concrete members. ACI structural journal, 98 (6).

Vuchic, V.R., 2005. Urban transit: operations, planning, and economics. Wiley.

Wang, H. and Belarbi, A., 2011. Ductility characteristics of fiber-reinforced-concrete beams reinforced with FRP rebars. Construction and Building Materials, 25 (5), 23912401.

Watkins, R.K. and Anderson, L.R., 1999. Structural mechanics of buried pipes. CRC press.

Williams, G.P. and Gold, L.W., 1976. Ground temperatures. NRC.

Yang, M.Z., 2000. Evaluation of factors affecting earth pressures on buried box culverts.

Yang, M.Z., Drumm, E.C., and Bennett, R.M., 1999. Measurement of earth pressures on concrete box culverts under highway embankments. ASTM Special Technical Publication, 1358, 87-100.

Yang, Z.J., Dutta, U., and Zhu, D., 2007. Seasonal frost effects on the soil-foundationstructure interaction system. Journal of Cold Regions Engineering, 21 (4), 108-120.

Yost, J.R., Gross, S.P., and Dinehart, D.W., 2001. Shear strength of normal strength concrete beams reinforced with deformed GFRP bars. Journal of composites for construction, 5 (4), 268-275.

Yunovich, M., et al., 2003. Life cycle cost analysis for reinforced concrete bridge decks. Corrosion 2003.

Zhang, T., 1998. Global annual freezing and thawing indices. Boulder, CO, USA: National Snow and Ice Data Center. Digital media. 
Zhu, M., 2005. Modeling and simulation of frost heave in frost-susceptible soils. University of Michigan. 
REFERENCES 
REFERENCES 